\title{
Economists in the 2008 Financial Crisis: Slow to See, Fast to Act*
}

\author{
Daniel Levy ${ }^{\text {a, b, c, d, e, Tamir Mayer }}{ }^{\mathrm{f}}$, Alon Raviv ${ }^{\mathrm{f}, * *}$ \\ ${ }^{a}$ Department of Economics, Bar-Ilan University, Ramat-Gan 5290002, Israel \\ b Department of Economics, Emory University, Atlanta, GA 30322, United States \\ c ICEA, Wilfrid Laurier University, Waterloo, Ontario, Canada \\ ${ }^{\mathrm{d}}$ RCEA, University of Bologna, Rimini, Italy \\ e ISET at TSU, Tbilisi, Georgia \\ ${ }^{\mathrm{f}}$ Graduate School of Business Administration, Bar-Ilan University, Ramat Gan, 5290002, Israel
}

Last Revision: February 13, 2022

We study the economics and finance scholars' reaction to the 2008 financial crisis using machine learning language analyses methods of Latent Dirichlet Allocation and dynamic topic modelling algorithms, to analyze the texts of 14,270 NBER working papers covering the 1999-2016 period. We find that academic scholars as a group were insufficiently engaged in crises' studies before 2008. As the crisis unraveled, however, they switched their focus to studying the crisis, its causes, and consequences. Thus, the scholars were "slow-to-see," but they were "fast-to-act." Their initial response to the ongoing Covid-19 crisis is consistent with these conclusions.

JEL classification: E32, E44, E50, F30, G01, G20

Key Words: Financial crisis, Economic Crisis, Great recession, NBER working papers, LDA textual analysis, Topic modeling, Dynamic Topic Modeling, Machine learning

* We thank three anonymous reviewers for constructive comments and suggestions and the editor Iftekhar Hasan for advice. In
addition, we are grateful to Meni Abudy, George Akerlof, the late Alberto Alesina, Doron Avramov, Olivier Blanchard, Avinoam
Blum, John Campbell, Wendy Carlin, Steve Cecchetti, John Cochrane, Antonio Fatas, Roy Gelbard, Michael Gofman, Yuval
Heller, Arnold Kling, Narayana Kocherlakota, Bob Krainer, David Laidler, James Poterba, John Quiggin, Ricardo Reis, Dani
Rodrik, Oliviero Roggi, Ken Rogoff, Alex Rosenberg, Amir Rubin, Jeffrey Sachs, and Vernon Smith for commenting (many of
them-multiple times and in a great detail) on earlier versions of this manuscript. We thank also the participants of the 2020 Winter
Meeting of the Econometric Society, the 2020 International Risk Management Conference, the 2019 Workshop on "Sentiments
and Crises in Financial Texts” at the Data Science Institute at Bar-Ilan University, the 2019 Israeli Behavioral Finance Conference,
and the seminars at the Research Department of the Bank of Israel, Ben-Gurion University, Università Cattolica del Sacro Cuore,
and at the Department of Economics and at the Graduate School of Business at Bar-Ilan University, for useful comments,
conversations and suggestions. We thank Sara Markowitz for answering our questions about the way NBER working papers are
processed. This work was supported by the Data Science Institute at Bar-Ilan University [grant number 247009]. Harel Reinuss
provided excellent research assistance. A previous version of this paper was circulated under the title “Academic Scholarship in
Light of the 2008 Financial Crisis: Textual Analysis of NBER Working Papers.” The data we use in the study can be downloaded
from our website at Bar-Ilan University. The usual disclaimer applies.

${ }^{* * *}$ Corresponding author.

Email addresses: Daniel.Levy@biu.ac.il (D. Levy), Tamirmayer@gmail.com (T. Mayer), Alon.Raviv@biu.ac.il (A. Raviv) 
"Many professional economists now find themselves answering questions...on topics that did not seem at all central until a few years ago, and we are collectively scrambling to catch up."

Gary Gorton and Andrew Metrick, Journal of Economic Literature (2012, p. 128)

"The study of economics is driven by perceived economic problems, and when those problems seem to go away in the real economy, so does academic interest in the problem."

Robert Krainer, Finance in a Theory of the Business Cycle (1992, p. xi)

"In many sub-fields of economics, just about anyone well-known in the profession is an NBER research associate...The function of these [NBER working] papers...is to get research out quickly...For economists, the WPs provide what amounts to one-stop shopping for new developments in their field.”

Paul Krugman, “Understanding NBER,” The New York Times (April 22, 2013)

\section{Introduction}

The global financial crisis of 2007-2009 turned out to be the most serious economic crisis since the Great Depression. It began in 2007 with a crisis in the subprime mortgage market in the US, and developed into an international banking crisis with the collapse of Lehman Brothers on September 15, 2008. The crisis was followed by a global economic slowdown, the Great Recession. The European debt crisis that followed the global banking crisis, turned out to be a multi-year debt crisis that has been battering the EU since the end of 2009, when several countries were unable to repay or refinance their debt, or to bail out their over-indebted banking institutions without external assistance.

As the financial crisis began to unfold, the public began criticizing the economics and finance scholars for failing to recognize the coming of the financial crisis. Criticism was heard from all directions including the press, the electronic media, the late-night comedians, and even from Queen Elizabeth II. ${ }^{1}$ The criticism, however, was not limited to the general public. ${ }^{2}$ Many professional economists have joined the debate, expressing their critical views, sometimes using very strongly worded language, although not everyone agreed with them. ${ }^{3}$

Some critics have argued that the economics and finance scholars relied too much on the rational agent paradigm, ignoring the evidence that market participants often tend to act

\footnotetext{
${ }^{1}$ In a widely-publicized and quite extraordinary exchange, which took place during a dedication of a new building at the London School of Economics on November 4, 2008, Queen Elizabeth II asked the host, the Director of Research at the LSE's School of Management, "Whey did nobody notice it?" (Pierce 2008). In a 3-page reply to the Queen, which was drafted by a group of economists and was signed by Tim Besley, a member of the Bank of England's Monetary Policy Committee, the economists explained: "In summary, Your Majesty, the failure to foresee the timing, extent and severity of the crisis and to head it off, while it had many causes, was principally a failure of the collective imagination of many bright people, both in this country and internationally, to understand the risks to the system as a whole" (Stewart 2009).

${ }^{2}$ The public discourse is ongoing. See, for example, a recent episode of "The Late Show" with Stephen Colbert, where Paul Krugman explains to Colbert about macroeconomic booms and busts, as the two men ride the Nitro roller coaster at 6-Flags Great Adventure: https://www.youtube.com/watch?v=ir7lwqnPlrg, accessed May 12, 2019. ${ }^{3}$ For example, some economists described it as a "systemic failure of the economics profession" (Colander et al. 2009, 2014).
} 
irrationally, which may drive markets in ways and directions that the standard models cannot anticipate. Others have argued that the models that combine rationality with DSGE, left no room for financial markets, leading to the belief that developed countries with advanced financial systems and sound inflation-targeting monetary policies do not need to worry about crises. Recent studies which tend to be more retrospective, point to the limitations of the mainstream models' focus on aggregate demand and aggregate supply shocks, ignoring the possibility of other types of shocks such as credit cycles “...in which an initial boom is created by a boost in central bank credit that in turn leads to mal-investment and a subsequent bust," or "disruptions in financial intermediation,” which could lead to bank runs (Sachs 2019, p. 3). According to Razin (2014), most theorists concede now that the pre-crisis monetarist consensus was mistaken.

Bernanke (2018) argues that the full nature of the crisis was not anticipated by the profession because economists significantly underestimated the impact of the crisis on the real economy. Moreover, existing models did not assign significant roles to many credit-related factors and consequently to the behavior of financial intermediaries. In other words, in the existing models, the real side of the economy was disconnected from the financial markets.

Reinhart and Rogoff (2009a, p. 221), in a broad comparative study of historical financial crises episodes, note that “...many problems were hidden in the 'plumbing' of the financial markets,” (p. 221), particularly noting the extraordinary increase in housing prices fueled by mortgage expansion and rising leverage.

Following the crisis, economists and policymakers began emphasizing the need to revise the economic models, acknowledging that the academic community was not engaged sufficiently in the study of crises, and that there was a need to refocus its attention on empirical questions, models, and policy recommendations that might better explain and help in coping with future crises (Goldstein and Razin 2015). These sentiments, however, are based on perceptions and qualitative assessments, as little has been done to explore systematically and to quantify the extent of the actual engagement of the academic community in studying crisis-related issues before, during, and after the crisis.

To fill this gap in the literature, our goal in this paper is to measure and quantify the nature and the intensity of the academic efforts to study and understand the 2007-2009 financial crisis, as reflected in the academic economics and finance literature, published before, during, and after the crisis. In doing so, we make three specific contributions. First, we assess the aggregate scholarly effort around the crisis by quantifying the intensity and the speed of the response of the economics and finance scholars as the crisis was evolving. Second, we analyze the variation 
across subfields of economics and finance to assess which fields and subfields of economics and finance have led the change. Third, we assess how the focus on different crisis-related topics evolved over time and what was the role of different research communities in the process.

We address these questions by analyzing the texts of 14,270 National Bureau of Economic Research (NBER) WPs published during 1999-2016. We conduct seven sets of analyses. The first two use content analysis based on simple word count methods. First, we compute the aggregate appearance frequency of the term 'crisis/crises' in the WPs and correlate it with the index of economic stability. Second, we construct the time series of the \% of WPs with the term 'crisis/crises' in the period 1999-2016 for each NBER program.

While word counting sheds some light on the extent of the engagement of the scholars in crisis studies, it cannot identify the particular topics that scholars studied. We therefore implement topic modeling approach using the Latent Dirichlet Allocation (LDA) method of Blei et al. (2003) and Griffiths and Steyvers (2004), to quantify the frequency of the appearance of crisis-related topics and words in the WPs, and measure associations between them.

In the third analysis, we apply LDA to the abstracts of the WPs, to identify crisis topics, and to assess the changes in their weights over time. The title we gave to the crisis topics we identify, is based either on the words that appear in the topic with the highest frequency, or on one representative word in case synonyms are present. ${ }^{4}$ Fourth, we study the degree of engagement of the scholars of each NBER program in studying crisis topics by matching between the WPs of each program and the topics that we label as 'crisis topics' based on the LDA analysis. Fifth, to assess the effect of the crisis on the study of crisis topics and as an additional analysis, we apply the LDA method to the (abstracts and the first five paragraphs of the) crisis WPs only, i.e., to the WPs that primarily focus on the 2008 crisis. Sixth, we use dynamic topic modeling (DTM) method of Blei and Lafferty (2006) to assess the evolution of topics in the crisis WPs. Finally, seventh, we assess the extent of the convergence in the study topics of different NBER programs.

Although the NBER WPs do not go through a blind review process like regular journal articles, they nevertheless offer several advantages. First, the WPs are published and circulated faster than journal articles. Second, NBER affiliates are highly influential and leading scholars, topping the lists of contributors to the top journals in both economics and finance. Third, the NBER affiliates form a diverse group, specializing in various fields of economics and finance. Fourth, the WPs are free from journal-type editorial management and intervention. Finally, the WPs are widely circulated and cited. We believe therefore, that NBER WPs are particularly

\footnotetext{
${ }^{4}$ In case of synonyms, we add up the frequencies based on one representative word.
} 
useful and relevant for answering the questions we pose.

Our findings are as follows. As a whole, the NBER research community was barely engaged in studying financial crisis before 2008, but its reaction to the crisis was fast and intense. The share of WPs with the word 'crisis' increases from 8\% in 1999-2007 to 14\% in 2008-2016, on average. Moreover, the weights of the crisis topics we identify using the LDA algorithm are almost tripled in the post-crisis period.

Further, we find that the volume of crisis-related WPs is counter-cyclical and lags financialinstability indexes. The results of data analyses suggest that in the post-crisis period, all relevant NBER programs significantly increased their engagement in the study of crisis-related topics. The International Finance and Macro program members were engaged in the study of crisis before the crisis, and structural breaks were not observed. The Monetary Economics program had a low engagement before the crisis, but became very active in the post-crisis period, converging with the efforts of the International Finance and Macro program. The members of the Asset Pricing and the Corporate Finance programs hardly refer to "crisis" in the pre-crisis period. However, as the crisis develops, their study efforts of crisis-related issues increase most aggressively in comparison to other programs.

As a test of robustness, we look at the track record of four top field economics and finance journals in publishing crisis-related papers during our sample period and compare them to the WP output of the NBER programs that match the journals' broad interests. We find that similar to the two NBER finance programs (Asset Pricing and the Corporate Finance), the top-3 finance journals showed little engagement in crisis-related topics in the pre-crisis period, but reacted quite dramatically to the crisis, like the two finance programs, but with a two year lag, which may be ascribed to the editorial reviewing and decision process. We find a similar "slow to see, fast to act” type pattern of behavior at most other leading finance journals that are ranked below the top-3 journals. An exception is the Journal of Financial Stability where the majority of the published papers discuss crises - before, during and after the 2008 financial crisis.

Based on the LDA analysis, we identify 9 crisis topics (out of 500 considered) in the abstracts of the WPs published between 1999 and 2016. We find that the topic of 'Emerging Markets,' typically identified with a crisis in small open economies, lost influence in the post-crisis period. Similarly, the topic of 'Sudden Stops,' which concerns the macroeconomic adjustments needed to deal with a sudden reversal in the net capital inflows, had also disappeared. These topics were studied mainly by the members of the International Finance and Macro and Economic Fluctuations and Growth programs. 
Two new topics emerged as a result of the crisis. The first, 'Repo and Securitization,' is mainly studied by the Asset Pricing and Corporate Finance programs, which were almost uninvolved in crises-studies before 2008, and by the Monetary Economics program. This topic was almost ignored by the International Macro and Finance program, the most active program in studying financial crises before 2008. We find a sharp drop in the study of the topic from 2013 and on. The second topic that emerged in the post-crisis period is 'Great Recession,' which relates to the spread of the financial crisis to the real economy. In contrast to the other crisis topics, we find a persistence in the study of the topic of 'Great Recession.' Indeed, the topic's weight increases also in the post-crisis period of 2013-2016.

The topics of 'Liquidity,' 'International Reserves,' and 'Sovereign Debt' are pro-cyclical. Similar patterns are observed for the topic of 'Financial Intermediaries,' which deals with the structure of the financial sector and financial institutions while focusing on the task of regulators, and for the topic of 'Global Crisis.' The latter focuses on how crisis spread across markets and countries. While the topic received almost no attention before the crisis, it topped the list of all economics topics in the post-crisis years. In contrast to all other topics, the topics of 'Global Crisis' and 'Financial Intermediaries' drew attention from multiple program members in the post-crisis period, consistent with the assessments of Goldstein and Razin (2015).

To understand how the crisis literature evolved over time, we identify 'crisis WPs,' i.e., the WPs with a primary focus on the financial crisis and conduct two LDA topic analyses, comparing the pre-crisis, the crisis, and the post-crisis periods. We find significant differences in the average weights of 5 topics (out of the 20 topics considered) between the pre-crisis (20052008), the crisis (2009-2012), and the post-crisis (2013-2016) periods. However, there is no single topic with a significant difference between its weights in the crisis (2009-2012) and the post-crisis (2013-2016) periods. These results are indicative of a significant change in the crisis studies brought about by the 2008 crisis, and of a stability in the crisis study practices and interests in the post-crisis period.

When we match the crisis topics with NBER programs, we find that the International Finance and Macro program members were engaged in the study of crisis before 2008, but they abandoned the topics of 'Sudden Stops' and 'Emerging Markets' in the post-crisis period, shifting their focus to 'Monetary Policy' and 'Sovereign Debt.' In contrast, the members of the Asset Pricing and Corporate Finance programs, who were not engaged in the study of crisis before 2008, began studying a new topic, 'Repo and Securitization’

Before proceeding, we shall emphasize what we do not do. Because we study the collective 
effort of the economics and finance scholars affiliated with NBER programs, we do not focus on any individual scholar, and thus we do not study WPs of individual scholars, we do not measure their impact, we do not rank their contributions, etc. ${ }^{5}$ Also, because our focus is on efforts and not on impact, each WP receives the same weight in our analysis regardless of its impact.

The paper is organized as follows. In section 2, we review the literature. In section 3, we describe the data and the methods. In section 4, we study the frequency of the word 'crisis/crises' in NBER WPs, followed in section 5, by an analysis of its variability across NBER programs, and across leading finance journals. In section 6, we describe the LDA machine learning algorithm for topic modeling and identify the crisis topics in the NBER WPs. In section 7, we present a meta-study where we assess how the engagement in different crisis topics evolved over time. In section 8, we assess the effect of the 2008 crisis on the academic literature by limiting the analyses to the crisis WPs only. In section 9, we summarize the findings, discuss main conclusions in the context of the ongoing Covid-19 crisis, offer caveats and limitations, and assess possible avenues for future research.

\section{Literature review}

In a particularly timely series of papers Reinhart and Rogoff assess the causes of the 2008 crisis. Reinhart and Rogoff (2008) document parallels and similarities between the 2008 crisis and other historical episodes of bank-centered crises. Reinhart and Rogoff (2009b) discuss the aftermath of the crisis in the international comparative context. Gjerstad and Smith (2014) focus on a balance sheet aspect of the crisis in which the prices of widely held and highly leveraged assets collapse. Gorton and Metrick (2012) summarize some key facts around the events that led to the crisis. Romer and Romer (2017) is a more recent study of the aftermath of financial crises in advanced economies. Griffin (2021) offers a synthesis of much of this literature.

We use the LDA topic modeling to study the evolution of the crisis study around the 2008 financial crisis and thus our paper is related to two strands in this literature. The first are studies that use a topic modeling to understand the effects of the financial crisis on policy making. Examples include the analyses of the transcripts of the FOMC meetings, or the transcripts of the meetings of the governing boards of central banks. The second are studies that use topic modeling methods to analyze the contents of economic journals and the trends therein over time. We combine the two by studying the effect of the 2008 financial crisis on the economic literature

\footnotetext{
${ }^{5}$ Clearly, there are highly accomplished and widely cited individual scholars, well-known to the readers, who have made major and significant contributions to the study of crises and crises-related topics. Moreover, these scholars have been asking many relevant crises-related questions before the 2008 crisis hit. Indeed, it is thanks to their work that the share of crisis WPs written before the 2008 crisis is positive, as we report below.
} 
using the LDA. ${ }^{6}$

A particularly relevant paper in the context of our study is Fligstein et al. (2017), who analyze the texts of the Federal Open Market Committee (FOMC) meeting minutes to understand why the committee members failed to see the severity of the 2008 crisis as it was unfolding. They find that FOMC members tended to see and interpret discomforting news and facts in a positive light, essentially discounting them, and thereby making them appear less worrisome. They conclude that macroeconomic theory served as the primary frame of reference for the FOMC members to assess and interpret the events prior and during the crisis, which limited their ability to connect the events around foreclosures in the housing market with the financial instruments that were used to market mortgages, and see the risks they posed to the economy. The policy makers' inability to see the severity of the crisis even when it was unfolding is perhaps most vividly demonstrated by the following extraordinary observation Fligstein et al. (2017) make: even after seeing the collapse of Lehman Brothers, on September 16, 2008, the FOMC issued a statement, saying, “... The downside risks to growth and the upside risks to inflation are both of significant concern to the Committee.” In retrospect, this assessment seems very naïve, and not very alarming, compared to what was about to happen. Clearly, as Fligstein et al. (2017) assess, “...the FOMC consistently underestimated the risks to the economy during the months and years that preceded the financial crisis of 2007 to 2008” (p. 880).

Our study is consistent with, and indirectly confirms, the main conclusion of Fligstein et al. (2017): prior to the crisis, much of the economic scholarly effort were put in other places, crisisrelated topic receiving insufficient attention. However, unlike Fligstein et al. (2017), who study the 2000-2008 period, our data cover the 1999-2016 period, and thus we study the post-crisis period as well, which sheds a new light on the response of the economics and finance scholars to the crisis, yielding new insights. For example, we find that once the severity of the crisis was recognized, the scholars switched gears, putting a lot of efforts in studying and understanding the crisis and its likely causes.

A large related literature studies the communication strategies of the Fed and of the FOMC, and their effects on markets, by analyzing the contents of the FOMC minutes, the Fed's announcements, etc. Hansen and McMahon (2016) use LDA method combined with factoraugmented VAR, to assess how the information released by the FOMC on the state of the economic conditions and the forward guidance the FOMC provides about its future monetary

\footnotetext{
${ }^{6}$ Ambrosino et al. (2018), Lüdering and Tillmann (2020), Athey and Imbens (2019), and Gentzkow et al. (2019) survey the methods applicable to the analysis of textual data with applications in economics and finance. 
policy affects the market and the real economic variables. Hansen, McMahon, and Prat (2018) apply the LDA methods to the transcripts of FOMC meetings to assess the effect of transparency on deliberation of monetary policy makers at these meetings. Other papers in this strand of the literature include Born et al. (2010), Boukus and Rosenberg (2006), Cecchetti (2003), Cukierman (2009), Ehrmann and Fratzscher (2005, 2007, 2009), Ehrmann et al. (2019), Kansoy (2019), Kryvtsov and Petersen (2019), Poole (2005), Romer (2010), Shiller (2017), Thornton (2006), Jansen and de Haan (2013), and Woodford (2005). Blinder et al. (2008) survey the earlier studies in this literature.

Other studies of texts in the context of economic and financial crises include Shirota (2016), who identifies and extracts topics concerning the 1997-1998 Asian financial crisis, Keida and Takeda (2018), who apply the method to analyze the transcripts of the press-conferences of the governors of the Bank of Japan, and Larsen and Thorsrud (2019), who employ LDA to quantify media narratives related to business cycles in the US, Japan, and EU.

The second strand of the literature is composed of several recent papers that study the content of economics journals. Kosnik (2017) assess the distribution of journal pages between micro and macro. Angrist et al. (2017, 2020) use LDA to assess the impact of economics scholarship on other disciplines. Lüdering and Winker (2016) use a combination of LDA with VAR to analyze the corpus of the articles published in the Journal of Economics and Statistics during 1949-2010 to assess to what extent does the academic economic scholarship lead the macroeconomic events, or perhaps it is the other way around. Wehrheim (2019) analyses the topics of the articles published in the Journal of Economic History. Goldstein et al. (2019) try to understand the topics of "FinTech" by analyzing the abstracts of 156 proposals submitted to a special issue of Review of Financial Studies. Bowles and Carlin (2020) apply the LDA method to the corpus of published economic research from 1999 to 2014 in the top economics journals to generate topics, which they use to explore the evolution of the contents of the introductory economics textbooks. Glandon et al. (2022) assess the trends in modern macroeconomic research.

Aigner et al. (2019) analyze top-cited economic papers before and after the 2008 financial crisis based on the papers' keywords and report several findings that are in line with our findings. First, they also find that the term 'financial crisis' only had a marginal presence in the pre-crisis years, but in the post-crisis years, the relative frequency of the term quadrupled. Second, their data is also consistent with "slow to see, fast to act" pattern, the theme of our paper. Third, their assessment of the way the discussion of financial markets has changed, particularly in the context of the emergence of the liquidity and the securitization topics, is also 
in line, at least partially, with our findings, although they conclude that the crisis has not led to substantial changes in the way economists view the financial markets. That is, overall, they find a stable topical orientation.

However, our study differs from theirs in several important ways, including the data, the methods, and some of the findings. First, we ask how the crisis-related literature evolved around the 2008 crisis. Aigner et al. (2019) in contrast, consider the effect of the crisis on the entire economics scholarship. Second, we use a topic modeling algorithm to analyze the WPs, as in Kosnik (2015), Angrist et al. (2017), and Fligstein et al. (2017), and thus we do not limit our analyses to a small number of keywords as Aigner et al. (2019) do. Third, we consider different fields and subfields of economics and their contribution to the study of crisis over time and across different topics. Finally, we study the texts of NBER WPs, which unlike journal papers, are unaffected by editorial policies and preferences and, are published with no delay.

More importantly however, and counter to the findings of Aigner et al. (2019), we find a significant change around the crisis years in the study of almost all crisis-related topics. In addition, we identify several new topics that have emerged in response to the crisis, and several old topics that have disappeared in response to it. We also offer evidence of the way the academic reaction varied across different subfields of economics.

\section{Data: NBER working papers ${ }^{7}$}

Our primary data consist of the 14,270 WPs published by the NBER during 1999-2016. NBER, a private, non-profit leading academic think-tank, is based in Cambridge, MA. ${ }^{8}$ Over 1,400 professors from universities and colleges, primarily in North America, but also in Latin America, Europe, Japan, Korea, China, Australia, Israel, etc., have NBER affiliations.

NBER activities are organized around 20 research programs, which form the backbone of the NBER. ${ }^{9}$ Each of the 20 programs is led by a Director or co-Directors, and corresponds loosely to a traditional field of study within economics and/or finance, holding regular meetings and conferences. ${ }^{10}$ In addition, NBER holds a Summer Institute, hosting dozens of workshops. ${ }^{11}$

One of the main NBER activities, however, is its WP Series, a highly influential series of

\footnotetext{
${ }^{7}$ The data we use in the study can be downloaded from our website at Bar-Ilan University.

${ }^{8}$ Detailed information on NBER and its activities can be found at: https://www.nber.org/.

${ }^{9}$ There are also 13 working groups. Working groups are smaller and more narrow-focused than programs.

10 The list of the NBER programs and working groups can be found at https://www.nber.org/ $\rightarrow$ Activities. The papers presented at these conferences are often published as edited volumes jointly by the NBER and the University of Chicago Press.

${ }^{11}$ For example, during the Summer Institute 2019, 52 workshops were held from July 8, 2019 to July 26, 2019. For the list of the workshops, see https://conference.nber.org/conferences/2019/SI2019/SI2019_rev.html. 
studies authored by the NBER affiliated faculty, covering different fields and subfields of economics and finance, and studying a wide range of topics and issues. The WPs are grouped according to the 20 programs, and they are circulated and distributed widely. ${ }^{12}$

We choose to study the NBER WPs for several reasons. First, they offer a speed of knowledge dissemination far higher than the traditional academic journals because of the slow review process on which journal editors rely. Indeed, according to Krugman (2013), the function of NBER WPs is to get research out as soon as possible so other economists can discuss it.

Second, the NBER WPs are highly influential, widely circulated and frequently cited. For example, according to IDEAS/RePec (the largest bibliographic database of economics research), the NBER WP series rank first (Technical WPs included), among the 2,235 WP series included in the ranking. ${ }^{13}$ NBER WPs rank first also based on the $h$-Index, with the index value of 350 and a total of 865,620 adjusted citations. ${ }^{14}$

Third, with over 1,400 affiliates, NBER is one of a kind community of academics. The volume of the output produced by the NBER members is extraordinary. Indeed, based on the number of WPs, the NBER WPs series tops the list of the WP series, when we consider all the single-source WP series. According to IDEAS/RePec, the NBER WP series include 26,223 WPs (including the Technical WPs), followed by CEPR Discussion Papers with 13,635 WPs. ${ }^{15}$ There was a sharp increase in 2001 in the number of the WPs published by the NBER, from about 200 WPs/year to about $700 \mathrm{WPs} / \mathrm{year}$, and it has been increasing since then.

Fourth, the NBER affiliates are leading scholars, specializing in different areas of economics and finance. Many are senior figures, often in charge of editing, coediting, or managing the disciplines’ premiere journals. Indeed, according to Krugman (2013), “In many sub-fields of economics, just about anyone well-known in the profession is an NBER research associate.”16 To get a sense of the academic impact the NBER members really have, we compute the contributions of the academic organizations to top-8 journals (top-5 in economics and top-3 in

\footnotetext{
12 The list of the WPs by research programs can be found at: https://conference.nber.org/papersbyprog/.

${ }^{13}$ Some of the WP series included in this ranking are actually pre-prints of accepted and/or forthcoming papers, which are different from regular WPs because of the blind review process the latter have to go through. In the ranking cited above, the NBER WP series is actually ranked second after Princeton Papers, which is ranked first, but the latter is a series of accepted papers. See: https://ideas.repec.org/top/top.wpseries.all.html.

14 The CEPR Discussion Papers rank second, with an $h$-Index of 221, and a total of 310,301 adjusted citations. $h$-Index of a WP series is the number of WPs in the series with at least $h$ citations. The citation count figures are adjusted to exclude citations from the same WP series. See: https://ideas.repec.org/top/top.wpseries.hindex.html, column 2. For explanatory notes, see: https://ideas.repec.org/top/top.wpseries.hindex.html\#explain.

15 See: https://ideas.repec.org/top/top.wpseries.all.html, column 2.

${ }^{16}$ According to the NBER, 29 Nobel Prize winners in Economics, and 13 past Chairmen of the President's Council of Economic Advisers have held NBER affiliations. See: https://www.nber.org/info.html.
} 
finance) during 2017-2019, based on the Web of Science data. ${ }^{17}$ Table 1a ranks 10 organizations according to their contribution counts. The NBER members rank first with 553 contributions, followed by the CEPR, the University of California System, the Federal Reserve System, and the University of Chicago with 261, 211, 173 and 168 contributions, respectively. We find that the NBER members rank first also when we consider each journal individually, as Table 1b shows. Indeed, the contribution count of the NBER members is at least 2-4 times greater than the contribution of the organizations ranked below the NBER. The contribution of the NBER members seem substantial in absolute terms as well, as the figures in the table show.

Fifth, the NBER WP series are produced by highly diverse group of scholars, without any kind of journal-type editorial intervention, review, or guidance. Therefore, NBER WPs are relatively free from biases that journal editorial boards might have towards their preferred questions, methodology, modelling framework, empirical strategy, etc.

Additional advantage of the NBER WPs is their particular attention to policy-related issues. Indeed, according to Fabricant (1984, p. 2), the NBER's Director of Research from 1953 to 1965, one of the guiding principles of the NBER from its establishment in 1920, was that "Its research should concentrate on determining facts, and the connections among facts, that are important in dealing with major problems of economic policy.”18

Out of the 20 NBER research programs, we focus on the six most relevant programs in the areas of macroeconomics and finance (macro/finance programs). These are Monetary Economics, International Trade and Investment, Corporate Finance, Asset Pricing, International Finance and Macroeconomics, and Economic Fluctuations and Growth. We choose these programs for several reasons. First, the topics of these programs cover are perhaps the closest and therefore most relevant for the study of financial crises. ${ }^{19}$ Second, the great majority of the Research Associates that are members in these programs, specialize in either monetary economics, macroeconomics, or finance, the subfields of economics that are most closely associated with issues related to financial crises. Third, these program members have produced the highest \% of crisis WPs. Finally, they are among the largest NBER programs in terms of

\footnotetext{
${ }^{17}$ The top-5 economics journals are Quarterly Journal of Economics, Journal of Political Economy, American Economic Review, Review of Economic Studies, and Econometrica. The top-3 finance journals are the Review of Financial Studies, Journal of Finance and the Journal of Financial Economics.

${ }^{18}$ Despite this, the authors of the NBER WPs are expected "...to ascertain and present to the economics profession, and to the public more generally, important economic facts and their interpretation in a scientific manner without policy recommendations.” Source: Amended and Restated By-Laws of NBER, Inc., Adopted April 28, 2014. See: https://www.nber.org/NBERByLaws.pdf, accessed June 11, 2019.

${ }^{19}$ We exclude from the analyses the NBER program on Developments of the American Economy because, unlike other NBER programs, it specializes in a particular geographic region.
} 
research output, and the number of members. ${ }^{20}$

Descriptive statistics for the six (macro/finance) programs are presented in Table 1c. ${ }^{21}$ During 1999-2016, the annual average number of WPs per program was 98.8. The largest program is Economic Fluctuations and Growth with 191.28 WPs/year, on average, and the smallest is Health Care (not shown), with 32 WPs. The activities of all programs increased significantly during the last few years. For example, the total number of WPs published annually increased from 199 in 1999, to a peak of 1,180 in 2013, and then declining but still remaining above 1,000 WPs annually. The average annual number of WPs per program has also increased, from 71.1 before the crisis, 1999-2007, to 132.7 after the crisis, 2008-2016.

\section{Content analysis}

The most basic notion in content analysis is the words' frequency because the words that are mentioned most often are presumably also the words that reflect the greatest relevance (Stemler 2000). Our starting point, therefore, is the frequency of the word 'crisis/crises' in the WPs.

\subsection{Counter-cyclicality of academics' interest in the crisis study}

We calculate the \% of the WPs that mention the word crisis at least once, and their share in the total number of WPs annually. ${ }^{22}$ Figure 1 shows the \% of crisis WPs, which we define as WPs that mention the word 'crisis/crises' at least once in the first five paragraphs of the introduction. ${ }^{23}$ The $\%$ decreased from $10 \%$ in 1999 , to $6 \%-7 \%$ in the pre-crisis years. In 2009 , in the midst of the crisis, it jumped to $13.8 \%$, and climbed to $17.8 \%$ in 2011 . It then went down, reaching a trough in 2015-2016, but still above the pre-crisis level, around 12\%-14\%. These figures suggest that the academic interest in crisis is counter-cyclical: the sharp increase in the number of crisis WPs occurs during the period of the great recession.

According to Table 2, the \% of crisis WPs averaged 8.3\% during the pre-crisis period, 19992007, and 13.5\% during the post-crisis period, 2008-2016. The difference is statistically

\footnotetext{
${ }^{20}$ In Table A1 in the Appendix, we briefly discuss the remaining 16 (non-Macro/Finance) NBER programs and their publication record of crisis-related papers.

${ }^{21}$ In Table A2 in the Appendix, we present these figures for all the remaining 16 (non-Macro/Finance) NBER research programs.

${ }^{22}$ We should note two potential difficulties in the context of the word frequency count. First, the use of synonyms can lead to an underestimation of the importance of a concept (Weber 1990). Indeed, there are several synonyms for the word 'crisis' such as a 'recession, 'financial turmoil,' 'market crash,' 'depression', etc. However, none of these synonyms are as strong and as charged as the word 'crisis,' as none of them encompass the entire set events and circumstances that are captured by the word 'crisis.' Second, some words may have multiple meanings. For instance, “state” could mean a political body, a situation, or a verb meaning "to speak.” Therefore, we also use LDA topic modeling in sections $6-8$ and in section 10, to conduct multiple robustness checks to validate our results.

${ }^{23}$ This somewhat arbitrary definition of a crisis WP is not fool proof, and thus we address it further below in section 8. However, if a WP fails to mention the word 'crisis/crises' even once, then arguably, it cannot be considered a crisis WP. Thus, our definition imposes a lower bound on the engagement of the WP author/s in the crisis study.
} 
significant at $1 \%$, with $z=9.95$. Moreover, according to Table 3, the sup-Wald test statistic for structural breaks, attains its maximum value of 70.36 in 2009, also significant at the 1\% level.

\subsection{Crisis study and financial instability indexes}

To assess the correlation of the crisis study intensity with financial instability, we consider two indexes of financial instability. The first is the Kansas City Financial Stress Index (KCFSI), a monthly measure of a stress in the U.S. financial system based on 11 financial market variables (Hakkio and Keeton 2009). The second index, Composite Indicator of Systemic Stress (CISS), is based on the aggregation of 5 market-specific sub-indices constructed from 15 individual financial stress measures of EU. The index puts a high weight on situations where stress prevails in several market segments simultaneously, capturing the idea that financial stress is more systemic and thus more dangerous if financial instability spreads widely (Holló et al. 2012). ${ }^{24}$

When we consider Google Trends, we find that the indexes are strongly correlated with the weight of the topic 'crisis' in Google Trends, but they capture the early stages of the crisis and start to pick up the signals of instability starting in 2007, while a jump in the Google Trend is observed only around the collapse of Lehman Brothers at the end of 2008 (see Figure A3b in the Appendix). Google Trends reflects contents of blogs, and economics and news sites that may not require an in-depth work to produce new data and materials, which can explain the leading response of Google Trends. However, the comparison with Google Trends also reflects, we believe, the deviation between the interests of the general public and professional economists.

We calculate annual averages of the two indexes to match the annual frequency of our data. Figures 1a and 1b indicate a high correlation between the \% of crisis WPs and 2-year lagged CISS and KCFSI indexes, respectively. In other words, the number of crisis WPs lags the financial instability indexes. Indeed, the regression estimation results of annual \% change in crisis WPs on annual changes in the stability indexes in column 1 of Table 4 are consistent with this interpretation. The slope and the intercept of the estimated regression are both positive and statistically significant at the $1 \%$ level, with $\overline{R^{2}}=0.46$.

We obtain similar results when we include in the regression a dummy variable for the 2008-2012 period. The regression coefficients are still positive and significant at the $1 \%$ level with $\overline{R^{2}}=0.53$ (column 3, Table 4). When the CISS index is added to the regression, the estimated coefficients are positive and significant at the $1 \%$ level with $\overline{R^{2}}=0.68$ (column 4 , Table 4).

\footnotetext{
${ }^{24}$ For more details about the methodology behind the KCFSI and the CISS indexes, see the Online Appendix.
} 
The 2-year lagged US index for financial stability, KCFSI, also has a positive and statistically significant correlation with the frequency of crisis WPs, but to a lesser extent than the European index. Here $\overline{R^{2}}=0.34$, and the slope of the regression equation is significant at the $5 \%$ level (column 2 of Table 4).

When we include among the regressors leads and lags, as we do in Tables A4b and A4c in the appendix, we find that only the 1-year lagged CISS indexes is significant at the $10 \%$ level. When we run a similar regression for the KCFSI index, only the $2 \mathrm{y}$ lagged index yields significant results at the $5 \%$ level.

Stability indexes are composed of various individual interest rate spreads which differ depending on the credit quality and the corresponding risks they reflect. As Hakkio and Keeton (2009) argue, these differences capture distinct aspects of financial stress-flight to quality, flight to liquidity, asymmetry of information between buyers and sellers of financial assets, etc.

To explore how individual spread measures may correlate with the \% of crisis WPs, we regress five different (two-year lagged) yield spread variables on the \% of crisis WPs. Only two of the 5 variables are statistically significant (Figure A3 and Table A4 in the Appendix): the spread of the Baa Corp Bond over 10-year treasury, and the spread between Moody’s Baa and Aaa Corporate Bonds. Based on Hakkio and Keeton (2009), we suspect that these two variables were the most relevant for the 2008 financial crisis, as the risks and the credit quality attributes that the other three variables reflect were perhaps less relevant, or they were relevant only for a portion of the crisis period. When we include in the regression a dummy for the post-2008 period, then the regression coefficient is significant only for the spread between Moody's Baa and Aaa Corporate Bonds, suggesting a particular importance of a flight to quality and increases in information asymmetries during the crisis (Hakkio and Keeton 2009).

\section{Global crisis and academic scholarship}

We start textual analysis by looking at the crisis study efforts of different NBER research programs. We then consider the crisis-related publication track record of top finance journals.

\subsection{Global crisis and the NBER research programs}

Out of the 14,270 NBER WPs that were published during 1999-2016, 1,632 of them, i.e. 11.4\%, are crisis WPs. The six macro/finance NBER programs noted above are the ones that engage most extensively in crises study, in terms of both the absolute number and the \% of crisis WPs. The total number of WPs published by the members of these programs ranges between 1,977 and 3,634. Of these, between 189 (International Trade) and 737 (International Finance and 
Macroeconomics) are crisis WPs. The programs, however, differ in both, the intensity as well as the speed of their reaction to the crisis.

For each program, we run three tests to understand how the program' members were engaged in studying the crisis and how they have reacted to the crisis. First, we use z-test to compare the average \% of crisis’ WPs written before and after 2008 (Table 2). Second, for each program we run a regression of the average annual \% of crisis WPs published by the program members, on the average annual \% of crisis WPs produced by all programs (Table 5). A regression coefficient of greater (less) than 1 suggests that the program is more (less) “active” in studying the crisis in comparison to the average of the entire NBER community. The intercept can be interpreted as the program members' efforts to study crisis when the rest of the community is not engaged in studying it. Third, we apply sup-Wald (Quandt Likelihood Ratio) test for identifying structural breaks (Table 3). The time series plots of the average annual \% of crisis WPs for eight NBER research programs (the six programs listed above, plus two additional programs, Industrial Organization and Health Care, for reference), are shown in Figure 2.

Table 2 presents descriptive statistics on crisis WPs for the six programs. According to the table, the members of the International Finance and Macroeconomics, and Monetary Economics programs published the highest numbers of crisis WPs, 737 and 468, respectively, during the sample period. These are the only two programs that have an average \% of crisis' WPs before 2008, 29.6\% and 11.9\%, respectively, that exceed the average of all NBER programs, $8.3 \%$.

The crisis effect on the scholarly interests of the members of the International Finance and Macroeconomics program is small, but statistically significant. The average \% of crisis WPs the program members published increased from 29.6\% before 2008, to 36.9\% after 2008, with $t=$ 3.70, $p<0.01$. According to Table 5 , the regression of the annual \% of crisis WPs of this program, on the annual \% of crisis WPs of all NBER programs, yields a positive intercept of $15.2 \%$, significant at the $5 \%$ level. This suggests that this program members were engaged in studying crisis-related topics when all other programs were studying other topics. ${ }^{25}$ The slope estimate, 1.65 , is low, but statistically significant at the $1 \%$ level.

In contrast, we observe a big change in the intensity of the Monetary Economics program members in the post-crisis period, averaging 31.6\% crisis WPs after 2008, compared to $11.9 \%$ before 2008. By 2016, the two programs, International Finance and Macroeconomics and

\footnotetext{
${ }^{25}$ The early interest of the members of the International Finance and Macroeconomics group in crises-related topics is likely the result of the LDC debt crisis of the 1980s and the Asian crises of 1990s, both of which were extensively studied by the members of this group. The results of some these studies were published in Sachs (1989a, 1989b) and in other follow up NBER volumes.
} 
Monetary Economics, converge to the same peak, 46\% of the average \% of crisis WPs, as Figure 2 indicates. In other words, by 2016 almost half of the WPs produced by these two research groups, had some crisis-related content. Using topic modelling analysis, however, we show below that there are important differences between the questions that the two program members ask and the particular topics they chose to study.

The Monetary Economics program is the most “counter cyclical” and aggressive in studying the crisis with a slope of 2.92, significant at the 1\% level, relative to the average of the entire NBER community (Table 5). Nevertheless, the reaction of its members was relatively slow compared to the finance-focused programs. Indeed, according to Table 3, the sup-Wald statistic for a structural break in 2008 for this program is significant only at the $10 \%$ level $(p=5.58 \%$ ). Also, according to Figure 2, in terms of its engagement intensity, the Monetary Economics program caught up with the International Finance and Macroeconomics program only in 2011.

The members of two finance-related programs, Corporate Finance and Asset Pricing, had barely referred to a crisis before 2008. According to Figure 2, the average annual frequency of crisis WPs published before 2008 by the members of these two programs are $7.3 \%$ and 5.3\%, respectively. ${ }^{26}$ Moreover, these are the only two programs with negative and statistically significant intercept estimates, about $-11 \%$ in both cases, in the regression estimates in Table 5. While these program members seem to have been completely disconnected from the study of crisis related issues prior to the 2008 crisis, their reaction to the crisis was the fastest and perhaps also the most dramatic among all programs. The sup-Wald statistic for the two programs attains its maximum value in 2008. According to Table 2, the average \% of crisis WPs published after 2008 by the members of the Corporate Finance program equals 26.1\%, more than triple in comparison to the pre-crisis period. For the Asset Pricing program, it is 22.5\%, which is more than quadruple in comparison to the pre-crisis period. Moreover, Figure 2 shows that the two programs are still very active in studying the crisis, with a similar extent of engagement over time. The slope estimates, according to Table 5, equal 2.52 and 2.3 for Corporate Finance and Asset Pricing programs, respectively, both significant at the $1 \%$ level.

Two programs, International Trade and Investment, and Economic Fluctuations and Growth, behave very similarly until 2012, as Figure 2 shows. Prior to the crisis, both program members have a low engagement in crisis-related topics, but it jumps following the 2008 crisis. However, the two programs diverge in 2012. The members of the Economic Fluctuations and Growth

\footnotetext{
${ }^{26}$ As an illustration, only 4 WPs out of 86 WPs published in 2007 by the Corporate Finance program, mention the word "crisis." Even more extreme, only one WP out of 92 WPs published by the Asset Pricing program in 2007 mentions the word "crisis."
} 
program seem to keep the same level of engagement, but the members of the International Trade and Investment program reduce their crisis-related study efforts to the pre-crisis levels.

Finally, according to Figure 2, considering the last three years of our sample period, 20142016, we find that the Monetary Economics, International Finance and Macroeconomics, Corporate Finance, Asset Pricing, and Economic Fluctuation and Growth program members are still engaged in studying the crisis in the same intensity as in the crisis period, 2009-2012. The program of International Trade and Investment along with other programs, however, have reduced their efforts to study crises. ${ }^{27}$

\subsection{Finance journals and the financial crisis}

For robustness, we look at the track record of top finance journals in publishing crisis-related papers and compare them to the corresponding NBER program members’ output. We consider the correlation between the \% of crisis papers that were published in the top-3 finance journals, and the \% of crisis WPs published by the NBER's (a) Asset Pricing and (b) Corporate Finance programs during 2004-2016. This is reasonable comparison because the journals are the primary publication outlets, i.e., they are the target field journals, for the members in these programs. ${ }^{28}$ Table A20 in the Appendix shows that more than 21\% of the programs' WP were published in the top-3 finance journals. Further, on average around 11\% of the journals' papers are NBER WPs (Table A21 in the appendix). As Figure 3a shows, the NBER finance programs lead the top3 finance journals by about 2 years, a reasonable amount of time for editorial review and decision process. But the correlation coefficient between the series, after adjusting for the 2-year lag, equals 0.91. Indeed, the plot shows a strong similarity between the two time-series. In particular, the pattern of a very low engagement before the crisis and a sharp increase in the study efforts following the crisis, and the continued persistence in the study efforts, thereafter, is observed in both series. ${ }^{29}$

Figures 3b and 3c show that the behavior of other leading finance journals is mostly similar to the behavior of the top-3 journals, consistent with "slow to see, fast to act" pattern of publication record. These journals are ranked “A” by the Australian Business Dean Council, and includes the Journal of Banking and Finance, Journal of Corporate Finance, Financial Management, Review

\footnotetext{
${ }^{27}$ See Table A2 in the Appendix for details.

${ }^{28}$ We refer only to top finance journals because top economics journals serve the general readership and thus, they cannot be classified as the primary target journals for the scholars in the two NBER research programs.

${ }^{29}$ The reaction speed of the three finance journals differ, at least in part because two of them published special issues devoted to the crisis. The Journal of Financial Economics published two special issues (Kashyap and Zingales 2010, and Kashyap, Rajan and Stulz 2012), and the Review of Financial Studies, one (Spiegel 2011).
} 
of Finance, Journal of Financial Markets, and the Journal of Financial Intermediation. The Journal of Financial Intermediation was the first to react in 2008 with an increase of more than $20 \%$ in the percentage of papers that mention “crisis” at least once. Moreover, by 2015, almost all its published papers refer to the crisis. A similar behavior but with a lower intensity and a slower reaction is observed at the Journal of Banking and Finance, Review of Finance, and the Journal of Corporate Finance. In contrast, Financial Management and the Journal of Financial Markets start to refer heavily to the crisis only after 2015.

The Journal of Financial Stability is an exception. A majority of its paper discuss crises before, during and after the 2008 financial crisis. In the years 2010-2016, almost all its published papers refer to the crisis. The journal, which was established in 2004, just 4 years before the 2008 crisis, has an explicit goal to provide an international forum for studying the causes, management, resolution and preventions of financial crises. The results we report, underscore the importance of such an outlet, fully dedicated to the study of financial stability and crises.

Overall, these findings suggest that that the sentiments, the learning curve, and the scholarly interests of the editors of top field journals and the NBER scholars in the relevant programs were similar, in line with each other.

\section{Topic Modelling Using LDA}

\subsection{Topic modeling: A brief review}

Topic modelling machine learning algorithms are generative models designed to replicate the process by which an author may produce a document. The algorithms accomplish this by conducting statistical analyses on bags of words. Topic modelling algorithms take as input textual information, for example documents, ignoring the order of words in them, treating them as a bag of words where syntax rules play no role. The algorithms identify the topics in the documents and produce a list of words found in the documents. In other words, the algorithms take texts, and break them down into lists of words, such that the words in each list are related to each other. A topic is a probability distribution over the words. The algorithms assign to each word the probability of how likely it is to appear in the context of a given topic. The resulting model consist of the topics, the words, and the context, which is viewed as approximately resembling the human brains’ interpretation of textual information.

The algorithms use words' statistical co-occurrence patterns to produce a group of related words, which form a topic. A word can belong to many topics. The importance of each word is determined relative to other words in the topic, and thus the occurrence frequency of each word 
in a topic is ranked relative to the occurrence frequencies of other words.

LDA, introduced by Blei, Ng and Jordan (2003), is one of the most popular methods in topic modeling. The algorithm assumes that words in a given text are related (Fligstein et al. 2017, Knispelis 2016). For example, in our case, NBER WPs are usually addressing few research questions and thus their texts are highly contextualized. The algorithms assume also that a given text/document contains multiple topics, where a topic is defined as a distribution over a fixed vocabulary of terms. For example, if NBER WPs cover $K$ topics, then we can assume that each WP covers these topics with different proportions. This is reasonable because NBER WPs are quite heterogeneous, and therefore we can think of them as combining a subset of topics that are found in all NBER WPs. In other words, in LDA analysis we can think of a document as a probability distribution over topics, and we think of a topic as a probability distribution over words. The model's goal, therefore, is to simultaneously estimate the word content of each topic, and the topic content of each document.

As an example, consider a set of $D$ documents (in our case, the introductions and/or the abstracts of the NBER WPs) that consist of a total of $W$ different words, and consider a matrix whose elements are the probabilities that word $w_{i}$ is present in document $d_{j}$. By breaking down the document texts into $K$ topics, the algorithm produces two probability matrices. The $(i, k)^{\text {th }}$ element of the first matrix is the probability that word $w_{i}$ is present in topic $k$. The $(k, j)^{\text {th }}$ element of the second matrix is the probability that topic $k$ is present in document $d_{j}$.

More formally, topic modelling algorithms model the probability that word $w_{i}$ is present in document $d_{j}$ as a product of two probabilities. The first is the probability that word $w_{i}$ is present in topic $k, P\left(w_{i} \mid z_{i}=k\right)$. The second is the probability that topic $k$ is found in document $d_{j}, P\left(z_{i}=k \mid D=d_{j}\right)$. In other words, the algorithm assumes that $P\left(w_{i} \mid D=d_{j}\right)=\sum_{k=1}^{K}\left[P\left(w_{i} \mid z_{i}=k\right) P\left(z_{i}=k \mid D=d_{j}\right)\right]$ where $P\left(w_{i} \mid D=d_{j}\right)$ is the probability distribution of words in document $d_{j}, P\left(w_{i} \mid z_{i}=k\right)$ is the probability distribution of words in topic $k$, and $P\left(z_{i}=k \mid D=d_{j}\right)$ is the probability distribution of topics in document $\boldsymbol{d}_{j}$. 


\subsection{Implementation of the LDA model}

To implement the LDA algorithm, three inputs are needed. The first is the number of topics, which the model has no way of determining on its own. By choosing the number of topics $K$, we are "forcing" the algorithm to identify $K$ topics in the text. The other two inputs are hyperparameters $\alpha$ and $\beta$, both parameters of Dirichlet distribution. The parameter $\alpha$ governs the prior topic distribution per document, while the parameter $\beta$ governs the prior word distribution per topic, controlling for the expected density of words in topics. High (low) $\alpha$ will lead to many (few) topics per document. High $\beta$ yields topics with words that contribute more uniformly to topics, while low $\beta$ will lead to few words dominating a topic. This implies, for example, that high $\alpha(\beta)$ will make documents (topics) appear more similar to each other because it makes every topic appear in every document, while low $\alpha(\beta)$ will make documents (topics) appear more distinct from each other because it will make every document be represented by fewer topics (Fligstein et al. 2017, Jegadeesh and Wu 2016).

To apply the LDA topic modelling algorithm, the raw textual data (in our case, the NBER WPs), had to be pre-processed and cleaned to remove all the "irrelevant" information, i.e., all possible sources of "noise," as follows. First, we downloaded the WPs from the NBER website, and converted them from PDF format to a Text format. Second, we filtered out of the text files the paper titles, the author/s names and other author-related information, the page numbers, graphs, equations, references, etc., keeping only the primary text. We had to repeat this process several times with different filtering instructions, because different WPs have different layouts and patterns. Third, we remove from each file, all the text except the first 5 paragraphs of the introduction. Fourth, we removed from the 5-paragraph texts, the "stop words" ("is," "the," etc.). In addition, we used a word-stemmer to remove any generic suffixes from the words, which enabled us to group them into similar word groups, when running the algorithm. Fifth, we combined different spellings of a given term such as “crisis" and "crises," into a single word “crisis.” Note that the third step applies only to the second part of our study, where we analyze the first five paragraphs of the introduction of the WPs (section 8), rather than their abstracts (section 6).

Our decision to limit the analysis to the abstract and the first five paragraphs of the introduction, is based on the findings reported by studies that conclude that analyzing full texts of papers can introduce too much noise in the topics, making it hard to interpret. For example, Shah et al. (2003) and Schuemie et al. (2004) find that the ratio of relevant to irrelevant 
keywords ("information density") is the highest in the abstracts. Blair and Maron (1985) note the limitations of comprehending full texts as they typically contain a lot of "noise” which may obfuscate more relevant information. Consistent with this observation, Sybrandt et al. (2018) find that, quantitatively, corpora with a higher median document length leads to higher quality results only marginally (if at all). However, qualitatively, full-length papers introduce a significant number of "intruder terms" into the resulting topics, which decrease the interpretability of the results. Similarly, Sinclair and Webber (2004) find that titles and abstracts yield classification analyses with the highest precision. Consistent with these findings, Chen et al. (2020), Cretchley et al. (2010), Lee et al. (2016), Yan (2015) and Zhong et al. (2016) conclude that abstracts are sufficient for capturing summaries of articles in terms of research aims and problems, as well as major findings. We thus conclude that the papers' abstract and introductory paragraphs will usually contain most (if not all) topic-related statements and words. Multiple robustness analyses which we discuss below, suggest that this was indeed the case.

The model starts by assigning to each word a generic label, based on their appearance in the text. Next, the model combines the context (WPs), the words that remain after pre-processing, and the topics, producing a topic distribution, i.e., what topics appear in the WPs. The algorithm sorts the words and ranks them based on their appearance frequency by computing for each word a probability that it will belong to a topic. Because the labels the algorithm assigns to the topics, Topic 1, Topic 2, etc., are meaningless, we replace them with a more meaningful labels, based on the topic's content, based on the list of the words in the topic (Paul and Girju, 2009).

We programmed the steps outlined above in a special Python module, which automated the entire process. We cached the results of each step which made it easier to run the analysis multiple times, and to monitor the process to ensure that the results were reliable and optimized.

After implementing the preliminary steps, the database was ready for processing using the LDA. As noted, we had to choose three parameters. It turns out that a reasonable number of topics in the first part of the analyses is $K=500$. We set $\alpha=0.01$, which is a common default value of the algorithm we employed, and $\beta=0.01$, following the seminal papers of Griffiths and Stayvers (2004), Stayvers and Griffiths (2007), Kaplan and Vakili (2015), Jegadeesh and Wu (2016), and Huang et al. (2018).

To assess the sensitivity of the results to the parameter choices, we explored other possible values for $\alpha$ and $K$. See Table 6 . The figures in the table are the number of crisis' topics that we identified for each combination of $\alpha$ and $K$. As the table indicates, an increase in number of topics $K$, increases the number of crisis’ topics we identify. However, it turns out that any 
additional crisis topics beyond 9, are either irrelevant or indistinguishable from the first 9 topics. We have therefore settled on $\alpha=0.01=1 \%$ and $K=500$. Jegadeesh and Wu (2016) report a similar figure. In analyzing their data, they settle on 8 topics, after conducting a similar sensitivity analysis.

\subsection{Crisis topics in $L D A$}

Because we focus on crisis studies and how they are affected by the state of the economy, we want to focus mainly on papers that deal with crisis topics, where we define a 'crisis topic' as a topic that contains the word crisis/crises. ${ }^{30}$ We find 9 crisis topics among the 500 topics LDA generated. ${ }^{31}$ Table 7 presents the list of these topics, and 10 most frequent words in each topic. The title we gave to each topic are based on the words that appear with the highest frequency in the topic. ${ }^{32}$

The 9 topics are labeled “International Reserves," "Sovereign Debt," "Liquidity,” "Emerging Markets,” "Repo and Securitization,” "Global Crisis,” “Great Recession,” "Sudden Stops,” and "Financial Intermediaries." To confirm that the topics indeed deal with the crisis, we checked that the word 'crisis' is actually mentioned in the 20 WPs with the highest probability for each topic. Following our analyses above, we define a “crisis-WP” as a WP that mentions the word 'crisis/crises' at least once in the first five paragraphs of the introduction.” Out of the 180 WPs that we review, 178 WPs indeed mention the word crisis at least once.

As expected, the correlations between the annual weights of the 9 crisis topics and the remaining 491 topics in the same WPs are quite low, ranging between -0.15 and 0.15 . However, these correlations can be high for topics found in different WPs if they relate to events during the same time period. Indeed, it turns out that the weights of the 9 crisis topics are often correlated with topics which have little to do with the 2008 financial crisis such as 'School Achievements' or 'Artist Life Cycle,' as Table A18 in the Appendix shows. This analysis did not yield any new crisis-related topic, supporting the robustness of our identification of the crisis-related topics. ${ }^{33}$

\footnotetext{
${ }^{30}$ In section 8, we employ a stricter criterion for identifying crisis WPs. The usage of keywords and JEL codes is not mandatory for NBER WPs. Consequently, they are rarely used and therefore we could not use them to identify crisis WPs.

${ }^{31}$ If we use bigram-LDA, we identify 7 crisis topics instead of 9. See Table A7b in the Online Appendix for details.

32 In case of synonyms, we add up the frequencies based on one representative word. For example, 'intermediaries' summarizes the words 'bank,' 'institutions,' 'sector,' and 'intermediaries,' which together appear more frequently than the second most frequent word in the topic-'market.'

33 The topic of 'International Reserves' which is correlated with the topics of 'Default Risk' and 'CEO Turnover,' and the topic of 'Repo \& Securitization' which is correlated with the topic of 'Credit Cycle,' are exceptions.
} 


\section{Meta-study of crisis topics}

To assess how scholars dealt with the crisis, we focus on the 9 crisis topics that we have identified, and examine the discipline's treatment of the topics in terms of the amount of the attention the topics received, and how that attention varied over time, particularly around the crisis' years. We also try to determine whether the evolution of the crisis topics was a stable process, or perhaps it had experienced changes.

\subsection{Topics' ranks and structural breaks}

To assess the effect of the 2008 crisis on the crisis topics and their trends, we look at 9 time series of the weights of each crisis topic in the WPs' abstracts. We find that the behavior of the sum of the weights of all topics (Figure 4), is similar to the \% of crisis WPs (Figure 1a).

Figure 5 shows the average weight of each crisis topic between 1999 and 2016. We analyze the trends in three ways. First, Table 8 shows the annual rank of each topic among the 500 topics that were considered by the LDA algorithm. Second, to determine whether the evolution of the topics has followed a stable processes over time, or perhaps experienced a break, we use QuandtAndrews sup-Wald test for structural breaks, which is particularly useful in settings with unknown break points. ${ }^{34}$ To apply the method, we choose $15 \%$ symmetric trimming from both ends of the sample $(0.15 T<T B<0.85 T)$. We also calculate the Wald statistic for the years 2007, 2008, and 2009 to test for a known structural break during the period of the financial crisis. ${ }^{35}$

Finally, we use z-test to compare the average \% of crisis WPs written before the crisis (20052008), during the crisis (2009-2012), and during the post-crisis (2013-2016) periods. We interpret a positive or a negative significant z-test statistic as an evidence of the effect of the crisis on the importance of a topic. We can identify the "persistence" in the study of a topic if the z-test statistic is positive and significant when comparing between both the post-crisis and the pre-crisis periods, and between the crisis and the pre-crisis periods. Similarly, a sign of a “reversal” or no evidence of persistence is identified by an insignificant $z$-test statistic between the post-crisis and the pre-crisis periods, and a positive and significant $z$-test statistic between the post-crisis and the pre-crisis periods.

\subsection{Trends in crisis topics over time}

\footnotetext{
34 The sup-Wald test for structural breaks is based on Quandt's (1960) sequential application of the traditional Chow test for an unknown breakpoint. The test, known as the Quandt-Andrews sup-Wald test, is based on computing Wald test statistic for each of the possible breakpoints within a range of dates, and then finding their supremum. Hansen (1997) generates the approximate $p$-values for the sup-Wald statistic. See also Andrews (1993).

${ }^{35}$ Because of the trimming, structural breaks that occur in the proximity of the end points, 1999-2002 and 2014-2016, cannot be detected.
} 
Here we consider the evolution of the crisis topics over time and assess the effects of the 2008 crisis.

\subsubsection{General trends}

Based on the ranking of the crisis topics, we classify the 9 topics into three groups. One group includes the topic of 'Great Recession,' a topic that emerged during the crisis period and is related to the spread of the financial crisis to the real economy. The second group of topics are the disappearing topics, 'Emerging Markets' and 'Sudden Stops.' The third group of topics are topics in which the crisis had a short-lived but positive effect on their weights. These topics include 'Financial Intermediaries,' that deals with the structure of financial markets and institutions that make them fragile, 'Liquidity,' which deals with both market dry out and liquidity traps, 'Repo and Securitization,' which deals with the effect of short term liabilities backed by risky portfolio of loans and bonds, 'Global Crisis,' which relates to the global spread of local crisis, and 'International Reserves' and 'Sovereign Debt.' Interestingly, there is a decline in all crisis' topics from the end of 2013 and on, except in 'Sovereign Debt' and 'Great Recession,' which remain relatively flat in the post-crisis period.

The effect of the crisis on each topic can be seen through the plots in Figure 6 and Tables 10, which shows the time series of the Wald-statistic for a structural break for each topic. The results indicate that all topics except 'Emerging Markets,' experienced statistically significant structural breaks during the sample period. Moreover, with the exception of 'Sovereign Debt,' all breaks occur either during the 2007-2009 financial crisis, or thereafter. All breaks with the exception of 'Sudden Stop' and 'Sovereign Debt,' are followed by an increase in the topics' weights. See Figures 4 and 5 as well as Table 8.

The topics of 'International Reserves' and 'Global Crisis' experience the most significant breaks in 2009 according to the sup-Wald test, although for the latter we find a structural break in 2008 also. In 2007, the LDA model ranks the topics of “International Reserves” and 'Global Crisis' at 181 and 218 out of 500 (Table 8). However, in 2009 the two topics are ranked at 53 and at the $1^{\text {st }}$ place respectively. The increase in the importance of the topic of 'Global Crisis' is also captured by a positive significant difference between the means of the pre-crisis (20052008) and the crisis (2009-2012) periods. There is no significant difference in means for the same periods for the topic of “International Reserves," which can be explained by the decline in the importance of the topic since 2012.

The first structural break during the crisis period occurs in 2008 for "the topic of "Liquidity." In 2007 the topic was ranked at 202 and in 2008 at 72. Similar to the topic of "International 
Reserves," there is no persistency in studying this topic and in 2012 the topic is ranked at 145. The topic of “Great Recession” experiences the first significant structural break only in 2009 based on Wald test and in 2010 based on sup-Wald test. The topic is ranked at 241 in 2007 and at 19 in 2010. The topic of 'Financial Intermediaries' experienced the most significant break in 2012, moving from the $86^{\text {th }}$ place in 2007 to the $38^{\text {th }}$ place in 2012 . However, in 2015 the topic is ranked at 179 , returning to levels of the dot.com crisis period.

\subsubsection{Sudden stop in the "Sudden Stop"}

The term "Sudden Stop,” coined by Calvo (1998) following the 1994 Mexican crisis, describes situations where there is a sharp reversal in the aggregate foreign capital inflows. While there is no consensus on what triggers such reversals, two consequences have been amply documented - exchange rate drops and economic downturns, effectively constricting domestic consumption smoothing. Moreover, sudden stops typically come in clusters: the 1994 Mexican crash triggered a sudden stop in Argentina in 1995. In 1997-1998, the East Asian crisis engulfed 7 neighboring countries.

Macroeconomists' efforts to develop models that could explain sudden stops followed. According to Claessens and Kose (2013), these models tend to focus on the role of international factors, as captured by changes in international interest rates or spreads on risky assets, in causing sudden stops in capital flows. These models can explain the current account reversals, as well as the real exchange rate depreciations typically observed during emerging market crises.

In 2000, the LDA model ranks the topic of "Sudden Stop” at 450 out of 500 (Table 8). In the following years, the topic receives a lot of attention, so much so that by 2004, it ranks 32, the highest rank a crisis' topic attained in that year. While the topic was still ranked at 181 in 2008, it disappears in the post-crisis period, ranking at 477 by 2009. Consistent with this variability in the ranking, we observe two significant structural breaks. The first in 2004, when the topic reaches its peak, and the second in 2007, when it starts to leave the stage and disappear from the literature. ${ }^{36}$ Moreover, as shown in Table 9, the topic of 'Sudden Stop' is the only topic for which a significant negative $z$-test $(p=0.05)$ is observed between both the crisis and the pre-crisis periods, and between the post-crisis and the pre-crisis periods.

\footnotetext{
${ }^{36}$ While explaining the reasons for the decline in the topic's importance is beyond the scope of our paper, according to Caballero (2010), the key concern of international macroeconomists before the crisis burst was that the US would experience a sudden stop in capital flows along with a sharp depreciation in the dollar, predictions which did not materialize. Mendoza and Yue (2012) propose a general equilibrium model which links sovereign default to business cycles and note that in most of the sudden stops' literature, a loss of credit market access is modeled as an outcome of an exogenous shock, whereas in their model the exclusion from credit markets and the economic collapse are endogenous and influence each other.
} 


\subsubsection{A reversal in the study of 'Repo and Securitization'}

The financial crisis led many prominent scholars to suggest new study directions in order to understand the sources of the crisis, to cope with it, and to prevent future crisis. One natural candidate that was viewed as amplifying the financial crisis was the use of short-term debt instruments such as repo agreements and asset-backed commercial papers (ABCP), to finance securitized long-term debt. These types of transactions were considered a likely culprit in fueling the crisis because such instruments were almost non-existent during the previous crises, and there was an explosive growth in their usage in the years prior to the 2008 crisis. Gorton and Metrick (2012b) suggest that securitization was a major channel for the fast growth of the "shadow banking” system. The increased vulnerability of the system came as a surprise to policymakers and economists, but understanding these instruments is critical for understanding the contagion that eventually spread to the real economy.

Indeed, our results show a significant structural break in 2009 for 'Repo and Securitization.' The Wald-statistic for the topic equals 39.1 (Table 10) and the rank of the topic shifts from the $423^{\text {rd }}$ place in 2008 to the $40^{\text {th }}$ place in 2009 ( $3^{\text {rd }}$ among the crisis topics in that year). The topic remains at the center of the academic research until 2012, where it ranks $29^{\text {th }}\left(3^{\text {rd }}\right.$ among the crisis topics in that year). However, the interest in the topic declines fast in the post-crisis period, where the topic is ranked 371 in $2015 .{ }^{37}$ The robustness of the results is strengthened by the $z$ test for a difference in means. The average weight of the topic in the crisis period (2008-2012) is significantly higher $(p=0.01)$ than in the pre-crisis period (2005-2008). However, the average weight of the topic in the post-crisis period does not differ significantly from the pre-crisis levels, and there is no evidence of persistence in the study of the topic.

\subsubsection{Momentum in the study of 'Great Recession'}

The topic of 'Great Recession,' which is related to the effects of the financial crisis on the real economy, hardly existed before the financial crisis, as it was ranked $414^{\text {th }}$ in 2008 . However, our results show a significant structural break in 2010 for the topic, where the Wald-statistic equals 12.6 (Table 10). The topic is ranked $19^{\text {th }}$ among all topics in that year (Table 8). Moreover, the average weight of the topic in the crisis period is significantly higher than its weight in the precrisis period. The topic differs from other topics that emerge during, and right-after the crisis, as

\footnotetext{
${ }^{37}$ While there may be many possible reasons for the emergence of this research topic, including unregulated shadow banking system, moral hazard, too complex financial structures, and lack of transparency, we find in the literature only few explanations for its decline after 2012. Benmelech et al. (2012) show that adverse selection problems in corporate loan securitizations are less severe than commonly believed. Krishnamurthy et al. (2014) argue that the size of the repo market was too small to trigger a collapse in the financial system.
} 
there is a clear evidence of persistence in its study in the post-crisis period. The topic is ranked $6^{\text {th }}$ among all crisis topics in 2012 and 2014 (Table 8). Moreover, the average weight of the topic in the post-crisis period is higher than in the pre-crisis period, significant at 1\% (Table 9).

\section{Crisis literature: Pre-crisis vs. post-crisis}

To further assess the effect of the 2008 crisis on the academic literature, we apply the LDA method to papers that focus primarily on crises research, which helps us understand if and how the structure of the crisis-related literature was affected by the 2008-2009 crisis. Moreover, the analysis serves as a test of robustness of the results we reported above on the effect of the crisis on the entire macro/monetary/finance economic literature. In the following analyses, we define a WP as a 'crisis WP' if (1) it includes the word crisis at least once in the first five paragraphs of the introduction, (2) crisis topics comprise at least 10\% of the paper, and (3) crisis topics are among the three topics with the highest weight for each paper. Applying this definition, the algorithm identified 612 WPs, where 165 WPs were written in the pre-crisis period 1999-2007, and 447 in the crisis and post-crisis period 2008-2016.

To assess the evolution of the crisis study over time, we run four complementary analyses. First, following Griffiths and Steyvers' (2004) approach to identify "hot” and “cold” topics in the PNAS, we fit an LDA model for the entire database and then derive the topic distribution for three time-windows: pre-crisis period (till 2008), crisis period (2009-2012) and post-crisis (2013-2016), and search for significant differences in the topics weight between the sub-periods. In the second analysis, we pre-divide the data into discrete time slices and fit a separate topic model to each slice as in Wang et al. (2005).

While the above analyses are useful in identifying the emergence of new topics, they have two shortcomings. First, they may not reflect the temporal ordering of the documents. Second, they assume that the same words compose a topic over time, and thus they cannot capture time variability in topic words. For example, a topic devoted to articles about sovereign risk could give high probability to words related to “Argentina” 40 years ago but shift around the 2011 to sovereign debt crisis by including words like "Greece” or "Italy.” In the third analysis, therefore, we employ dynamic topic modelling (DTM) approach which addresses this particular issue by allowing the distribution of words in topics to change over time (Blei and Lafferty, 2006).

Finally, while in section 7 we assess the contribution of each NBER program to the study of different research topics, here we consider the distribution of the topics studied by each NBER program before, during and after the 2008 crisis. We show the effect of the crisis on the study 
topics of each program and search for significant changes. Next, using the Jensen-Shannon divergence measure, we estimate the similarities between the distributions for each pair of NBER programs before and after the crisis to assess the extent of the convergence of the programs in their study topics.

\subsection{Trends in the topics of the crisis WPs over time}

We start by identifying 20 topics in the 612 crisis WPs. We calculate the average weight of each topic in the pre-crisis period (2005-2008), during the crisis period (2009-2012), and in the post-crisis period (2013-2016). As in Table 9, we use z-tests to compare the average weight of a topic in the pre-crisis period with its average weight during the crisis and the post-crisis periods. In the analysis of the 500 topics which we discussed in Section 7, an increase in the weight of a crisis topic could be at the expense of the non-crisis topics. However, in the current analysis, an increase in the weight of a topic is at the expense of other crisis topics. ${ }^{38}$ See Table 11.

Similar to the results of the analysis of the crisis topics which we report above for all the NBER WPs in our database, we find that when we compare the pre-crisis and the crisis periods, and the pre-crisis and the post-crisis periods, the topic of 'Sudden Stop' has a negative z-test statistic, significant at the $1 \%$ level. Thus, we see a drop in the study of the topic. A negative $z$ test statistic, significant at the $1 \%$ level, is also observed for the topic of 'Emerging Markets,' when we compare the pre-crisis and the crisis periods, and the pre-crisis and the post-crisis periods. Thus, consistent with the results of the analysis of all WPs sampled (Section 7), we see a persistent decline in the importance of these two topics when we focus on the crisis WPs only.

We find a delayed reaction for two topics. The first is 'Fiscal and Monetary Policy.' The papers that study this topic primarily focus on the coordination of fiscal and monetary policies in the EU. ${ }^{39}$ There is a positive and statistically significant difference between the average means of the pre-crisis and the post-crisis periods. The second topic is 'International Reserves,' which shows a significant drop in its average weight in the post-crisis period. The papers that belong to this topic, primarily focus on the accumulation of foreign reserves by China.

We find a positive and statistically significant difference between the weights of "Great Recession" and "Repo and Securitization" in the pre-crisis and the crisis periods. However, similar to the results we reported in the analysis of the crisis literature using all WPs in our dataset, we find here a positive and statistically significant difference between the pre- and postcrisis periods only for the topic of "Great Recession."

\footnotetext{
${ }^{38}$ The 20 topics and the words that belong to each one of them are presented in Table A7, in the Appendix.

${ }^{39}$ For details, see Table A7 in the Appendix.
} 
The comparison between the crisis and the post-crisis periods does not indicate any significant change in the weights of the topics. Thus, while the 2008-2009 crisis led to a structural break in the study of crisis-related topics, where the weights of 5 out of the 20 topics had changed significantly between the pre-crisis and the crisis periods, no such change is observed in the postcrisis period. Further, the topics that are related to the crisis, remain relatively stable. This conclusion is supported by the findings that, the average absolute change in the topics' weight between the pre-crisis and the crisis periods is only $2 \%$, and the absolute average change between the crisis and the post-crisis periods is only $1.4 \%$. This finding is supported by the Jensen-Shannon divergence measure, which measures dissimilarity between two distributions. The measure equals 0.19 when we compare the distribution of the topics in the pre-crisis period to the distribution during the crisis period. The measure increases slightly to 0.2 when we compare the pre-crisis period to the post-crisis period. The measure, however, equals only 0.12 when we compare the crisis period to the post-crisis period.

\subsection{Evolution in the topics of the crisis WPs: Pre-crisis vs. post-crisis periods}

Next, we divide the crisis WPs into two groups: WPs that were written in the pre-crisis (20052008) period, and WPs that were written in the post-crisis (2009-2016) period, similar to Wang et al., (2005), who divide UN voting records data into 15-year segments. Here we identified 10 topics for each group of WPs.

In Table 12, we present the topics using the labels we attach to them, along with the 10 most frequent words in each topic (out of 20), in the pre-crisis 1999-2007 period. In Table 13, we do the same for the post-crisis 2008-2016 period. Words that appear only in the pre-crisis or only in the post-crisis period, are indicated in italic. In these tables, the words of each topic are ranked according to their appearance frequency in the topic. For example, the word 'liquidity' appears 171 times in the topic of 'Liquidity' in the pre-crisis period.

We find important differences between the two periods. First, a topic that makes a first-time appearance only in the post-crisis period is 'Currency Union' in the context of fiscal union and the EU. Under this topic we find WPs that focus on the weaknesses of the European monetary union, and on the need for a robust common fiscal policy framework which could have alleviated the consequences of the crisis, as discussed by Aizenman (2012), Bordo et al. (2011), Conesa and Kehoe (2014), Razin and Rosefielde (2012), and Vegh and Vuletin (2014).

While the EU is getting a lot of attention in the post-crisis period, the topics related to IMF and its restructuring programs disappear from the post-crisis topics' list. This may be a reflection of the view that this institution is less relevant for the debt-crisis of large developed countries, as 
they may have easier access to more attractive lenders.

The topic of 'Sudden Stop,' which refers to a situation where international capital inflows shrink in emerging markets, creating balance of payment crises, as discussed, for example by Calvo (1998), Calvo and Mendoza (2000), Durdo and Mendoza (2004), Mendoza (2006, 2008), and Mendoza and Smith (2002), is another important topic that leaves the stage, stopping suddenly in the post-crisis 2008-2016 period. This finding is consistent with the result we report in section 7, that sudden-stop models are mostly relevant in the context of foreign exchange management in small open economies, but not in the US or in a large currency union. Indeed, the topic of 'Monetary Policy' in the post-crisis period does not include such words as 'currency,' 'exchange,' and 'emerging.' Instead, the topic now refers to the 'central bank' and its activities.

Two new additional topics that enter the stage in the post-crisis 2008-2016 period are 'Great Recession,' touching the ways of achieving economic recovery and growth, and the 'Federal Reserve,' whose activities now appear as a separate topic. While in the pre-crisis period the monetary policy is mostly focused on determining the short-term interest rates, in the post-crisis period the Fed implemented a quantitative easing program through purchasing long-term debt and risky assets from financial institutions. It is not surprising therefore, that the new topic refers now to the balance sheet of the Fed and to its responsibility in preventing a bank run.

The issues related to the activities of the central bank relate also to the changing nature of the banking topics as a result of the crisis. In the post-crisis period, these refer to the short-term debt (repo) that were used to finance long-term mortgage-backed securities and other collateralized loans. These topics were not among the leading crisis' topics in the pre-crisis period.

\subsection{Evolution in the topics of crisis WPs: Dynamic topic modeling}

Dynamic Topic Modeling (DTM) approach of Blei and Lafferty (2006) identifies latent topics within a data set for a given set of time slices (“epochs”). While static topic modeling considers a snapshot of documents without modeling how they change over time, DTM considers their temporal dynamics by treating the texts as a time-stamped collection of documents. DTM estimates the topics distribution for different time slices, using Gaussian priors for the topic parameters instead of Dirichlet priors. In DTM, all documents are grouped by time slices and the primary assumption is that the topics of each epoch evolve from the topics of the previous epoch.

To estimate the DTM, we assume annual time slices, and set the number of topics to equal 20 (as in section 8.1). ${ }^{40}$ Table 14 presents the words in topics in which we identify a considerable

\footnotetext{
${ }^{40}$ We also analyzed the case of three time slices (pre-crisis, crisis period and post-crisis), but the differences in the results were marginal. DTM was implemented using the gensim library in Python.
} 
change in their weight ranks over time. Consistent with Fligstein et al. (2017), the weight of the word 'inflation target' drops from the $8^{\text {th }}$ and $10^{\text {th }}$ places in 1999 and 2006 , to the $15^{\text {th }}$ and $17^{\text {th }}$ places in 2014 and 2016, respectively. In contrast, the word 'macroprudential,' which is part of the approach that believes that the main goal of financial regulation is to mitigate risks to the financial system as a whole, emerges only after the crisis. The words 'Repo' and 'Fragility' emerge in 2007 and 2006, respectively. Further, after the crisis, the topics of 'Market risk,' 'Fragility' and 'Sovereign debt', include the words 'Euro,' 'Lehman,' and 'Eurozone,' respectively. Interestingly, in the topic of 'Household finance,' the word 'Bubble' climbs gradually from the $10^{\text {th }}$ place before the crisis to the $5^{\text {th }}$ place in the post-crisis period.

To examine the robustness of our findings, we calculate the average weight of each topic in the pre-crisis period (2005-2008), around and during the crisis period (2009-2012), and in the post-crisis period (2013-2016). We use z-tests to compare the average weight of a topic in the pre-crisis period with its average weight during the crisis and the post-crisis periods. As the figures in Table 15 indicate, we find that when we compare the pre-crisis and the crisis periods, and the pre-crisis and the post-crisis periods, the topic of 'Sudden Stop' has a negative z-test statistic, significant at the $5 \%$ level. Thus, we see a drop in the study of the topic. A negative $z$ test statistic, significant at the 1\% level, is also observed for the topic of 'Currency Markets,' when we compare the pre-crisis and the crisis periods, and the pre-crisis and the post-crisis periods. We find a positive and statistically significant difference between the weights of 'Repo and Securitization' in the pre-crisis and the crisis periods. These results are consistent with the results of the LDA analysis of crisis WPs. However, there is a significant increase in the study of 'Great Recession' only in the post-crisis period. Overall, the results of DTM analyses are consistent with the analyses of the entire NBER WPs sample (section 7), and with the analysis of crisis WPs (section 8.1).

The Jensen-Shannon divergence measure which is included in the last row of Table 15, suggests a behavior consistent with the LDA analysis of section 8.1, where we find a high divergence between the distribution of the topics of the pre-crisis and the crisis periods, and between the pre-crisis and the post-crisis periods, but a low divergence between the crisis and the post-crisis periods.

\subsection{Evolution of topics in crisis WPs for different NBER research programs}

While in section 8.1-8.3 we describe the evolution of research topics over time, we ignore the change in the focus of the different research programs and the effect of the crisis on their research topics. We therefore calculate the topic distribution for each NBER program for the pre- 
crisis period 2005-2008 (Table A16 in the Appendix), for the crisis period 2009-2012 (Table A16b in the Appendix), and for the post-crisis period 2013-2016 (Table A16c in the Appendix).

Table 16 lists the topics for which there is as significant change in the weight for at least one NBER research program that we consider in section 5. The topic of 'Sudden Stop' and 'Emerging Markets' comprised respectively 10.4\% and 13.4\% of the topics studied by the International Finance and Macro program members before the crisis. However, their weights in the crisis period declined significantly at the $5 \%$ level to $5.0 \%$ and $6.3 \%$, respectively. These weights drop further in the post-crisis period to 3.6\% and 5.7\%, respectively. The program members appear to have shifted their attention to studying the topics of 'Monetary Policy' and 'Sovereign Debt,' where their weights more than doubles and even triples significantly at the 5\% level.

For the program of Corporate Finance, the weight of the topic of 'Repo \& Securitization' increases from $5.4 \%$ to $26.6 \%$ between the pre-crisis and the crisis periods. However, the weight drops to $14.1 \%$ in the post-crisis period. The increase is only significant at the $5 \%$ level, since the program had only a few crisis papers before 2008. For the same reason, the increase in the weight of the topic of 'Economic Shocks' from 6.4\% in the pre-crisis period to $11.0 \%$ in the postcrisis period is not significant for the Monetary Economics program. For this program, we observe also a decrease in the weight of the topic of 'Currency Market' from 10.3\% in the precrisis period to only $2.0 \%$ in the post crisis period (significant at the $10 \%$ level).

The Economic Fluctuations and Growth program shows similar trends as the International Finance and Macro program of a strong decline in the weight of the topics of 'Sudden Stop' and 'Emerging Markets' and a sharp increase at the post-crisis period in the topics of 'Sovereign Debt' and 'Monetary Policy.' However, only the increase in the topic of 'Sovereign Debt' is significant at the $5 \%$ level. Moreover, the program is primarily focused during all three periods, before, during and after the crisis, on the topic of 'Economic Shocks'.

\subsection{Convergences between NBER programs following the 2008 financial crisis}

Following the 2008 financial crisis, Goldstein and Razin (2013) observed that "the biggest challenge policymakers and economists face is in developing integrative models that better describe contemporary economic realities.” To explore how well the scholars fared with this challenge, we look at the extent of the convergence between different fields of economics in their study efforts by comparing the similarity of the topics that each pair of NBER programs studied before and after the crisis. We conduct the analysis in two steps. First, as in section 8.4, we calculate the topic distribution for each NBER program for the pre-crisis period 2005-2008 
(Table A16 in the Appendix), the crisis period 2009-2012 (Table A16b in the Appendix), and for the post crisis period (Table A16c in the Appendix). Next, following Hansen et al. (2017), we calculate for each pair of NBER programs, the Jensen-Shannon divergence measure, which measures similarity between two distributions for a given time period. We also compare the similarity of each program with itself between the sub-periods.

Table 17 presents the measures for the 2005-2008, 2009-2012, and 2013-2016 periods. For all pairs of NBER programs except two, there is a decline in the measure in 2009-2012, suggesting that the crisis has pushed different NBER programs towards studying the same topics. A strong convergence is observed between the Monetary Economics and the Asset Pricing programs, and between the International Trade program and all other programs. However, in the post-crisis period the similarity between most programs decreases, suggesting that the convergence was relatively temporary. The Monetary Economics program is an exception: it increases even further its similarity with the International Finance and Macro and with the Economic Fluctuation and Growth programs.

When we measure the similarity of the topics of each program in different sub-periods, we see that the similarity between the post-crisis and the crisis periods is always higher than the similarity between the pre-crisis and the crisis periods, except for the International Trade program, suggesting that there is persistence in crisis studies in the post-crisis period. When we compare the post-crisis and the pre-crisis periods, we see no sign of reversal in economics programs, where similarity decreases in comparison to the crisis period. There is a moderate reversal, however, in the behavior of the two finance programs, Corporate Finance, and Asset Pricing.

\section{Summary, discussion, limitations, and future research}

\subsection{Summary and discussion of the main findings}

We use LDA topic modelling machine learning and DTM methods, to offer quantitative measures of the nature and the intensity of the overall academic efforts to study and understand the crisis, as reflected in the 14,270 NBER WPS, published before, during, and after the crisis.

In doing so, we make three specific contributions. First, we assess the aggregate scholarly efforts by quantifying the intensity and the speed of the NBER scholars' response as the crisis was evolving. Second, we analyze the variation across NBER programs to assess which scholars in which fields and subfields of economics and finance have led the change. Third, we assess how the popularity of and the attention to different crisis-related research topics evolved over 
time, and how different NBER research groups were involved in developing and pushing forward these research agenda, topics, and ideas.

We find that the volume of crisis-related WPs is lagging financial instability indexes. The WPs written by Monetary Economics, Asset Pricing, and Corporate Finance program members of the NBER, hardly refer to “crisis” in the pre-crisis period. However, as the crisis develops, their study efforts of crisis-related issues increase rapidly, focusing on the links between 'Repo and Securitization' and the crisis. In contrast, WPs in macroeconomics programs refer extensively to "crisis” in the pre-crisis period. These WPs abandon the topics of 'Sudden Stop' and 'Emerging Markets' with the crisis development and focus more on the topic of 'International Reserves.' and 'Great Recession.'

We find that the volume of crisis-related WPs is counter-cyclical, i.e., the academic economics and finance scholars tend to go where the problems are, consistent with Krainer's (1992) opening quote. Laidler (2011, p. 276) makes a similar observation: “As particular policy problems come and go,..., so do ideas that can address them, eventually falling into temporary neglect, not because they have been refuted by empirical happenings but because they have been rendered irrelevant by them for the time being. Thus, the problem of unemployment dominated inter-war discourse, but in the late 1960s... [there was a] need to cope with inflation.” 41

Overall, our findings are consistent with the critical arguments made by both the general public and the academics that many (but not all) macroeconomics and finance scholars, indeed failed to see the coming of the financial crisis. However, the results of our analyses suggest that as soon as the financial crisis began to unravel, the academic community responded quite dramatically to the crisis, and to the public criticism that the crisis has generated. Many academic economists and finance scholars, working in the relevant areas of research, stopped studying relatively less urgent topics, and switched their focus and efforts to studying and understanding the crisis, its causes and its consequences.

Thus, although the economists were slow to see the coming of the financial crisis, they were fast to act. This endogenous response of the academic world to the 2008 financial crisis is counter to the popular perception and the public image of the academic finance and economics scholars, which portrays the academic economists as disconnected from the real world events (see, for example, Georgalakis 2017).

\footnotetext{
${ }^{41}$ The mainstream macroeconomic models and analyses tend to treat cyclical fluctuations-booms and bustssymmetrically, in which the term "crisis" does not really fit because typically these models assess the effects of frequent small symmetric shocks. For example, productivity shocks are usually modeled as small symmetric shocks, which automatically rules out the possibility of a large-scale crisis occurring.
} 
This is also the conclusion of Reis (2018, p. 147): "Within days or weeks of the failure of Bear Sterns or Lehman Brothers, economists provided diagnoses of the crisis, and central banks and finance ministries implemented aggressive measures to minimize the damage, all of which were heavily influenced by economic theory. Economic concepts such as asymmetric information, bank runs, the role of liquidity, saturating the market for reserves, and forward guidance at the zero lower-bound, all provided concrete interpretations of the crisis, suggestions for policies, and discussion of trade-offs. The economy did not die, and a Great Depression was avoided, in no small part due to the advances in economics over many decades.”

Reinhart and Reinhart (2018) express similar sentiments: "For most advanced economies, the events of 2008-9 will go down in history as 'the Great Recession,' not 'the Second Great Depression.' That should stand as a credit to the governments that prevented a new depression by actively managing their economies. This was a far cry from the 1920s and early 1930s, when politicians believed that it was best to let the economy correct on its own. From 2008 to 2011, across the 11 countries hit hardest by the crisis, governments spent an average of 25 percent of GDP on stimulating their economies” (p. 90).

Our findings, however, also point at the possibility that the economists were not only "slow to see” and "fast to act," but also “quick to forget.” This cannot be ruled out considering the picture that emerges from Figures 1, which shows that the frequency of the word "crisis/crises" in the NBER WPs started to decline in 2011. Other results we report, however, offer a mixed evidence in support of “quick to forget” conclusion. Figure 4 shows that by 2015, the average weight of crisis topics had gone down to the pre-crisis levels observed in 1999-2004, but the \% of WPs that mention the word crisis at least once is still above that the pre-crisis level in 2015 as Figure 1 shows. It appears therefore that the interest that the economics and finance scholars showed in the study of crises during the 2008 crisis-period, did not persist.

The declining interest in crisis studies could be a reflection of Krainer's (1992) observation that "the study of economics is driven by perceived economic problems, and when those problems seem to go away in the real economy, so does academic interest in the problem” (p. xi). It could also be that financial (in)stability became a trendy topic for its policy importance as well as academic visibility, attracting the attention of many journal editors and policy makers, which the academic economics and finance scholars followed. These arguments are in line with our finding that the volume of crisis-related WPs is counter-cyclical.

\subsection{Assessment in light of the ongoing Covid-19 crisis}

The 2008 crisis turned out to be the most serious since the Great Depression, until Covid-19. 
The response of the profession to Covid-19 can serve as a test case for our findings. While the similarities and differences between the 2008 and the Covid-19 crises are still assessed (Danielsson, et al. 2020), we can already see similar patterns in the response of the economists to the two crises: they were slow to see, but fast to act in both cases. In fact, it appears that in the case of Covid-19, the economists are even faster than our findings would have predicted.

Until Covid-19, economists were scarcely engaged in studying the effects of epidemics. NBER, for example, lists on its website only 8 epidemics' papers that were written before $2020 .{ }^{42}$ However, as soon as Covid-19 struck, it led to an intense engagement of the economists. For example, as of October 26, 2020, the NBER lists 280 new WPs on the Covid-19. Examples include Acemoglu et al. (2020), Alvarez et al. (2020), Barro et al. (2020), Caballero and Simsek (2020, Eichenbaum et al. (2020), Krueger et al. (2020), Pindyck (2020), Stock (2020), etc. ${ }^{43}$

The CEPR has published even more studies on the pandemic in a short period of time. For example, as of October 26, 2020, VoxEU lists 772 Covid-19 policy papers. ${ }^{44}$ The IMF began publishing Special Series on Covid-19. ${ }^{45}$ As of October 26, 2020, 84 studies have been released. The World Bank has also published dozens of studies. ${ }^{46}$ Individual scholars began addressing Covid-19 in their blogs. See, for example, Cecchetti (2020).

This crisis is still ongoing. Nevertheless, the fast response of the scholars to it is consistent with our key findings that (a) economists are slow to see a crisis coming, but they are fast to act once the crisis hits, and (b) the academics’ interest in research topics is counter-cyclical.

\subsection{Limitations and future research}

Our study has limitations, because it is limited to three questions - “who, when, and how,” and because we analyze only NBER WPs. The first question we ask is: Who are the NBER scholars that study the crisis-related topics? To answer it, we focus on the NBER research groups, and try to assess the research focus and the research agenda of each group.

The second question we ask is: When did the NBER scholars begin studying the crisis-related topics? To answer it, we consider the pre-crisis period, the period when the crisis was still evolving, and the post-crisis period, and in each sub-period we characterize and document the

\footnotetext{
${ }^{42}$ See http://www2.nber.org/wp_covid19.html, accessed October 26, 2020.

${ }^{43}$ See the NBER's website at http://www2.nber.org/wp_covid19.html for a complete list.

${ }^{44}$ Among these studies are even books, written/edited in a lightning speed, by Baldwin and di Mauro (2020a, 2020b). Moreover, CEPR began publishing a periodical, Covid Economics: Vetted and Real Time Papers, entirely devoted to the economic aspects of Covid-19. See: https://cepr.org/content/covid-economics-vetted-and-real-timepapers-0, accessed October 26, 2020.

${ }^{45}$ Source: https://www.imf.org/en/Publications/SPROLLs/covid19-special-notes, accessed October 26, 2020.

${ }^{46}$ Source: https://www.worldbank.org/en/who-we-are/news/coronavirus-covid19 and https://blogs.worldbank.org/covid19, accessed June 7, 2020.
} 
scholarly efforts of the different NBER program members. The goal of these analyses is to identify the program members' timing in relation to the crisis, and to assess their lead-lag relationship, such as which program members led the efforts, which program members were more forward-looking, and which program members were more late-comers.

The third question we ask is: How did the NBER scholars study the crisis-related topics? To answer it, we identify the specific crisis-related topics that the NBER members chose to study, which topics got a particular attention, and which topics the scholars ended up abandoning.

Future work should address several issues, in light of the limitations of our paper. In terms of data, to make the project manageable, we had to limit our analyses to the NBER WPs, which clearly, are note a representative of the entire economics discipline, not in terms of the content, nor in terms of people or geography. Rather, it represents elite economic discourse, and is primarily limited to the US and US-based scholars. On the other hand, the NBER scholars, although small in numbers, exert a significant influence on the top academic journals, and more generally on the general academic discourse in economics and finance, as we show in Section 3 and in Tables 1a and $1 \mathrm{~b}$ ), and consequently on policymakers.

Nevertheless, other important WP series (e.g., CEPR WPs), papers published in academic journals and in edited volumes, or books, were all excluded from our analyses. Clearly this leads to a partial picture. To the extent that most of the NBER WPs are eventually published in journals and/or in edited volumes, these publications are included in our data in their early stage, while they are still WPs. Therefore, the exclusion of journal articles and book chapters authored by NBER-affiliated economists do not pose a problem. However, that still leaves out WPs, journal articles, book chapters, and books written by non-NBER scholars.

In addition, future work should address two important questions. The first is, "where:” Where were the crisis-related topics studied? In the paper, we focus exclusively on the NBER member scholars. While NBER scholars are leading scholars, there are other leading scholars, who are not affiliated with the NBER. We suspect that many of these scholars have also contributed to the crisis-related literature and to the crisis-understanding efforts. These include scholars at universities and colleges in many countries, scholars at central banks (such as at the research departments and at the financial stability divisions at Federal Reserve Bank and its branches, at the ECB, and at the central banks of many countries), the economics and finance scholars employed by the IMF and the World Bank, and scholars at research institutes and independent 
think tanks. The relevant work of all these and other scholars were excluded from our analyses. ${ }^{47}$

The second question our study did not address is, “why:” Why some topics were studied but not others? Why did some topics emerge as central to understanding the crisis dynamics, while other topics were considered less important? While we briefly touch these points sporadically in the paper, we do not make a systematic effort of doing so, because the extent of the analyses that is required to answer these and related questions, would be beyond the scope of this paper. Some studies already attempt to do precisely that. A related question of interest concerns the extent of the impact of the studies of the crisis. Does the academic interest in the topics that these papers address persist over a longer term?

Finally, since the crisis there seems to be greater linkages between the finance and economics scholars. For example, if financial economists were not paying much attention to what macroeconomists were doing prior to the crisis, now they are paying a greater attention to it. Moreover, financial economists are showing greater interest in macroeconomic policy implications of their work. Similarly, an emerging trend in macroeconomics puts a greater emphasis on the role of financial markets in macroeconomic models (Cochrane, 2017). For example, Angrist et al. (2020, Figure 10) report that finance scholars cite papers in macroeconomics in increasing numbers, recently approaching a quarter of all citations.

Another possible avenue for future research is motivated by the observations that our discipline is divided between (a) closed-economy and (b) open-economy macroeconomists, and between (i) developed-country and developing-country oriented macroeconomists. ${ }^{48}$ Clearly, given their different experiences with their models, the countries, and the data, economists in some of these groups were better equipped than others to foresee the crisis, and/or to better understand its dynamics in its early stages, and/or to be more receptive of the idea of the financial market fragility, and/or to be more mindful of the possibility of a financial crisis hitting economies with advanced and sophisticated financial markets. Future work could explore and assess the extent of the engagements of these different groups in the study of the crisis.

\footnotetext{
${ }^{47}$ For example, many widely used WP archives such as the SSRN, RePec, ResearchGate, etc. contain far more WPs, and they represent far more numerous and diverse scholars, in comparison to the NBER WPs. Their study, therefore, may shed light on the work of a larger and more representative sample of academics.

48 These groups are not mutually exclusive.
} 


\section{References}

Acemoglu, D., Chernozhukov, V., Werning, I., Whinston, M. 2020. A multi-risk sir model with optimally targeted lockdown. NBER Working Paper 27102.

Aigner, E., Aistleitner, M., Glötzl, F., Kapeller, J., 2018. The focus of academic economics: Before and after the crisis. Working Paper No. 75, IFNET.

Aizenman, J., 2012. The Euro and the global crises: Finding the balance between short term stabilization and forward-looking reforms. NBER Working Paper No. 15636.

Alvarez, F., Argente, D., Lippi, F., 2020. A simple planning problem for covid-19 lockdown. NBER Working Paper 26981.

Ambrosino, A., Cedrini, M., Davis, J., Fiori, S., Guerzoni, M., Nuccio, M., 2018. What topic modeling could reveal about the evolution of economics. Journal of Economic Methodology 25(4), 329-348.

Andrews, D., 1993. Tests for parameter instability and structural change with unknown change point. Econometrica 59, 817-858.

Angrist, J., Azoulay, P., Ellison, G., Hill, R., Lu, S., 2017. Economic research evolves: Fields and styles. American Economic Review: Papers and Proceedings 107(5), 293-297.

Angrist, J., Azoulay, P., Ellison, G., Hill, R., Lu, S., 2020. Inside job or deep impact? Extramural citations and the influence of economic scholarship. Journal of Economic Literature 58(1), 352.

Athey, S., Imbens, G., 2019. Machine learning methods that economists should know about. Annual Review of Economics 11, 685-725.

Baldwin, R., di Mauro, B., 2020a. Economics in the Time of COVID-19, CEPR Press.

Baldwin, R., di Mauro, B., 2020b. Mitigating the COVID Economic Crisis: Act Fast and Do Whatever It Takes, CEPR Press.

Ball, L., 2018. The Fed and Lehman Brothers: Setting the Record Straight on a Financial Disaster, Cambridge University Press.

Barro, R., Ursúa, J., Weng, J., 2020. The coronavirus and the great influenza pandemic: Lessons from the 'Spanish flu' for the coronavirus's potential effects on mortality and economic activity. NBER Working Paper No. 26866.

Benmelech, E., Dlugosz, J., Ivashina, V., 2012. Securitization without adverse selection: The case of CLOs. Journal of Financial Economics 106(1), 91-113.

Bernanke, B., 2013. The Federal Reserve and the Financial Crisis, Princeton University Press.

Bernanke, B., 2018. The real effects of disrupted credit: Evidence from the global financial crisis. Brookings Papers on Economic Activity 49(2), 251-342.

Blair, D., Maron, M., 1985. An evaluation of retrieval effectiveness for a full-text documentretrieval system. Communications of the ACM 28(3), 289-299.

Blei, D., Ng, A., Jordan, M., 2003. Latent Dirichlet allocation. Journal of Machine Learning Research 3, 993-1022.

Blei, D., Lafferty, J., 2006. Dynamic topic models. In Proceedings of the $23^{\text {rd }}$ International Conference on Machine Learning, 113-120.

Blei, D., Lafferty, J., 2009. Topic models. In A. Srivastava and M. Sahami, Eds., Text Mining: Classification, Clustering, and Applications, Chapman and Hall.

Blinder, A., 2013. After the Music Stopped: The Financial Crisis, The Response, and The Work 
Ahead, Penguin Books.

Blinder, A., Ehrmann, M., Fratzscher, M., de Haan, J., Jansen, D., 2008. Central bank communication and monetary policy: A survey of theory and evidence. Journal of Economic Literature 46(4), 910-945.

Bordo, M., Jonung, L., Markiewicz, A., 2013. A fiscal union for the Euro: Some lessons from history. CESifo Economic Studies 59(3), 449-488.

Born, B., Ehrmann, M., Fratzscher, M., 2010. Macroprudential policy and central bank communication. CEPR Discussion Paper No. 8094.

Boukus, E, Rosenberg, J., 2006. The Information content of FOMC minutes. Available at SSRN: https://papers.ssrn.com/sol3/papers.cfm?abstract_id=922312.

Bowles, S., Carlin, W., 2020. What students learn in economics 101: Time for a change. Journal of Economic Literature 58(1), 176-214.

Caballero, R., 2010. The 'other' imbalance and the financial crisis. NBER Working Paper No. 15636.

Caballero, R., Simsek, A., 2020. A model of asset price spirals and aggregate demand amplification of a 'covid-19' shock. NBER Working Paper 27044.

Calvo, G., 1998. Capital flows and capital-market crises: the simple economics of sudden stops. Journal of Applied Economics 1, 35-54.

Calvo, G., Mendoza, E., 2000. Rational contagion and the globalization of securities markets. Journal of International Economics 51(1), 79-113.

Carey, M., Kashyap, A., Rajan, R., Stulz, R., Eds., 2012. Market institutions, financial market risks, and the financial crisis. Journal of Financial Economics 104(3), 421-424.

Cecchetti, S., 2003. What the FOMC says and does when the stock market booms. manuscript, presented at the 2003 Reserve Bank of Australia annual conference, https://www.rba.gov.au/publications/confs/2003/cecchetti.html.

Cecchetti, S., 2020. The virus wars. http://people.brandeis.edu/ cecchett/covid19.html, accessed June 7, 2020.

Chari, V., Kehoe, P., McGrattan, E., 2005. Sudden stops and output drops. American Economic Review 95(2), 381-387.

Chen, X., Zou, D., Cheng, G., Xie, H., 2020. Detecting latent topics and trends in educational technologies over four decades using structural topic modeling: a retrospective of all volumes of Computers \& Education. Computers \& Education 151, 103855.

Cochrane, J., 2017. Macro-finance. Review of Finance 21(3), 945-985.

Colander, D., Goldberg, M., Haas, A., Juselius, K., Kirman, A., Lux, T., 2009. The financial crisis and the systemic failure of the economics profession. Critical Review: A Journal of Politics and Society 21(2-3), 249-267.

Colander, D., Goldberg, M., Haas, A., Juselius, K., Kirman, A., Lux, T., 2014. The financial crisis and the systemic failure of academic economics. In A. Lanteri and J. Vromen, eds, The Economics of Economists: Institutional Setting, Individual Incentives, and Future Prospects, Cambridge University Press.

Conesa, J., Kehoe, T., 2014. Is it too late to bail out the troubled countries in the eurozone? American Economic Review 104(5), 88-93.

Cretchley, J., Rooney, D., Gallois, C., 2010. Mapping a 40-year history with Leximancer: themes 
and concepts in the journal of cross-cultural psychology. Journal of Cross-Cultural Psychology 41(3), 318-328.

Cukierman, A., 2009. The limits of transparency. Economic Notes 38(1-2), 1-37.

Claessens, S., Kose, M., 2013. Financial crises: explanations, types, and implications. manuscript.

Danielsson, J., Macrae, R., Vayanos, D., Zigrand, J., 2020. The coronavirus crisis is no 2008. VoxEU.org, Centre for Economic Policy Research, London, https://voxeu.org/article/coronavirus-crisis-no-2008.

Durdu, C., Mendoza, E., 2006. Are asset price guarantees useful for preventing sudden stops? A quantitative investigation of the globalization hazard-moral hazard tradeoff. Journal of International Economics 69(1), 84-119.

Ehrmann, M., Fratzscher, M., 2005. How should central banks communicate? WORKING PAPER No. 557, European Central Bank.

Ehrmann, M., Fratzscher, M., 2007. Communication by central bank committee members: different strategies, same effectiveness? Journal of Money, Credit, and Banking 39(2-3), 509541.

Ehrmann, M., Fratzscher, M., 2009. Purdah—on the rationale for central bank silence around policy meetings. Journal of Money, Credit, and Banking 41(2-3), 517-528.

Ehrmann, M, Gaballo, G, Hoffmann, P., Strasser, G., 2019. Can more public information raise uncertainty? The international evidence on forward guidance. Journal of Monetary Economics 108, 93-112.

Eichenbaum, M., Rebelo, S., Trabandt, M., 2020. The macroeconomics of epidemics. NBER Working Paper No. 26882.

Fabricant, S., 1984. Toward a firmer basis of economic policy: the founding of the NBER. available at: https://data.nber.org/nberhistory/sfabricantrev.pdf.

Fligstein, N., Brundage, J., Schultz, M., 2017. Seeing like the Fed: culture, cognition, and framing in the failure to anticipate the financial crisis of 2008. American Sociological Review 82(5), 879-909.

Gentzkow, M., Kelly, B., Taddy, M., 2019. Text as data. Journal of Economic Literature 57(3), 535-574.

Georgalakis, J., 2017. Academic in ivory towers? It's time to change the record. Times Higher Education, May 24, 2017.

Gjerstad, S., Smith, V., 2014. Rethinking Housing Bubbles: The Role of Household and Bank Balance Sheets in Modeling Economic Cycles, Cambridge University Press.

Glandon, P., Kuttner, K., Mazumder, S., Stroup, C., 2022. Macroeconomic research, present and past. Journal of Economic Literature, forthcoming.

Goldstein, I., Razin, A., 2015. Three branches of theories of financial crises. Foundations and Trends in Finance 10(2), 113-180.

Goldstein, I., Jiang, W., Karolyi, G., 2019. To fintech and beyond. Review of Financial Studies 32(5), 1647-1661.

Gorton, G., 2010. Shaped by Invisible Hand: The Panic of 2007, Oxford University Press. Gorton, G., 2012. Misunderstanding Financial Crises: Why We Don’t See Them Coming, Oxford University Press. 
Gorton, G., Metrick, A., 2012a. Getting up to speed on financial crisis: a one-weekend-reader's guide. Journal of Economic Literature 50(1), 128-150.

Gorton, G., Metrick, A., 2012b. Securitized banking and the run on repo. Journal of Financial Economics 104, 425-451.

Griffin, J., 2021. The years of evidence: was fraud a force in the financial crisis. Journal of Economic Literature 59(4), 1293-1321.

Griffiths, T., Steyvers, M., 2004. Finding scientific topics. Proceedings of the National Academy of Sciences 101(1), 5228-5235.

Hakkio, C., Keeton, W., 2009. Financial stress: what is it, how can it be measured, and why does it matter? Federal Reserve Bank of Kansas City Economic Review 94(2), 5-50.

Hansen, B., 1997. Approximate asymptotic p-values for structural change tests. Journal of Business and Economic Statistics 15, 60-67.

Hansen, S., McMahon, M., 2016. Shocking language: understanding the macroeconomic effects of central bank communication. Journal of International Economics 99(1), S114-S133.

Hansen, S., McMahon, M, Prat, A., 2017. Transparency and deliberation within the FOMC: a computational linguistics approach. Quarterly Journal of Economics 133(2), 801-870.

Holló, D., Kremer, M., Lo Duca, M., 2012. CISS-a composite indicator of systemic stress in the financial system. Working Paper No. 1426, European Central Bank.

Huang, A., Lehavy, R., Zang, A., Zheng, R., 2018. Analyst information discovery and interpretation roles. Management Science 64(6), 2833-2855.

Jansen, D., de Haan, J., 2013. An assessment of the consistency of ECB communication using word scores. In Sturm, J.E. and Siklos, P., eds., Central Bank Communication, DecisionMaking and Governance: The Issues, Challenges, and Case Studies, MIT Press.

Jegadeesh, N. Wu, D., 2016. Deciphering fed speak: the information content of FOMC meetings. Manuscript, presented at the 2016 American Economic Association Annual Conference.

Kansoy, F., 2019. FOMC minutes: as a source of monetary policy surprise. manuscript, University of Nottingham.

Kaplan S., Vakili, K., 2015. The double-edged sword of recombination in breakthrough innovation. Strategic Management Journal 36(10), 1435-1457.

Kashyap, A., Zingales, L., Eds., 2010. The 2007-2008 Financial crisis: lessons from corporate finance. Journal of financial Economics 97(3), 303-305.

Keida, M., Takeda, Y., 2018. The arts of central bank communication: a topic analysis on words of the bank of Japan's governors. Presented at the 2019 American Economic Association Annual Conference.

Knispelis, A., 2016. LDA topic models: turning words into meaning. a presentation, available at: https://www.youtube.com/watch?v=3mHy4OSyRf0.

Kosnik, L., 2015. What have economists been doing for the last 50 years? A text analysis of published academic research from 1960-2010. Economics e-Journal 9, 1-38.

Krainer, R., 1992. Finance in a Theory of the Business Cycle, Blackwell.

Krishnamurthy, A., Nagel, S., Orlov, D., 2014. Sizing up repo. Journal of Finance 69(6), 23812417.

Krueger, D., Uhlig, H., Xie, T., 2020. Macroeconomic dynamics and reallocation in an epidemic: evaluating the "Swedish solution.” NBER Working Paper 27047. 
Krugman, P., 2013. Understanding the NBER. The New York Times, April 22, 2013, https://krugman.blogs.nytimes.com/2013/04/22/understanding-the-NBER/.

Kryvtsov, O., Petersen, L., 2019. Central bank communication that works: lessons from lab experiments. Staff Working Paper, No. 2019-21, Bank of Canada.

Larsen, V., Thorsrud, L., 2019. The value of news for economic developments. Journal of Econometrics 210(1), 203-218.

Laidler, D., 2011. Lucas, Keynes, animal spirits, co-ordination and the recent crisis. In A. Arnon, et al., eds., Perspectives on Keynesian Economics, Springer-Verlag.

Lee, K., Jung, H., Song, M., 2016. Subject-method topic network analysis in communication studies. Scientometrics 109(3), 1761-1787.

Lüdering, J., Winker, P., 2016. Forward or backward looking? The economic discourse and the observed reality. Journal of Economics and Statistics, Jahrbuecher fuer Nationaloekonomie und Statistik 236(4), 483-515.

Lüdering, J., Tillmann, P., 2020. Monetary policy on twitter and asset prices: evidence from computational text analysis. North American Journal of Economics and Finance 51, 100875.

McCallum, B., Plosser, C., Eds., 2009. Carnegie-Rochester Conference Series on Public Policy: distress in credit markets: theory, empirics, and policy, November 14-15, 2008. Journal of Monetary Economics 56(5), 617-748.

McCallum, B., Plosser, C., Eds., 2010. Carnegie-Rochester Conference Series on Public Policy: credit market turmoil: implications for policy, April 17-18, 2009. Journal of Monetary Economics 57(1), 1-120.

Mendoza, E., Yue, V., 2012. A general equilibrium model of sovereign default and business cycles. Quarterly Journal of Economics 127(2), 889-946.

Mendoza, E., 2006. Lessons from the debt-deflation theory of sudden stops. American Economic Review 96(2), 411-416.

Mendoza, E., 2008. Sudden stops, financial crises and leverage: a Fisherian deflation of Tobin's Q. NBER Working Paper No. 14444.

Mendoza, E., Smith, K., 2002. Margin calls, trading costs, and asset prices in emerging markets: the financial mechanics of the 'sudden stop’ phenomenon. NBER Working Paper No. 9286.

Paul, M., Girju, R., 2009. Cross-cultural analysis of blogs and forums with mixed-collection topic models. Proceedings of the 2009 Conference on Empirical Methods in Natural Language Processing 3, 1408-1417, Association for Computational Linguistics.

Pierce, A., 2008. The queen asks why no one saw the credit crunch coming? The Telegraph, November 5, 2008, https://www.telegraph.co.uk/news/uknews/theroyalfamily/3386353/TheQueen-asks-why-no-one-saw-the-credit-crunch-coming.html, accessed June 7, 2020.

Poole, W., 2005. How predictable is Fed policy? FRB of St. Louis Review 87(6), 659-668.

Pindyck, R., 2020. COVID-19 and the welfare effects of reducing contagion. NBER Working Paper 27121.

Quandt, R., 1960. Tests of hypotheses that a linear system obeys two separate regimes. Journal of the American Statistical Association 55, 324-330.

Razin, A., 2014. Understanding Global Crises: An Emerging Paradigm, MIT Press.

Razin, A., Rosefielde, S., 2012. What really ails the Eurozone? Faulty supranational architecture. Contemporary Economics 6(4), 10-18. 
Reinhart, C., Reinhart, V., 2018. The crisis next time: what we should have learned from 2008. Foreign Affairs 97(6), 84-96.

Reinhart, C., Rogoff, K., 2008. Is the 2007 sub-prime financial crisis so different? An international historical comparison. American Economic Review: Papers \& Proceedings 98(2), 339-344.

Reinhart, C., Rogoff, K., 2009a. This Time Is Different, Princeton University Press.

Reinhart, C., Rogoff, K., 2009b. The aftermath of financial crises. American Economic Review: Papers \& Proceedings 99(2), 466-472.

Reis, R., 2018. Is something really wrong with macroeconomics? Oxford Review of Economic Policy 34(1-2), 132-155.

Romer, D., 2010. A new data set on monetary policy: the economic forecasts of individual members of the FOMC. Journal of Money, Credit, and Banking 42(5), 951-957.

Romer, D., Romer, C., 2017. New evidence on the aftermath of financial crises in advanced countries. American Economic Review 107(10), 3072-3118.

Sachs, J., 1989a. Developing Country Debt and Economic Performance, NBER.

Sachs, J., 1989b. Developing Country Debt and the World Economy, NBER.

Sachs, J., 2019. Clinical macroeconomics and differential diagnosis. manuscript.

Schuemie, M., Weber, M., Schijvenaars, B., van Mulligen, E., van der Eijk, C., Jelier, R., Mons, B., Kors, J., 2004. Distribution of information in biomedical abstracts and full-text publications. Bioinformatics 20(16), 2597-2604.

Shah, P., Perez-Iratxeta, C., Bork, P., Andrade, M., 2003. Information extraction from full text scientific articles: where are the keywords? BMC Bioinformatics 4(1), 20.

Shiller, R., 2008. The Subprime Solution: How Today's Global Financial Crisis Happened, and What to Do about It, Princeton University Press.

Shiller, R., 2017. Narrative economics. American Economic Review 107(4), 967-1004.

Shirota, Y., Sakura, T., Chakraborty, B., 2016. Monetary policy topic extraction by using LDA: termination of Asian financial crisis. Information Modelling and Knowledge Bases 27, Frontiers in Artificial Intelligence and Applications, Vol. 280, 188-198.

Sinclair G., Webber, B., 2004. Classification from full text: a comparison of canonical sections of scientific papers. In Proceedings of the International Joint Workshop on Natural Language Processing in Biomedicine and its Applications, Association for Computational Linguistics, 66-69.

Spiegel, M., Ed., 2011. The academic analysis of the 2008 financial crisis: round 1. Review of Financial Studies 24(6), 1773-1781.

Stemler, S., 2001. An Overview of Content Analysis, Practical Assessment. Research and Evaluation 7, 137-146.

Stewart, H., 2009. This Is How We Let the Credit Crunch Happen, Ma’am... The Guardian, July 26, 2009, https://www.theguardian.com/uk/2009/jul/26/monarchy-credit-crunch, accessed June 7, 2020.

Steyvers, M., Griffiths, T., 2007. Probabilistic topic models. In Landauer, T.K., et al., Eds., Handbook of Latent Semantic Analysis, Lawrence Erlbaum Associates.

Stiglitz, J., 2010. Freefall: America, Free Markets, and the Sinking of the World Economy, W.W. Norton. 
Stock, J., 2020. Data gaps and the policy response to the novel coronavirus. NBER Working Paper No. 26902.

Sybrandt, J., Carrabba, A., Herzog, A., Safro, I., 2018. Are abstracts enough for hypothesis generation? arXiv:1804.05942v3 [cs.IR].

Thornton, D., 2006. When did the FOMC begin targeting the federal funds rate? Journal of Money, Credit and Banking 38(8), 2039-2071.

Vegh, C., Vuletin, G., 2014. Social implications of fiscal policy responses during crises. NBER Working Paper No 19828.

Wang, X., Mohanty, N., McCallum, A., 2005. Group and topic discovery from relations and text. In: Proceedings of the $3^{\text {rd }}$ International Workshop on Link Discovery, 28-35.

Weber, R., 1990. Basic Content Analysis, Second Edition, Sage Publishing.

Wehrheim, L., 2019. Economic history goes digital: topic modeling the journal of economic history. Cliometrica 13(1), 83-125.

Woodford, M., 2005. Central-bank communication and policy effectiveness. In the Greenspan era: lessons for the future, Kansas City: FRB of Kansas City, 399-474.

Yan, E., 2015. Research dynamics, impact, and dissemination: a topic-level analysis. Journal of the Association for Information Science and Technology 66(11), 2357-2372.

Zhong, S., Geng, Y., Liu, W., Gao, C., Chen, W., 2016. A bibliometric review on natural resource accounting during 1995-2014. Journal of Cleaner Production 139, 122-132. 


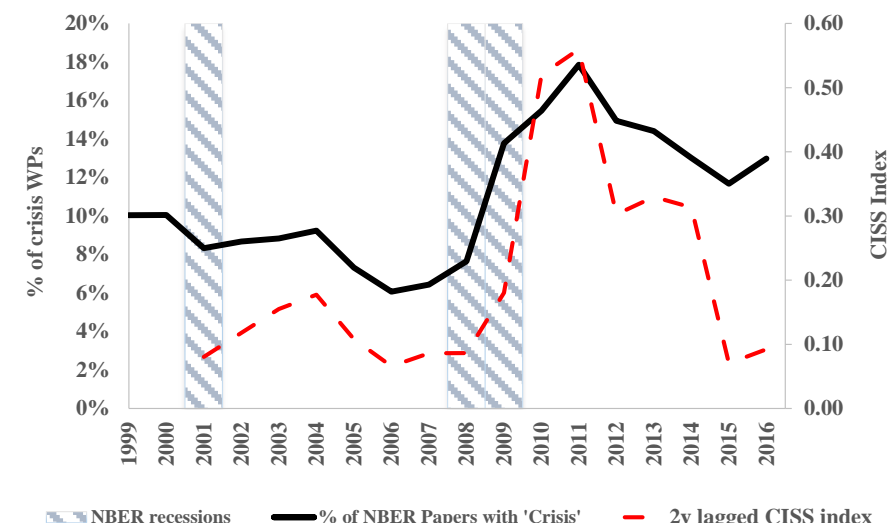

Fig. 1a. The \% of crisis WPs and 2-year lagged Index of Composite Indicator of Systemic Stress

Note: Crisis WPs are defined as the WPs that mention the word 'crisis/crises' at least once in the first five paragraphs of the introduction

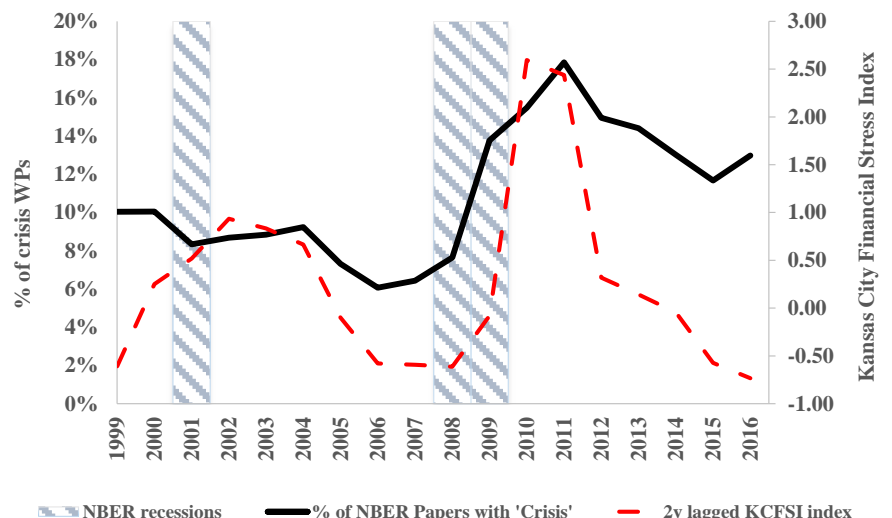

Fig. 1b. The \% of crisis WPs and 2-year lagged Kansas City Financial Stress Index

Note: Crisis WPs are defined as the WPs that mention the word 'crisis/crises' at least once in the first five paragraphs of the introduction 

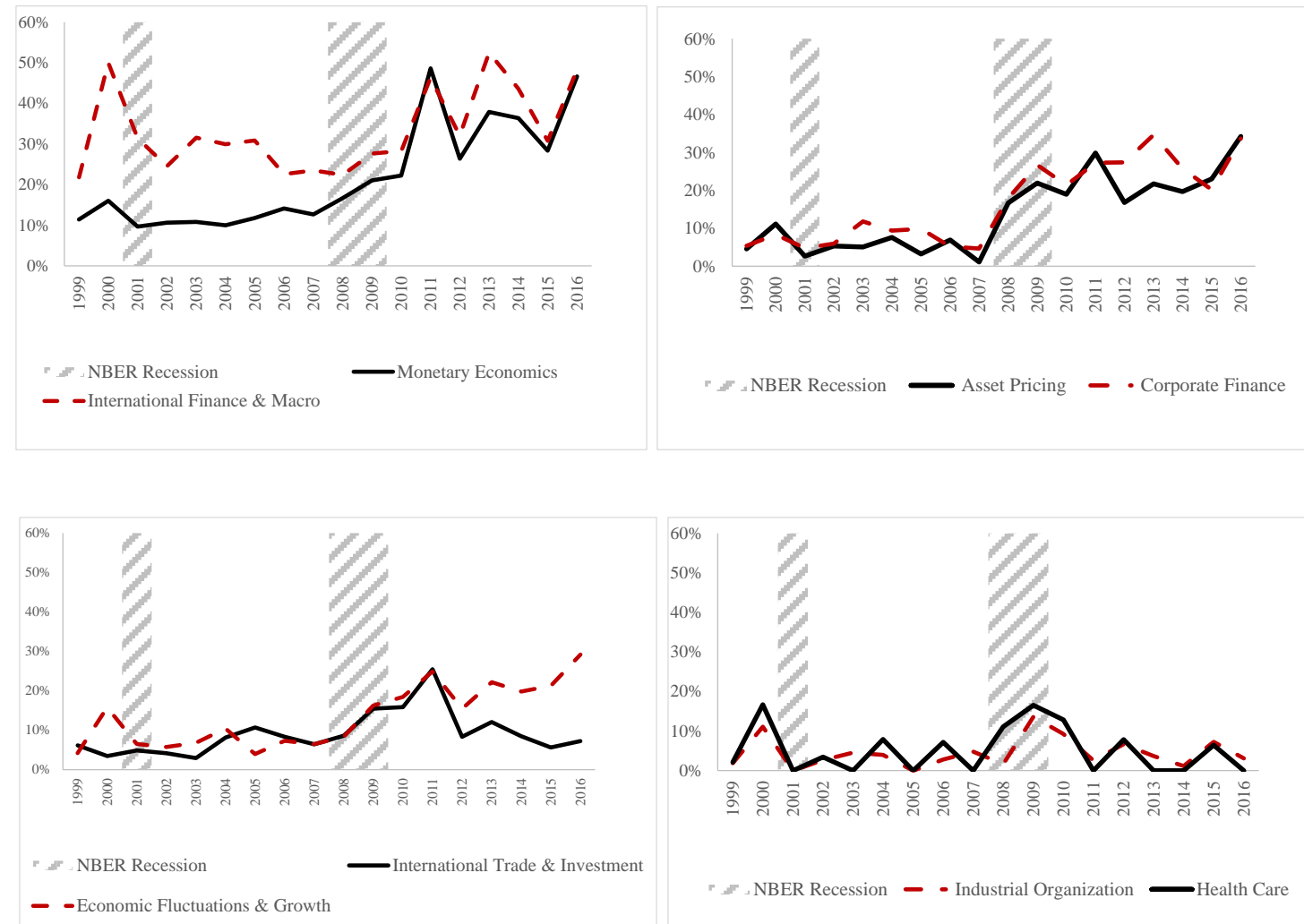

Fig. 2. Average annual \% of crisis WPs published by NBER research programs 


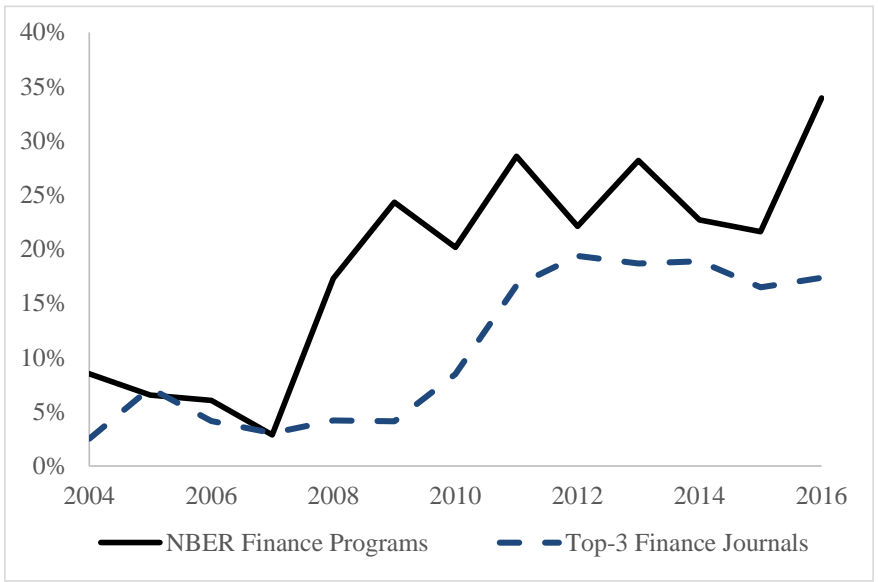

Fig. 3a. The \% of crisis WPs published by NBER finance programs (Asset Prices and Corporate Finance), and the \% of crisis papers published in the top-3 finance journals, 2004-2016

Note: The figure shows (i) the \% of papers that were published in the top-3 finance journals (Journal of Finance, Review of Financial Studies, and Journal of Financial Economics), and mention the word "crisis/crises" in the first 5 paragraphs at least once, and (ii) the \% of WPs published by the NBER's (a) Asset Pricing and (b) Corporate Finance programs that also mention the word "crisis/crises" in the first 5 paragraphs at least once. The data include 4,898 papers published in these journals during 2004-2016. 

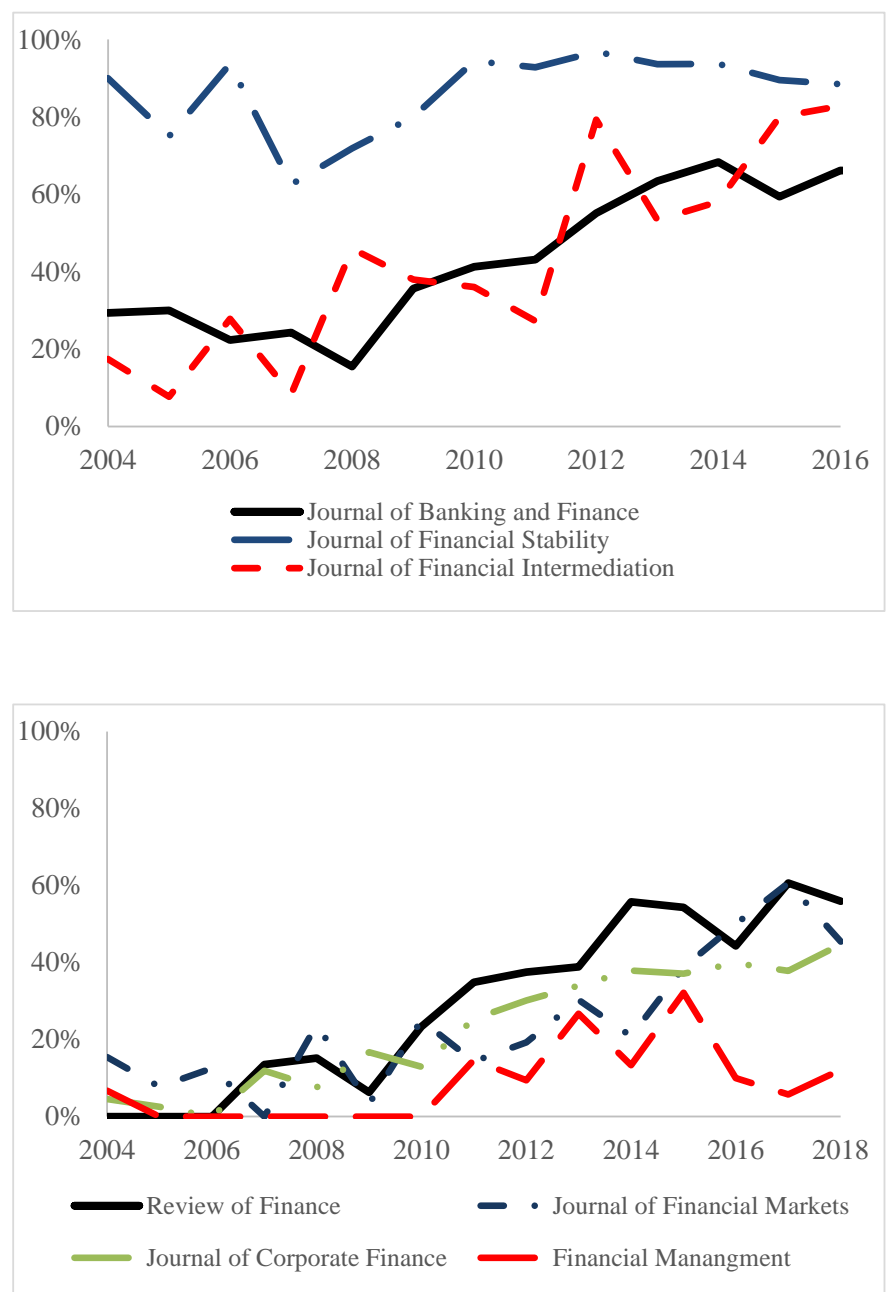

Fig. $3 \mathbf{b}$. The \% of crisis WPs published by leading finance journals, 2004-2016

Note: The figures show the \% of papers that were published in leading finance journals and mention at least once the word "crisis/crises." These journals are the Journal of Financial Stability, Journal of Financial Intermediation, Journal of Corporate Finance, Review of Finance, Journal of Banking and Finance, Journal of Financial Markets and Financial Management. 


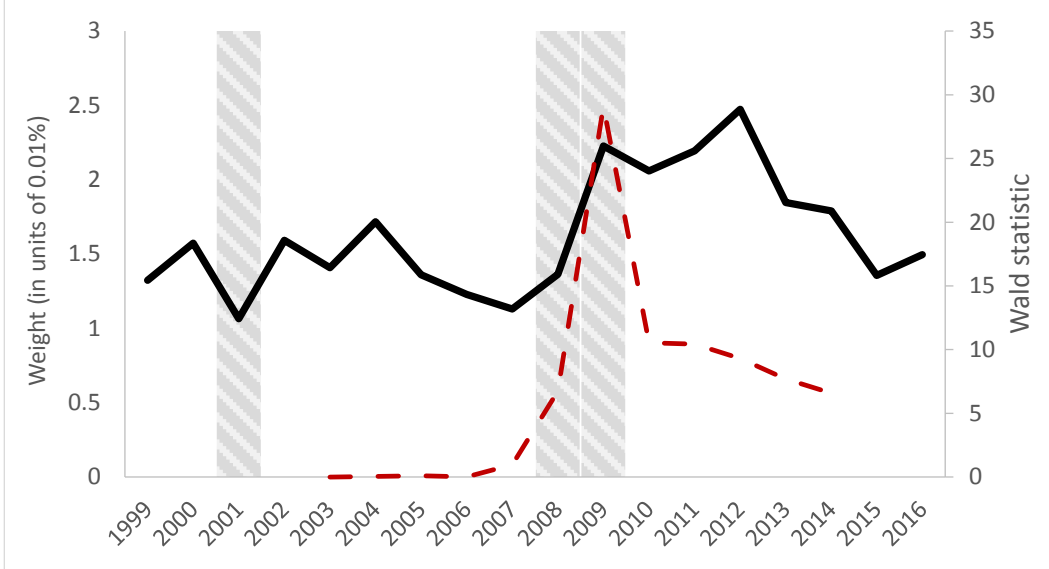

Fig. 4. Average weight of all crisis topics and the Wald statistic time series, 1999-2016

Note: The figure shows the sum of the weights of all 9 topics with the word 'crisis' out of the 500 topics that we have identified by applying the LDA algorithm to the abstracts of the entire database of NBER WPs published between 1999 and 2016 (solid line). We also present the annual Wald test statistic for the sum of all crisis' topics for the period between 2003 and 2014 (dashed line).

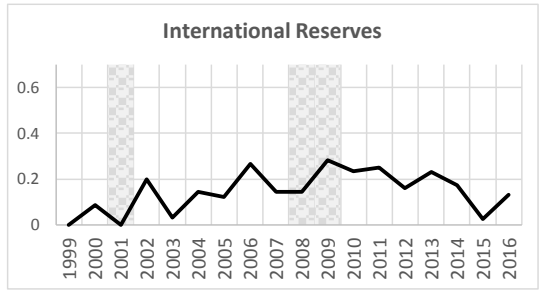

Liquidity
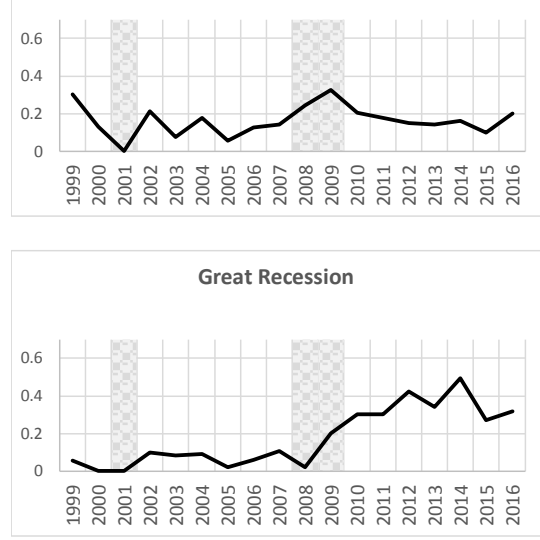
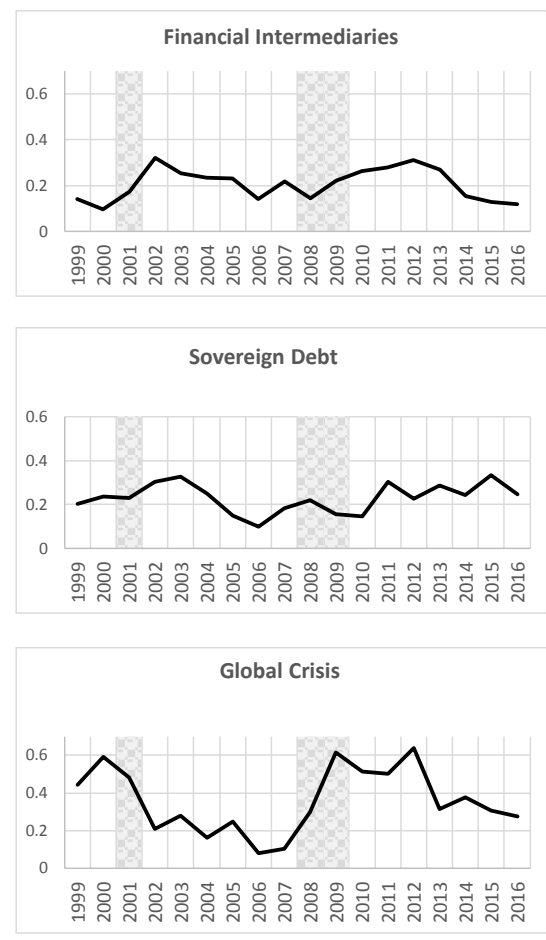
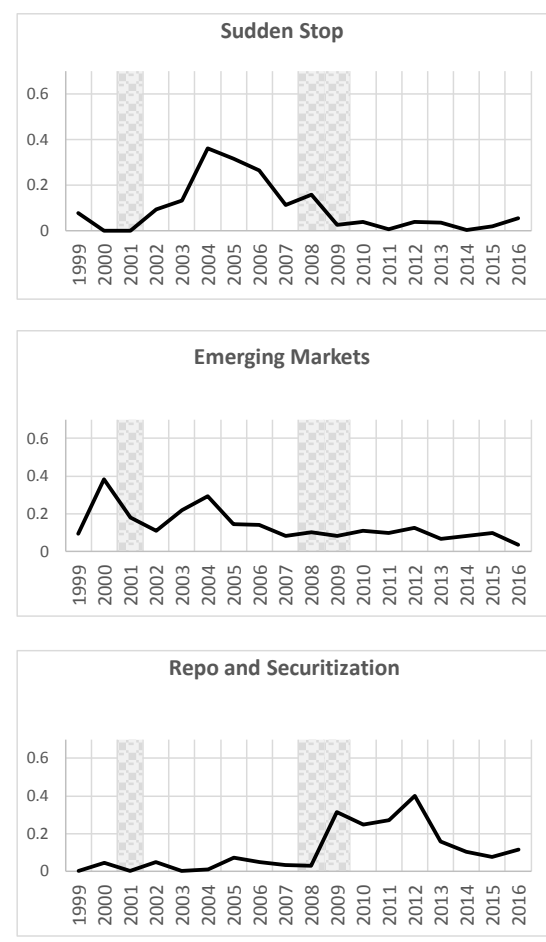

Fig. 5. The change in the average annual weight of the 9 crisis topics over time, 1999-2016 

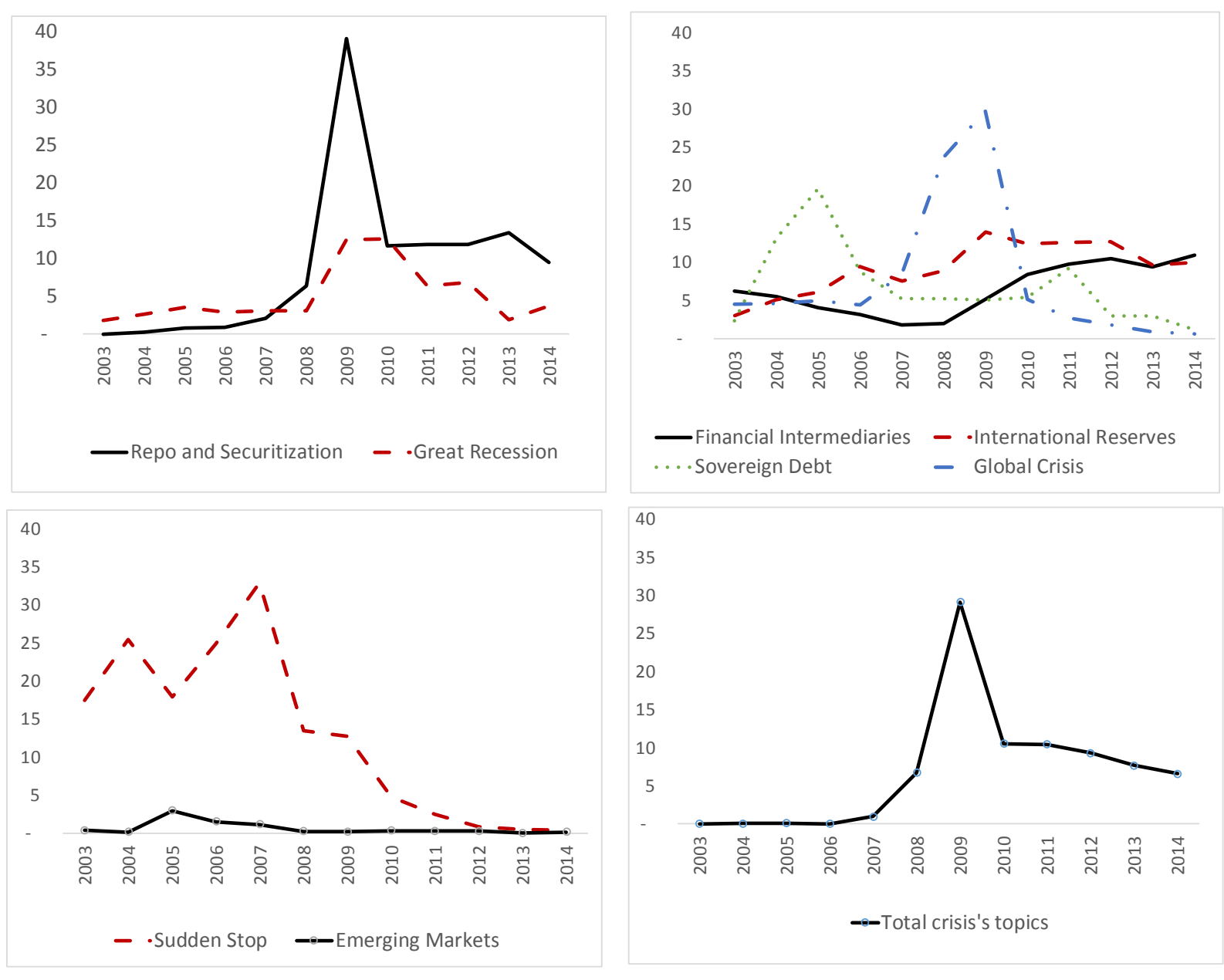

Fig. 6. The Wald test statistic time series for 9 crisis topics, 2003-2014

Note: The figure presents the annual Wald statistic for different crisis' topics for the period between 2003 and 2014 . First, the abstracts of the NBER WPs that were published between 1999 and 2016 were analyzed using LDA, yielding 500 topics. Each topic contains 20 words. Next, we calculate the average weight of a topic in a WP for each year, and finally we calculate the Wald test statistic for known structural breaks for each year. 
Table 1a

Contribution counts to the top-8 economics and finance journals by organization, 2017-2019.

\begin{tabular}{|c|l|c|}
\hline Rank & \multicolumn{1}{|c|}{ Institution } & Total Contribution Count \\
\hline 1 & NBER & 553 \\
\hline 2 & CEPR & 261 \\
\hline 3 & University of California System & 211 \\
\hline 4 & Federal Reserve System & 173 \\
\hline 5 & University of Chicago & 168 \\
\hline 6 & Harvard University & 159 \\
\hline 7 & University of London* & 104 \\
\hline 8 & University of Pennsylvania & 100 \\
\hline 9 & Columbia University & 95 \\
\hline 10 & New York University & 151 \\
\hline
\end{tabular}

Note: The figures in the table are the contribution counts to the top-8 journals by organizations, according to the Web of Science.

* University of London is a consortium of 17 universities, including the London School of Economics, University College London, London

Business School, Kings College, Royal Holloway, Queen Mary University, etc.

Table 1b

Contribution counts to the top-8 economics and finance journals by organization, 2017-2019.

\begin{tabular}{|c|l|c|c|l|c|}
\hline Rank & \multicolumn{2}{|c|}{ Journal of Finance } & Rank & \multicolumn{2}{c|}{ Journal of Political Economy } \\
\hline 1 & NBER & 63 & 1 & NBER & 44 \\
2 & CEPR & 33 & 2 & University of Chicago & 45 \\
3 & Federal Reserve System & 16 & 3 & CEPR & 31 \\
4 & University of California System & 15 & 4 & University of California System & 28 \\
5 & Stanford University & 14 & 5 & Stanford University & 25 \\
\hline Rank & \multicolumn{1}{|c|}{ Review of Financial Studies } & Rank & \multicolumn{1}{c|}{ Quarterly Journal of Economics } \\
\hline 1 & NBER & 63 & 1 & NBER & 73 \\
2 & CEPR & 47 & 2 & Harvard University & 25 \\
3 & Federal Reserve System & 30 & 3 & University of California System & 25 \\
4 & University of California System & 20 & 4 & University of Chicago & 19 \\
5 & University of London & 20 & 5 & MIT & 17 \\
\hline Rank & \multicolumn{1}{|c|}{ Journal of Financial Economics } & Rank & & 31 \\
\hline 1 & NBER & 63 & 1 & NBER & 20 \\
2 & CEPR & 40 & 2 & University of Chicago & 19 \\
3 & Federal Reserve System & 34 & 3 & Stanford University & 16 \\
4 & University of California System & 27 & 4 & MIT, and University of London & 16 \\
5 & University of Pennsylvania & 15 & 5 & University of California System & 16 \\
\hline Rank & Review of Economic Studies & & Rank & & American Economic Review \\
\hline 1 & NBER & 47 & 1 & NBER & 129 \\
2 & CEPR & 28 & 2 & University of California System & 57 \\
3 & University of California System & 23 & 3 & CEPR & 52 \\
5 & University of London & 19 & 4 & Harvard University & 51 \\
\hline
\end{tabular}

Note: The figures in the table are the contribution counts to journals by organizations according to the Web of Science. 
Table 1c

NBER WPs, descriptive statistics, 1999-2016.

\begin{tabular}{|lccccccc|}
\hline $\begin{array}{l}\text { Panel A: Descriptive } \\
\text { statistics for all WPs }\end{array}$ & $\begin{array}{c}\text { Monetary } \\
\text { Economics }\end{array}$ & $\begin{array}{c}\text { Int. } \\
\text { Trade }\end{array}$ & $\begin{array}{c}\text { Corporate } \\
\text { Finance }\end{array}$ & $\begin{array}{c}\text { Asset } \\
\text { Pricing }\end{array}$ & $\begin{array}{c}\text { Int. } \\
\text { Finance } \\
\text { and Macro }\end{array}$ & $\begin{array}{c}\text { Economic } \\
\text { Fluctuations } \\
\text { and Growth }\end{array}$ & $\begin{array}{c}\text { Av. of all } \\
\text { programs }\end{array}$ \\
\hline Average number of WPs & 109.90 & 106.61 & 104.06 & 117.83 & 127.72 & 191.28 & 98.8 \\
\hline $\begin{array}{l}\text { Average number of WPs } \\
\text { before 2008 }\end{array}$ & 80.10 & 96.89 & 77.78 & 96.67 & 109.00 & 145.11 & 71.1 \\
\hline $\begin{array}{l}\text { Average number of WPs } \\
\text { after 2008 }\end{array}$ & 139.80 & 116.33 & 130.33 & 139.00 & 146.44 & 237.44 & 132.7 \\
\hline$t$-test for mean-difference & 20.70 & 6.10 & 17.52 & 13.27 & 11.90 & 25.54 & 54.9 \\
\hline
\end{tabular}

\section{Table 2}

NBER crisis WPs, descriptive statistics, 1999-2016.

\begin{tabular}{|c|c|c|c|c|c|c|c|}
\hline & $\begin{array}{c}\text { Monetary } \\
\text { Economics }\end{array}$ & $\begin{array}{l}\text { Int. } \\
\text { Trade }\end{array}$ & $\begin{array}{l}\text { Corporate } \\
\text { Finance }\end{array}$ & $\begin{array}{l}\text { Asset } \\
\text { Pricing }\end{array}$ & $\begin{array}{c}\text { Int. } \\
\text { Finance } \\
\text { and Macro }\end{array}$ & $\begin{array}{l}\text { Economic } \\
\text { Fluctuations } \\
\text { and Growth }\end{array}$ & All WPs \\
\hline Average \% of crisis WPs & $21.7 \%$ & $9.0 \%$ & $16.7 \%$ & $13.9 \%$ & $33.2 \%$ & $13.5 \%$ & $11.4 \%$ \\
\hline Min. \% during 1999-2016 & $9.7 \%$ & $2.9 \%$ & $4.7 \%$ & $1.1 \%$ & $21.8 \%$ & $4.0 \%$ & $6.1 \%$ \\
\hline Max. \% during 1999-2016 & $48.6 \%$ & $25.5 \%$ & $34.6 \%$ & $34.2 \%$ & $52.5 \%$ & $29.2 \%$ & $17.9 \%$ \\
\hline Average \% before 2008 & $11.9 \%$ & $6.1 \%$ & $7.3 \%$ & $5.3 \%$ & $29.6 \%$ & $7.5 \%$ & $8.3 \%$ \\
\hline Average \% after 2008 & $31.6 \%$ & $11.9 \%$ & $26.1 \%$ & $22.5 \%$ & $36.9 \%$ & $19.5 \%$ & $13.5 \%$ \\
\hline (\% after)/(\% before) & 2.65 & 1.95 & 3.57 & 4.24 & 1.24 & 2.6 & 1.62 \\
\hline z-test for mean-difference & $11.04^{* * *}$ & $4.49 * * *$ & $11.68^{* * *}$ & $12.30 * * *$ & $3.70^{* * *}$ & $10.74^{* * *}$ & $9.95 * * *$ \\
\hline \% out of all crisis WPs & $26.4 \%$ & $10.6 \%$ & $19.1 \%$ & $18.1 \%$ & $46.8 \%$ & $28.5 \%$ & $100.0 \%$ \\
\hline Number of crisis WPs & 468 & 189 & 361 & 323 & 737 & 510 & 1,632 \\
\hline
\end{tabular}

Note: Crisis WPs are defined as the WPs that mention the word 'crisis/crises' at least once in the first five paragraphs of the introduction. $* * * p<0.01$ 
Table 3

Wald test statistic for structural breaks for the annual frequency of WPs with word crisis for selected NBER programs.

\begin{tabular}{|lccccccc|}
\hline & $\begin{array}{c}\text { Monetary } \\
\text { Economics }\end{array}$ & $\begin{array}{c}\text { Int. } \\
\text { Trade }\end{array}$ & $\begin{array}{c}\text { Corporate } \\
\text { Finance }\end{array}$ & $\begin{array}{c}\text { Asset } \\
\text { Pricing }\end{array}$ & $\begin{array}{c}\text { Int. } \\
\text { Finance } \\
\text { and } \\
\text { Macro }\end{array}$ & $\begin{array}{c}\text { Economic } \\
\text { Fluctuations } \\
\text { and Growth }\end{array}$ & $\begin{array}{c}\text { All } \\
\text { WPs }\end{array}$ \\
\hline Estimated break point & 2011 & 2012 & 2008 & 2008 & 2011 & 2009 & 2009 \\
\hline Sup-Wald (QLR) test statistic & 10.8 & 18.78 & 14.01 & 14.86 & 7.88 & 13.04 & 70.36 \\
\hline$p$-value & $6.00 \%$ & $0.21 \%$ & $1.75 \%$ & $1.21 \%$ & $22.00 \%$ & $2.67 \%$ & $0.00 \%$ \\
\hline Known break point at 2008 & & & & & & & 20.19 \\
\hline Sup-Wald (QLR) test statistic & 5.77 & 7.47 & 14.01 & 14.86 & 5.31 & 9.31 & $0.00 \%$ \\
\hline$p>\chi^{2}$ & $5.58 \%$ & $2.38 \%$ & $0.09 \%$ & $0.06 \%$ & $7.00 \%$ & $0.95 \%$ & $0.00 \%$ \\
\hline
\end{tabular}

\section{Table 4}

Regressions of the annual \% change in crisis WPs on the annual change in indexes of financial stability.

\begin{tabular}{|lcccc|}
\hline & $(1)$ & $(2)$ & $(3)$ & $(4)$ \\
\hline Intercept & $\begin{array}{c}0.00 \\
(0.67)\end{array}$ & $\begin{array}{c}0.00 \\
(0.67)\end{array}$ & $\begin{array}{c}-0.01 \\
(1.33)\end{array}$ & $\begin{array}{c}-0.00 \\
(0.90)\end{array}$ \\
\hline 2-year lagged CISS index & $\begin{array}{c}0.02^{* * *} \\
(3.32)\end{array}$ & & $\begin{array}{l}0.02^{* *} \\
(2.30)\end{array}$ \\
\hline 2-year lagged KCFSI index & & $\begin{array}{c}0.06^{* *} \\
(2.47)\end{array}$ & & \\
\hline Dummy for 2008-2011 & & $\begin{array}{c}0.03^{* * *} \\
(3.87)\end{array}$ & $\begin{array}{c}0.03^{* * *} \\
(2.85)\end{array}$ \\
\hline$p>F, p>\chi^{2}$ & $0.55 \%$ & $2.96 \%$ & $0.19 \%$ & $0.11 \%$ \\
\hline$R^{2}$ & 0.46 & 0.34 & 0.53 & 0.68 \\
\hline
\end{tabular}

Note: Crisis WPs are defined as the WPs that mention the word 'crisis/crises' at least once in the first five paragraphs of the introduction. $t$-test statistics are shown in parentheses. We estimate the regression in first differences because the series may contain unit root as ADF tests results were sensitive to specification (drift, trend, number of lags) and thus we could not rule out a possibility of a unit root.

\section{Table 5}

Regressions of the annual \% of crisis WPs on the annual \% of all NBER crisis WPs, by research program.

\begin{tabular}{|lcccccc|}
\hline & $\begin{array}{c}\text { Monetary } \\
\text { Economics }\end{array}$ & Int. Trade & $\begin{array}{c}\text { Corporate } \\
\text { Finance }\end{array}$ & Asset Pricing & $\begin{array}{c}\text { Int. Finance } \\
\text { and Macro }\end{array}$ & $\begin{array}{c}\text { Economic } \\
\text { Fluctuations } \\
\text { and Growth }\end{array}$ \\
\hline Intercept & -10.20 & -2.75 & $-10.91^{* *}$ & $-11.22^{* *}$ & $15.20^{* *}$ & $-6.64^{*}$ \\
\hline Slope & $(-1.54)$ & $(-0.82)$ & $(-2.18)$ & $(-2.24)$ & $(2.16)$ & $(-1.73)$ \\
\hline
\end{tabular}

Note: The figures in the parentheses are the $t$-test statistics. $* * * p<0.01, * * p<0.05, * p<0.10$. 
Table 6

Number of crisis topics for different values of $K$ and $\alpha$.

\begin{tabular}{|l|c|c|c|c|c|c|c|}
\hline \multicolumn{2}{|c|}{} & \multicolumn{7}{|c|}{ Document-topic density $(\alpha)$} \\
\cline { 2 - 9 } & 250 & 7 & 7 & 4 & 2 & 1 & 1 \\
\hline \multirow{3}{*}{ Number of topics $(K)$} & $50.5 \%$ & $1 \%$ & $5 \%$ & $10 \%$ & $20 \%$ & $50 \%$ \\
\cline { 2 - 9 } & 500 & 11 & 9 & 7 & 4 & 1 & 1 \\
\cline { 2 - 9 } & 750 & 15 & 13 & 8 & 5 & 3 & 1 \\
\cline { 2 - 9 } & 1,000 & 13 & 13 & 7 & 7 & 4 & 3 \\
\hline
\end{tabular}

Note: The figures in the table are the number of crisis topics we were able to identify based on different values of $K$ and $\alpha$.

Table 7

9 crisis topics and the 10 most frequent words in each topic.

\begin{tabular}{|c|c|c|c|c|c|c|c|c|c|c|}
\hline Crisis Topic & \multicolumn{10}{|c|}{ The most frequent words in the topic } \\
\hline $\begin{array}{l}\text { International } \\
\text { Reserves }\end{array}$ & $\begin{array}{l}\text { reserv } \\
253\end{array}$ & $\begin{array}{l}\text { crisi } \\
129\end{array}$ & $\begin{array}{l}\text { intern } \\
110\end{array}$ & $\begin{array}{l}\text { countri } \\
105\end{array}$ & $\begin{array}{l}\text { financi } \\
87\end{array}$ & $\begin{array}{l}\text { emerg } \\
76\end{array}$ & $\begin{array}{l}\text { extern } \\
74\end{array}$ & $\begin{array}{l}\text { debt } \\
62\end{array}$ & $\begin{array}{l}\text { accumul } \\
58\end{array}$ & $\begin{array}{l}\text { manag } \\
51\end{array}$ \\
\hline $\begin{array}{l}\text { Financial } \\
\text { Intermediaries }\end{array}$ & $\begin{array}{l}\text { financi } \\
1,069\end{array}$ & $\begin{array}{l}\text { market } \\
214\end{array}$ & $\begin{array}{l}\text { develop } \\
177\end{array}$ & $\begin{array}{l}\text { sector } \\
173 \\
\end{array}$ & $\begin{array}{l}\text { intermediari } \\
106\end{array}$ & $\begin{array}{l}\text { economi } \\
106\end{array}$ & $\begin{array}{l}\text { bank } \\
84\end{array}$ & $\begin{array}{l}\text { financ } \\
76\end{array}$ & $\begin{array}{l}\text { institut } \\
71\end{array}$ & $\begin{array}{l}\text { crisi } \\
60(14)\end{array}$ \\
\hline $\begin{array}{l}\text { Sudden } \\
\text { Stop }\end{array}$ & $\begin{array}{l}\text { stop } \\
209\end{array}$ & $\begin{array}{l}\text { sudden } \\
188\end{array}$ & $\begin{array}{l}\text { revers } \\
95\end{array}$ & $\begin{array}{l}\text { capit } \\
74\end{array}$ & $\begin{array}{l}\text { account } \\
55\end{array}$ & $\begin{array}{l}\text { current } \\
41\end{array}$ & $\begin{array}{l}\text { inflow } \\
35\end{array}$ & $\begin{array}{l}\text { foreign } \\
30\end{array}$ & $\begin{array}{l}\text { crisi } \\
28\end{array}$ & $\begin{array}{l}\text { probabl } \\
24\end{array}$ \\
\hline $\begin{array}{l}\text { Sovereign } \\
\text { Debt }\end{array}$ & $\begin{array}{l}\text { debt } \\
847\end{array}$ & $\begin{array}{l}\text { default } \\
192\end{array}$ & $\begin{array}{l}\text { govern } \\
117 \\
\end{array}$ & $\begin{array}{l}\text { sovereign } \\
111 \\
\end{array}$ & $\begin{array}{l}\text { countri } \\
83\end{array}$ & $\begin{array}{l}\text { borrow } \\
81\end{array}$ & $\begin{array}{l}\text { domest } \\
57\end{array}$ & $\begin{array}{l}\text { creditor } \\
50\end{array}$ & $\begin{array}{l}\text { crisi } \\
50\end{array}$ & $\begin{array}{l}\text { repay } \\
43\end{array}$ \\
\hline $\begin{array}{l}\text { Emerging } \\
\text { Markets }\end{array}$ & $\begin{array}{l}\text { market } \\
323\end{array}$ & $\begin{array}{l}\text { countri } \\
321\end{array}$ & $\begin{array}{l}\text { emerg } \\
300 \\
\end{array}$ & $\begin{array}{l}\text { economi } \\
192 \\
\end{array}$ & $\begin{array}{l}\text { develop } \\
165 \\
\end{array}$ & $\begin{array}{l}\text { advanc } \\
93\end{array}$ & $\begin{array}{l}\text { capit } \\
40 \\
\end{array}$ & $\begin{array}{l}\operatorname{imf} \\
35 \\
\end{array}$ & $\begin{array}{l}\text { strong } \\
34 \\
\end{array}$ & $\begin{array}{l}\text { crisi } \\
26 \text { (13) }\end{array}$ \\
\hline $\begin{array}{l}\text { Great } \\
\text { Recession } \\
\end{array}$ & $\begin{array}{l}\text { recess } \\
381 \\
\end{array}$ & $\begin{array}{l}\text { great } \\
311 \\
\end{array}$ & $\begin{array}{l}\text { depress } \\
130 \\
\end{array}$ & $\begin{array}{l}\text { recoveri } \\
118 \\
\end{array}$ & $\begin{array}{l}\text { declin } \\
109 \\
\end{array}$ & $\begin{array}{l}\text { downturn } \\
73 \\
\end{array}$ & $\begin{array}{l}\text { larg } \\
72 \\
\end{array}$ & $\begin{array}{l}\text { period } \\
71 \\
\end{array}$ & $\begin{array}{l}\text { econom } \\
64 \\
\end{array}$ & $\begin{array}{l}\text { crisi } \\
39 \text { (17) }\end{array}$ \\
\hline $\begin{array}{l}\text { Repo and } \\
\text { Securitization }\end{array}$ & $\begin{array}{l}\text { loan } \\
97\end{array}$ & $\begin{array}{l}\text { secur } \\
80\end{array}$ & $\begin{array}{l}\text { securit } \\
68\end{array}$ & $\begin{array}{l}\text { collater } \\
66\end{array}$ & $\begin{array}{l}\text { market } \\
63\end{array}$ & $\begin{array}{l}\text { crisi } \\
60\end{array}$ & $\begin{array}{l}\text { financi } \\
51\end{array}$ & $\begin{array}{l}\text { credit } \\
49\end{array}$ & $\begin{array}{l}\text { repo } \\
46\end{array}$ & $\begin{array}{l}\text { facil } \\
46\end{array}$ \\
\hline
\end{tabular}

Note: The figure presents the 10 most frequent words in crisis' topics for a corpus that includes all abstracts of the NBER WPs published in 1999-2016. First, the abstracts of the WPs that were published between 1999 and 2016 were analyzed using LDA, yielding 500 topics. Each topic contains 20 words. Out of the 500 topics, 9 contain the word 'crisis' and we present the words of these topics. The table shows the most frequent words in each topic as well as the frequency of the words in a topic. In case that the word 'crisis' is not a part of the 10 most frequent words, we replace the $10^{\text {th }}$ word with the word “crisis" and indicate in brackets the rank of the word "crisis" within the topics. 
Table 8

The change in the rank of the average weight of the 9 (out of 500) crisis topics over time, 1999-2016.

\begin{tabular}{|c|c|c|c|c|c|c|c|c|c|}
\hline Year & $\begin{array}{c}\text { International } \\
\text { Reserves }\end{array}$ & $\begin{array}{c}\text { Financial } \\
\text { Intermediaries }\end{array}$ & $\begin{array}{c}\text { Sudden } \\
\text { Stop }\end{array}$ & Liquidity & $\begin{array}{c}\text { Sovereign } \\
\text { Debt }\end{array}$ & $\begin{array}{c}\text { Emerging } \\
\text { Markets }\end{array}$ & $\begin{array}{c}\text { Great } \\
\text { Recession }\end{array}$ & $\begin{array}{c}\text { Global } \\
\text { Crisis }\end{array}$ & $\begin{array}{c}\text { Repo and } \\
\text { Securitization }\end{array}$ \\
\hline 1999 & 392 & 208 & 349 & 61 & 151 & 203 & 317 & 12 & 482 \\
\hline 2000 & 256 & 221 & 450 & 244 & 127 & 33 & 219 & 9 & 366 \\
\hline 2001 & 397 & 105 & 409 & 358 & 119 & 149 & 363 & 27 & 446 \\
\hline 2002 & 123 & 30 & 247 & 135 & 43 & 179 & 207 & 58 & 415 \\
\hline 2003 & 385 & 81 & 251 & 287 & 39 & 62 & 290 & 57 & 494 \\
\hline 2004 & 192 & 54 & 32 & 114 & 53 & 42 & 233 & 118 & 493 \\
\hline 2005 & 264 & 92 & 50 & 298 & 137 & 203 & 387 & 72 & 325 \\
\hline 2006 & 77 & 94 & 88 & 224 & 240 & 165 & 317 & 302 & 390 \\
\hline 2007 & 181 & 86 & 260 & 202 & 119 & 242 & 241 & 218 & 442 \\
\hline 2008 & 198 & 139 & 181 & 72 & 99 & 187 & 414 & 25 & 423 \\
\hline 2009 & 53 & 66 & 477 & 32 & 193 & 269 & 71 & 1 & 40 \\
\hline 2010 & 77 & 47 & 465 & 67 & 210 & 219 & 19 & 5 & 65 \\
\hline 2011 & 74 & 36 & 468 & 135 & 50 & 180 & 25 & 1 & 70 \\
\hline 2012 & 169 & 38 & 375 & 145 & 89 & 176 & 6 & 1 & 29 \\
\hline 2013 & 103 & 35 & 400 & 164 & 61 & 238 & 18 & 34 & 193 \\
\hline 2014 & 123 & 116 & 456 & 120 & 88 & 328 & 6 & 19 & 335 \\
\hline 2015 & 427 & 179 & 442 & 266 & 25 & 198 & 29 & 33 & 371 \\
\hline 2016 & 175 & 135 & 426 & 114 & 74 & 343 & 23 & 55 & 223 \\
\hline
\end{tabular}


Table 9

The average weights of NBER WPs for the pre-crisis period 2005-2008, the crisis period 2009-2012, and the postcrisis period 2013-2016.

9A. The pre-crisis period 2005-2008, and the crisis period 2009-2012.

\begin{tabular}{|lcccccccccc|}
\hline & $\begin{array}{c}\text { Int. } \\
\text { Reserves }\end{array}$ & $\begin{array}{c}\text { Fin. } \\
\text { Interm. }\end{array}$ & $\begin{array}{c}\text { Sudden } \\
\text { Stop }\end{array}$ & Liquidity & $\begin{array}{c}\text { Sovereign } \\
\text { Debt }\end{array}$ & $\begin{array}{c}\text { Emerging } \\
\text { Market }\end{array}$ & $\begin{array}{c}\text { Great } \\
\text { Recession }\end{array}$ & $\begin{array}{c}\text { Global } \\
\text { Crisis }\end{array}$ & $\begin{array}{c}\text { Repo \& } \\
\text { Securit. }\end{array}$ & $\begin{array}{c}\text { All } \\
\text { Topics }\end{array}$ \\
\hline Av 2005-2008 & 0.17 & 0.18 & 0.21 & 0.14 & 0.16 & 0.12 & 0.05 & 0.18 & 0.05 & 1.27 \\
\hline Av 2009-2012 & 0.23 & 0.27 & 0.03 & 0.22 & 0.21 & 0.10 & 0.30 & 0.56 & 0.31 & 2.23 \\
\hline Av 2005-2012 & 0.20 & 0.23 & 0.12 & 0.18 & 0.19 & 0.11 & 0.18 & 0.38 & 0.18 & 1.77 \\
\hline z-test for mean-diff & 0.6 & 0.7 & $-\mathbf{2 . 3 * *}$ & 0.8 & 0.5 & -0.2 & $\mathbf{2 . 5}^{* * *}$ & $\mathbf{2 . 7 * * *}$ & $\mathbf{2 . 6}$ *** & $\mathbf{3 . 1}^{* * * *}$ \\
\hline
\end{tabular}

9B. The crisis period 2009-2012, and the post-crisis period 2013-2016.

\begin{tabular}{|lcccccccccc|}
\hline & $\begin{array}{c}\text { Int. } \\
\text { Reserves }\end{array}$ & $\begin{array}{c}\text { Fin. } \\
\text { Interm. }\end{array}$ & $\begin{array}{c}\text { Sudden } \\
\text { Stop }\end{array}$ & Liquidity & $\begin{array}{c}\text { Sovereign } \\
\text { Debt }\end{array}$ & $\begin{array}{c}\text { Emerging } \\
\text { Market }\end{array}$ & $\begin{array}{c}\text { Great } \\
\text { Recession }\end{array}$ & $\begin{array}{c}\text { Global } \\
\text { Crisis }\end{array}$ & $\begin{array}{c}\text { Repo \& } \\
\text { Securit. }\end{array}$ & $\begin{array}{c}\text { All } \\
\text { Topics }\end{array}$ \\
\hline Av 2009-2012 & 0.23 & 0.27 & 0.03 & 0.22 & 0.21 & 0.10 & 0.30 & 0.56 & 0.31 & 2.23 \\
\hline Av 2013-2016 & 0.14 & 0.17 & 0.03 & 0.15 & 0.28 & 0.07 & 0.36 & 0.32 & 0.12 & 1.63 \\
\hline Av 2009-2016 & 0.19 & 0.22 & 0.03 & 0.18 & 0.24 & 0.08 & 0.33 & 0.44 & 0.21 & 1.92 \\
\hline z-test for mean-diff & -1.0 & -1.0 & 0.0 & -0.7 & 0.7 & -0.6 & 0.4 & $-\mathbf{1 . 8}^{*}$ & $-\mathbf{2 . 0}^{* *}$ & $-\mathbf{2 . 1}$ ** \\
\hline
\end{tabular}

9C. The pre-crisis period 2005-2008, and the post-crisis period 2013-2016.

\begin{tabular}{|lcccccccccc|}
\hline & $\begin{array}{c}\text { Int. } \\
\text { Reserves }\end{array}$ & $\begin{array}{c}\text { Fin. } \\
\text { Interm. }\end{array}$ & $\begin{array}{c}\text { Sudden } \\
\text { Stop }\end{array}$ & Liquidity & $\begin{array}{c}\text { Sovereign } \\
\text { Debt }\end{array}$ & $\begin{array}{c}\text { Emerging } \\
\text { Market }\end{array}$ & $\begin{array}{c}\text { Great } \\
\text { Recession }\end{array}$ & $\begin{array}{c}\text { Global } \\
\text { Crisis }\end{array}$ & $\begin{array}{c}\text { Repo \& } \\
\text { Securit. }\end{array}$ & $\begin{array}{c}\text { All } \\
\text { Topics }\end{array}$ \\
\hline Av 2005-2008 & 0.17 & 0.18 & 0.21 & 0.14 & 0.16 & 0.12 & 0.05 & 0.18 & 0.05 & 1.27 \\
\hline Av 2013-2016 & 0.14 & 0.17 & 0.03 & 0.15 & 0.28 & 0.07 & 0.36 & 0.32 & 0.12 & 1.63 \\
\hline $\begin{array}{l}\text { Av 2005-2008 \& } \\
\text { 2013-2016 }\end{array}$ & 0.16 & 0.18 & 0.11 & 0.15 & 0.23 & 0.09 & 0.22 & 0.26 & 0.08 & 1.47 \\
\hline -test for mean-diff & -0.3 & -0.1 & $-\mathbf{2 . 4 * * *}$ & 0.1 & 1.0 & -0.7 & $\mathbf{2 . 7} * * *$ & 1.2 & 1.0 & 1.3 \\
\hline
\end{tabular}

Note: The averages are reported in units of $0.01 \%$.

*** $p<0.01$, ** $p<0.05$, * $p<0.10$. 
Table 10

Wald test statistic for structural breaks for the annual weight of each of the 9 crisis topics.

\begin{tabular}{|l|lll|ccc|}
\hline \multicolumn{4}{|c|}{ Wald Test Statistic around the Crisis Time } & \multicolumn{3}{c|}{ sup-Wald Test } \\
\hline & 2007 & 2008 & 2009 & $\begin{array}{c}\text { Estimate } \\
\text { Break Point }\end{array}$ & $\begin{array}{c}\text { Sup-Wald } \\
\text { Statistic }\end{array}$ & $p$-value \\
\hline International Reserves & $7.5^{* *}$ & $8.9^{* *}$ & $14.0^{* * *}$ & 2009 & 14.0 & $1.78 \%$ \\
\hline Financial Intermediaries & 1.8 & 2.0 & $5.1^{*}$ & 2012 & 10.5 & $0.53 \%$ \\
\hline Sudden Stop & $32.8^{* * *}$ & $13.5^{* * *}$ & $12.7^{* * *}$ & 2007 & 32.8 & $0.00 \%$ \\
\hline Liquidity & 4.2 & $6.2^{* *}$ & 2.7 & 2008 & 6.2 & $4.57 \%$ \\
\hline Sovereign Debt & $5.2^{*}$ & $5.2^{*}$ & $5.1^{*}$ & 2005 & 19.6 & $0.14 \%$ \\
\hline Emerging Markets & 1.1 & 0.3 & 0.2 & 2005 & 3.0 & $88.96 \%$ \\
\hline Great Recession & 3.1 & 3.1 & $12.5^{* * *}$ & 2010 & 12.6 & $3.19 \%$ \\
\hline Global Crisis & 8.3 & $23.7^{* * *}$ & $29.8^{* * *}$ & 2009 & 29.8 & $0.00 \%$ \\
\hline Repo and Securitization & 2.1 & $6.4^{* *}$ & $39.1^{* * *}$ & 2009 & 39.1 & $0.00 \%$ \\
\hline \hline All NBER WPs & 1.0 & $6.7^{* *}$ & $29.1^{* * *}$ & 2009 & 29.1 & $0.00 \%$ \\
\hline
\end{tabular}

Note: The figures in the parentheses are the $t$-statistics.

${ }^{* * *} p<0.01,{ }^{* *} p<0.05, * p<0.10$. 


\section{Table 11}

The average weights of 20 different topics in crisis WPs for the pre-crisis period 2005-2008, the crisis period 2009-2012, and the post-crisis period 2013-2016.

\begin{tabular}{|c|c|c|c|c|c|c|}
\hline Topic Name & $\begin{array}{c}\text { Pre-Crisis: } \\
\text { Av 2005- } \\
2008\end{array}$ & $\begin{array}{l}\text { Crisis: } \\
\text { Av } \\
2009- \\
2012\end{array}$ & $\begin{array}{c}\text { Post- } \\
\text { Crisis: Av } \\
\text { 2013-2016 }\end{array}$ & $\begin{array}{c}\text { z-test for mean- } \\
\text { diff: pre-crisis vs } \\
\text { crisis }\end{array}$ & $\begin{array}{l}\text { z-test for mean- } \\
\text { diff: pre-crisis vs } \\
\text { post-crisis }\end{array}$ & $\begin{array}{l}\text { z-test for mean-diff: } \\
\text { crisis vs post-crisis }\end{array}$ \\
\hline International Finance & 8.0 & 8.9 & 7.7 & 0.3 & -0.4 & -0.1 \\
\hline Sudden Stop & 9.5 & 3.2 & 2.3 & $-3.0 * * *$ & -0.5 & $-4.4^{* * *}$ \\
\hline Repo \& Securitization & 2.0 & 6.6 & 3.4 & $2.1^{* *}$ & -1.3 & 0.7 \\
\hline Liquidity & 3.6 & 4.4 & 4.5 & 0.4 & 0.1 & 0.4 \\
\hline Crisis Event & 3.2 & 5.3 & 4.7 & 1.0 & -0.3 & 0.6 \\
\hline Government Bailout & 4.7 & 2.7 & 4.4 & -1.2 & 1.1 & -0.1 \\
\hline History of Crisis & 6.1 & 6.3 & 5.4 & 0.1 & -0.4 & -0.3 \\
\hline International Reserves & 7.3 & 4.0 & 3.1 & -1.5 & $-2.2 * *$ & -0.5 \\
\hline Monetary Policy & 2.3 & 4.5 & 6.8 & 1.1 & 1.2 & $1.9 *$ \\
\hline Systemic Risk & 3.7 & 5.7 & 4.3 & 0.9 & -0.6 & 0.3 \\
\hline Exchange Rates & 4.5 & 3.4 & 4.1 & -0.6 & 0.4 & -0.2 \\
\hline Great Recessions & 2.3 & 5.4 & 7.8 & 1.5 & 1.1 & $2.2 * *$ \\
\hline Economic Shocks & 6.8 & 6.5 & 9.4 & -0.1 & 1.2 & 0.9 \\
\hline Economic Growth & 5.1 & 5.0 & 4.6 & -0.0 & -0.2 & -0.2 \\
\hline Sovereign Debt & 4.1 & 4.5 & 7.8 & 0.2 & 1.6 & 1.5 \\
\hline Banks & 3.7 & 5.1 & 4.9 & 0.7 & -0.1 & 0.5 \\
\hline Household Credit & 2.7 & 3.4 & 4.1 & 0.4 & 0.4 & 0.7 \\
\hline Asset Pricing & 4.9 & 6.2 & 4.1 & 0.6 & -0.9 & -0.3 \\
\hline Emerging Markets & 9.9 & 4.0 & 3.5 & $-2.6 * * *$ & -0.3 & $-3.3 * * *$ \\
\hline Currency Markets & 5.6 & 5.0 & 3.2 & -0.3 & -0.8 & -1.2 \\
\hline $\begin{array}{l}\text { Jensen- Shannon } \\
\text { divergence }\end{array}$ & & & & 0.19 & 0.12 & 0.20 \\
\hline
\end{tabular}

Note: The table presents the average weights of topics we have identified for the 612 crisis WPs. Here we follow a stricter definition of a crisis WP, than the one we used in the previous sections of the paper: a WP is a 'crisis WP' if (1) it includes the word crisis at least once in the first five paragraphs of the introduction, (2) crisis topics comprise at least $10 \%$ of the paper, and (3) crisis topics are among the three topics with the highest weight in the paper. Applying this definition, we have identified 524 WPs, where 99 WPs were written in the pre-crisis period 2005-2009, 226 in the crisis period 2009-2012, and 197 WPs in the post-crisis period 2008-2016. An increase in a topic weight with respect to the initial period is marked in a boldface. In the bottom row, we show the Jensen Shannon divergence measure which assesses the similarity between two distributions. 
Table 12

10 crisis topics and the most frequent words in each topic, pre-crisis period, 1999-2007.

\begin{tabular}{|l|llllllllll|}
\hline Topic & \multicolumn{8}{|c|}{ The most frequent words in the topic } \\
\hline Sudden & sudden & stop & model & larg & current & capit & account & emerg & economi & market \\
Stop & 357 & 337 & 133 & 125 & 112 & 106 & 105 & 94 & 92 & 87 \\
\hline Capital & capit & countri & growth & flow & develop & account & Trade & liber & global & current \\
Flow & 403 & 300 & 180 & 163 & 155 & 142 & 121 & 104 & 92 & 91 \\
\hline Banking & bank & system & liquid & institut & risk & loan & Deposit & sector & fund & bailout \\
System & 443 & 103 & 69 & 69 & 65 & 54 & 49 & 39 & 37 & 35 \\
\hline Foreign & currenc & countri & debt & state & market & period & Global & recent & origin & differ \\
Debt & 161 & 128 & 98 & 92 & 81 & 69 & 66 & 61 & 59 & 57 \\
\hline Monetary & rate & polici & exchang & emerg & monetari & currenc & Regim & economi & domest & interest \\
Policy & 340 & 282 & 220 & 143 & 141 & 112 & 98 & 96 & 95 & 79 \\
\hline Real & market & countri & differ & find & effect & time & Aggreg & emerg & household & incom \\
Economy & 219 & 148 & 88 & 70 & 64 & 59 & 54 & 54 & 53 & 50 \\
\hline International & reserv & intern & countri & foreign & increas & develop & volatile & asian & east & manag \\
Reserves & 277 & 198 & 134 & 79 & 77 & 72 & 63 & 59 & 54 & 52 \\
\hline IMF & market & borrow & bond & countri & intern & imf & Privat & lender & issu & restructur \\
Restructuring & 134 & 98 & 97 & 96 & 87 & 86 & 69 & 52 & 50 & 43 \\
\hline Liquidity & asset & liquid & Price & market & investor & guarante & Trade & agent & risk & hazard \\
& 236 & 171 & 139 & 138 & 92 & 76 & 70 & 68 & 59 & 45 \\
\hline Sovereign & debt & default & govern & sovereign & model & increas & Level & rate & interest & risk \\
Debt & 400 & 146 & 105 & 92 & 80 & 63 & 59 & 59 & 56 & 52 \\
\hline
\end{tabular}

Note: The corpus includes 165 NBER WPs. Words that do not appear in the pre-crisis period are marked in italic. The hyper-parameter values are set at $\alpha=0.01$ and $\beta=0.01$.

\section{Table 13}

10 crisis topics and the most frequent words in each topic, post-crisis period, 2008-2016.

\begin{tabular}{|c|c|c|c|c|c|c|c|c|c|c|}
\hline Topic & & & & The $\mathrm{n}$ & ost freque & words in th & topic & & & \\
\hline Currency & fiscal & currenc & union & euro & countri & european & Govern & state & area & rate \\
\hline Union & 206 & 181 & 117 & 116 & 114 & 108 & 88 & 87 & 82 & 80 \\
\hline Monetary & polici & monetari & rate & interest & model & view & economi & central & bubbl & real \\
\hline Policy & 740 & 317 & 188 & 158 & 156 & 153 & 147 & 127 & 123 & 121 \\
\hline Credit & system & economi & credit & countri & boom & bank & advanc & unit & world & episod \\
\hline Boom & 245 & 223 & 223 & 185 & 169 & 166 & 159 & 158 & 152 & 147 \\
\hline Sovereign & debt & default & govern & sovereign & public & bond & Borrow & domest & privat & countri \\
\hline Debt & 1,312 & 382 & 361 & 314 & 250 & 171 & 168 & 145 & 142 & 127 \\
\hline Liquidity & asset & market & liquid & price & risk & investor & Valu & increas & return & equiti \\
\hline & 736 & 525 & 426 & 392 & 321 & 251 & 172 & 172 & 157 & 142 \\
\hline Great & recess & great & Growth & rate & percent & declin & recoveri & incom & $g d p$ & output \\
\hline Recession & 413 & 306 & 255 & 203 & 187 & 183 & 175 & 149 & 148 & 145 \\
\hline Global & countri & global & Intern & market & capit & emerg & develop & foreign & economi & reserv \\
\hline Markets & 802 & 433 & 423 & 420 & 377 & 327 & 303 & 252 & 251 & 234 \\
\hline Systemic & model & shock & sector & risk & system & capit & literatur & economi & measur & cost \\
\hline Risk & 593 & 314 & 292 & 235 & 191 & 171 & 158 & 157 & 154 & 152 \\
\hline Federal & bank & federal & reserv & central & liquid & system & Fund & deposit & provid & balanc \\
\hline Reserve & 1,208 & 308 & 237 & 217 & 156 & 142 & 140 & 133 & 112 & 94 \\
\hline Banking & bank & credit & Loan & firm & securit & rate & corpor & mortgag & геро & collater \\
\hline System & 398 & 373 & 340 & 308 & 290 & 258 & 219 & 197 & 111 & 110 \\
\hline
\end{tabular}

Note: The corpus includes 447 NBER WPs. Words that do not appear in the post-crisis period are marked in italic. The hyper-parameter values are set at $\alpha=0.1$ and $\beta=0.1$. 


\section{Table 14}

The change in the rank of words in a topic over time, using a dynamic topic modeling algorithm, 1999-2016.

\begin{tabular}{|c|c|c|c|c|c|c|c|c|}
\hline & $\begin{array}{c}\text { Credit } \\
\text { market }\end{array}$ & $\begin{array}{c}\text { Monetary } \\
\text { Policy }\end{array}$ & $\begin{array}{c}\text { Household } \\
\text { Finance }\end{array}$ & $\begin{array}{c}\text { Household } \\
\text { Finance }\end{array}$ & $\begin{array}{c}\text { Market } \\
\text { risk }\end{array}$ & $\begin{array}{c}\text { Monetary } \\
\text { Policy }\end{array}$ & Fragility & $\begin{array}{c}\text { Sovereign } \\
\text { debt }\end{array}$ \\
\hline Word & Repo & $\begin{array}{c}\text { Inflation } \\
\text { Target }\end{array}$ & Bubble & Leverage & Euro & $\begin{array}{c}\text { Macro- } \\
\text { prudential }\end{array}$ & Lehman & EuroZone \\
\hline 1999 & NR & 8 & 10 & NR & 18 & NR & NR & NR \\
\hline 2000 & NR & 9 & 10 & 20 & 17 & NR & NR & NR \\
\hline 2001 & NR & 9 & 10 & 19 & 17 & NR & NR & NR \\
\hline 2002 & NR & 9 & 10 & 19 & 17 & NR & NR & NR \\
\hline 2003 & NR & 10 & 10 & 18 & 16 & NR & NR & NR \\
\hline 2004 & NR & 10 & 10 & 18 & 16 & NR & NR & NR \\
\hline 2005 & NR & 10 & 10 & 18 & 15 & NR & NR & NR \\
\hline 2006 & NR & 10 & 9 & 17 & 14 & NR & 20 & NR \\
\hline 2007 & 19 & 11 & 7 & 15 & 12 & NR & 18 & NR \\
\hline 2008 & 18 & 11 & 7 & 14 & 11 & NR & 17 & NR \\
\hline 2009 & 17 & 11 & 6 & 14 & 10 & NR & 17 & 20 \\
\hline 2010 & 16 & 12 & 6 & 11 & 9 & NR & 17 & 19 \\
\hline 2011 & 15 & 13 & 5 & 13 & 8 & 19 & 16 & 15 \\
\hline 2012 & 13 & 13 & 5 & 13 & 7 & 18 & 13 & 15 \\
\hline 2013 & 12 & 14 & 4 & 11 & 4 & 16 & 10 & 15 \\
\hline 2014 & 10 & 15 & 4 & 11 & 4 & 15 & 10 & 15 \\
\hline 2015 & 9 & 15 & 5 & 11 & 5 & 14 & 9 & 14 \\
\hline 2016 & 10 & 17 & 5 & 11 & 4 & 13 & 8 & 14 \\
\hline
\end{tabular}

Note: The table presents the rank of a word in a topic based on a Dynamic Topic Modeling (DTM) algorithm. There are 20 words in each one of the 20 topics $(K=20)$, and the documents are partitioned into annual epochs, which means that a $K^{\text {th }}$ topic in a given year depends on the $K^{\text {th }}$ topic in the previous epoch. We mark by 'NR' a word which is not a part of the top-20 words of a topic in the corresponding year. 
Table 15

The average weights of 20 different topics in crisis WPs based on the DTM for the pre-crisis period 20052008, the crisis period 2009-2012, and the post-crisis period 2013-2016.

\begin{tabular}{|c|c|c|c|c|c|c|}
\hline Topic Name & $\begin{array}{c}\text { Pre-Crisis: } \\
\text { Av 2005- } \\
2008\end{array}$ & $\begin{array}{l}\text { Crisis: } \\
\text { Av } \\
2009- \\
2012 \\
\end{array}$ & $\begin{array}{c}\text { Post- } \\
\text { Crisis: Av } \\
\text { 2013-2016 }\end{array}$ & $\begin{array}{l}\text { z-test for mean- } \\
\text { diff: pre-crisis vs } \\
\text { crisis }\end{array}$ & $\begin{array}{l}\text { z-test for mean- } \\
\text { diff: pre-crisis vs } \\
\text { post-crisis }\end{array}$ & $\begin{array}{l}\text { z-test for mean-diff: } \\
\text { crisis vs post-crisis }\end{array}$ \\
\hline Asset pricing & 8.4 & 7.0 & 6.0 & -0.5 & -0.4 & -0.8 \\
\hline Currency Markets & 19.5 & 7.7 & 6.6 & $-3.2^{* * *}$ & -0.4 & $-3.5^{* * *}$ \\
\hline Banks' Liquidity & 4.8 & 8.3 & 6.4 & 1.2 & -0.8 & 0.6 \\
\hline US Current account & 2.2 & 1.5 & 1.3 & -0.5 & -0.2 & -0.6 \\
\hline World Econ system & 10.5 & 10.1 & 8.8 & -0.1 & -0.5 & -0.5 \\
\hline Market risk & 2.4 & 3.7 & 3.2 & 0.6 & -0.2 & 0.4 \\
\hline Great Recession & 4.7 & 7.6 & 10.2 & 1.0 & 1.0 & $1.8^{*}$ \\
\hline Credit market boom & 0.9 & 1.4 & 1.3 & 0.4 & -0.1 & 0.3 \\
\hline Fire sale $\&$ crash & 0.4 & 1.2 & 0.4 & 0.8 & -0.9 & 0.0 \\
\hline Capital liberalization & 2.6 & 1.7 & 1.0 & -0.6 & -0.6 & -1.1 \\
\hline Central bank/Fed & 1.5 & 2.5 & 2.5 & 0.6 & 0.0 & 0.6 \\
\hline Sudden stop & 6.3 & 1.6 & 1.8 & $-2.4^{* *}$ & 0.2 & $-2.1^{* *}$ \\
\hline Emerging Markets & 11.4 & 10.7 & 7.5 & -0.2 & -1.2 & -1.2 \\
\hline Fiscal Policy & 3.4 & 4.8 & 6.5 & 0.6 & 0.7 & 1.2 \\
\hline Repo \& credit & 4.2 & 12.1 & 6.8 & $2.4^{* *}$ & $-1.8^{*}$ & 1.0 \\
\hline Market fragility & 0.5 & 1.4 & 1.2 & 0.8 & -0.1 & 0.7 \\
\hline Household finance & 2.4 & 3.1 & 4.0 & 0.4 & 0.5 & 0.8 \\
\hline Economic shocks & 4.9 & 6.3 & 9.8 & 0.5 & 1.3 & 1.6 \\
\hline Monetary Policy & 3.8 & 5.0 & 8.0 & 0.5 & 1.3 & 1.5 \\
\hline Sovereign debt & 5.2 & 2.4 & 6.6 & -1.4 & $2.1^{* *}$ & 0.5 \\
\hline $\begin{array}{l}\text { Jensen-Shannon } \\
\text { divergence }\end{array}$ & & & & 0.21 & 0.14 & 0.22 \\
\hline
\end{tabular}

Note: The table presents the average weights of the topics we identified based on the Dynamic Topic Modeling (DTM) algorithm for the 612 crisis WPs. Here we follow a stricter definition of a crisis WP, than the one we used in the previous sections of the paper: a WP is a 'crisis WP' if (1) it includes the word crisis at least once in the first five paragraphs of the introduction, (2) crisis topics comprise at least 10\% of the paper, and (3) crisis topics are among the three topics with the highest weight in the paper. Applying this definition, we identified 524 WPs, where 99 WPs were written in the pre-crisis period 2005-2009, 226 in the crisis period 2009-2012, and 197 WPs in the post-crisis period 2008-2016. An increase in a topic weight with respect to the initial period is marked in a boldface. In the bottom row, we present the Jensen-Shannon divergence measure, to assess similarity between two distributions. 
Table 16

The average weights of selected topics in crisis WPs in the pre-crisis period 2005-2008, the crisis period 2009-2012, and the post-crisis period 2013-2016, across NBER research programs.

\begin{tabular}{|c|c|c|c|c|c|c|c|}
\hline Topic Name & Period & $\begin{array}{c}\text { Monetary } \\
\text { Economics }\end{array}$ & $\begin{array}{l}\text { Int. } \\
\text { Trade }\end{array}$ & $\begin{array}{l}\text { Corporate } \\
\text { Finance }\end{array}$ & $\begin{array}{c}\text { Asset } \\
\text { Pricing }\end{array}$ & $\begin{array}{c}\text { Int. Finance } \\
\text { and Macro }\end{array}$ & $\begin{array}{l}\text { Econ. Fluct. } \\
\text { and Growth }\end{array}$ \\
\hline \multirow{3}{*}{ Sudden Stop } & Pre- crisis & 3.4 & 6.4 & 1.7 & 1.4 & 10.4 & 9.3 \\
\hline & Crisis & 2.5 & 4.3 & 2.3 & 2.5 & $5.0 * *$ & 3.0 \\
\hline & Post crisis & 2.6 & 5.2 & 1.6 & 2.0 & $3.6 * *$ & $1.9 * *$ \\
\hline \multirow{3}{*}{$\begin{array}{l}\text { Repo and } \\
\text { Securitization }\end{array}$} & Pre- crisis & 3.7 & 1.5 & 5.4 & 6.7 & 1.4 & 2.0 \\
\hline & Crisis & 8.4 & 2.1 & $26.6^{* *}$ & 14.5 & 2.0 & 5.6 \\
\hline & Post crisis & 3.9 & 0.7 & 14.1 & 8.4 & 1.2 & 2.8 \\
\hline \multirow{3}{*}{ Monetary Policy } & Pre- crisis & 3.2 & 2.4 & 4.6 & 2.7 & 2.5 & 4.1 \\
\hline & Crisis & 5.5 & 2.6 & 1.6 & 1.5 & 4.5 & 5.8 \\
\hline & Post crisis & 8.8 & 0.2 & 2.1 & 4.0 & $8.2 * *$ & 7.0 \\
\hline \multirow{3}{*}{ Sovereign Debt } & Pre- crisis & 4.4 & 3.1 & 3.7 & 1.5 & 5.5 & 7.0 \\
\hline & Crisis & 5.6 & 4.8 & 3.0 & 3.1 & 6.0 & 3.4 \\
\hline & Post crisis & 7.4 & 9.3 & 3.5 & 4.0 & $13.9 * *$ & 10.2 \\
\hline \multirow{3}{*}{$\begin{array}{l}\text { Emerging } \\
\text { Markets }\end{array}$} & Pre- crisis & 6.0 & 11.6 & 9.3 & 4.8 & 13.4 & 8.7 \\
\hline & Crisis & 2.6 & 9.4 & $1.9 *$ & 1.1 & $6.3^{* *}$ & 4.1 \\
\hline & Post crisis & 2.7 & 11.6 & 2.1 & 2.1 & $5.7 * *$ & 2.1 \\
\hline \multirow{3}{*}{ Currency Markets } & Pre- crisis & 10.3 & 2.2 & 3.3 & 1.9 & 6.4 & 3.5 \\
\hline & Crisis & 3.9 & 6.4 & 2.5 & 3.8 & 8.9 & 2.5 \\
\hline & Post crisis & $2.0 *$ & 3.9 & 1.6 & 2.2 & 5.6 & 2.3 \\
\hline
\end{tabular}

Note: The table presents the average weights of the topics we have identified for the 513 crisis WPs that were published in $2005-2016$ by selected NBER programs. We show separately the weighs of the topic before the financial crisis (2005-2008), during the crisis (2009-2012) and in the post-crisis (2013-2016) periods. Out of the 20 topics we have identified, we present only those topics where there is a statistically significant change in the weight for at least one NBER program. The methods of the analysis are identical to the ones used in Table 11. We indicate with asterisks the results which statistically differ from the pre-crisis period.

$* * * p<0.01, * * p<0.05, * p<0.10$. 
Table 17

Jensen-Shannon divergence measure for assessing the similarity between the distributions of the topics studied by different NBER programs in the pre-crisis period 2005-2008, crisis period 2009-2012, and post-crisis period 2009-2016.

\begin{tabular}{|c|c|c|c|c|c|c|c|}
\hline Monetary Economics & $\begin{array}{l}2013-2016 \\
2009-2012 \\
2005-2008\end{array}$ & $\begin{array}{l}0.12 \\
0.19 \\
0.22 *\end{array}$ & $\begin{array}{l}0.39 \\
\mathbf{0 . 2 8} \\
0.36\end{array}$ & $\begin{array}{l}0.25 \\
\mathbf{0 . 2 0} \\
0.25\end{array}$ & $\begin{array}{l}0.21 \\
\mathbf{0 . 1 7} \\
0.29\end{array}$ & $\begin{array}{l}0.11 \\
\mathbf{0 . 1 7} \\
0.21\end{array}$ & $\begin{array}{l}0.09 \\
0.18 \\
0.18\end{array}$ \\
\hline Corporate Finance & $\begin{array}{l}2013-2016 \\
2009-2012 \\
2005-2008\end{array}$ & & & $\begin{array}{l}0.15 \\
0.26 \\
0.20\end{array}$ & $\begin{array}{l}0.18 \\
\mathbf{0 . 1 0} \\
0.20\end{array}$ & $\begin{array}{l}0.32 \\
\mathbf{0 . 3 0} \\
0.30\end{array}$ & $\begin{array}{l}0.24 \\
\mathbf{0 . 2 3} \\
0.28\end{array}$ \\
\hline $\begin{array}{l}\text { International Finance } \\
\text { and Macro }\end{array}$ & $\begin{array}{c}2013-2016 \\
2009-2012 \\
2005-2008\end{array}$ & & & & & $\begin{array}{l}0.12 \\
0.15 \\
0.29\end{array}$ & $\begin{array}{l}0.17 \\
0.16 \\
0.14\end{array}$ \\
\hline $\begin{array}{l}\text { Economic Fluctuations } \\
\text { and Growth }\end{array}$ & $\begin{array}{l}2013-2016 \\
2009-2012 \\
2005-2008\end{array}$ & & & & & & $\begin{array}{l}0.09 \\
0.18 \\
0.21\end{array}$ \\
\hline
\end{tabular}

Note: The table presents the Jensen-Shannon divergence measure for assessing the similarity between two distributions. In each off-diagonal cell, we show the measure for two NBER programs in the corresponding time periods, 2013-2016, 2009-2012, and 2005-2008, respectively. The figures in the cells that lie on the diagonal measure the similarity between the distributions of the study topics of a given program in the two periods, as follows: the top figure in each cell measures the similarity between 2013-2016 and 2009-2012, the middle figure measures the similarity between 2009-2012 and 2005-2008, and the bottom figure measures the similarity between 2005-2008 and 2013-2016. Cases where the Jensen-Shannon divergence measure is lower in 2009-2012 than in other periods, are marked in a boldface. 


\title{
Online Supplementary Appendix \\ (Not for Publication)
}

\section{Economists in the 2008 Financial Crisis: Slow to See, Fast to Act}

\author{
Daniel Levy \\ Department of Economics, Bar-Ilan University, Ramat-Gan 5290002, Israel \\ Department of Economics, Emory University, Atlanta, GA 30322, USA \\ ICEA, Wilfrid Laurier University, Waterloo, Canada \\ RCEA, University of Bologna, Rimini, Italy \\ ISET at TSU, Tbilisi, Georgia \\ Daniel.Levy@biu.ac.il
}

Tamir Mayer

Graduate School of Business Administration, Bar-Ilan University, Ramat Gan, 5290002, Israel Tamirmayer@gmail.com

Alon Raviv

Graduate School of Business Administration, Bar-Ilan University, Ramat Gan, 5290002, Israel

Alon.Raviv@biu.ac.il

Revised: February 12, 2022 
Table of Contents

$\underline{\text { Page }}$

Abbreviations used to denote the NBER research programs

Table A1. NBER WPs: descriptive statistics for 16 non-Macro/Finance NBER programs, 1999-2016

Table A2. The frequency of crisis WPs published by the 16 non-Macro/Finance NBER programs, 1999-2016

Figure A3. The \% of crisis WPs and 2-year lagged yield spread between the Moody's BAA10Y index (index of 10y bonds with a rating of BAA) and AAA10Y index (index of 10y bonds with a rating of AAA)

Figure A3b. The \% of crisis WPs and the average frequency of the topic "crisis" in Google Trends in the US and Worldwide

Table A4. Regressions of the annual \% of crisis WPs on different indexes of yield spread

Table A4b. Regressions of the annual \% change in crisis WPs on the change in CISS index of financial stability with leads and lags

Table A4c. Regressions of the annual \% change in crisis WPs on the change in KCFSI index of financial stability with leads and lags

Table A7. Twenty topics in 612 crisis WPs

Table A7. (cont.)

Table A7b. Bigram-LDA Analysis: Seven crisis topics and the 10 most frequent words in each topic

Table A16. The average weights of 20 different topics in crisis WPs for the pre-crisis period (2005-2008) across NBER research programs

Table A16b. The average weights of 20 different topics in crisis WPs for the crisis period (2009-2012) across NBER research programs

Table A16c. The average weights of 20 different topics in crisis WPs for the post-crisis period (2013-2016) across NBER research programs

Table A18. The correlation between the annual weights of the 9 crisis topics and the annual weights of the three most correlated topics out of the 500 topics 
Table A20. \% of NBER WPs published in the top-3 finance journals in the total number of publications in these journals

Table A21. \% of NBER WPs that were published between 1999 and

2016 by the two NBER finance programs (Asset Pricing, and Corporate

Finance) in the top-3 finance journals

$\begin{array}{ll}\text { Kansas City Financial Stress Index (KCFSI) } & 18\end{array}$

Composite Indicator of Systemic Stress (CISS) 21 


\section{Supplementary Tables}

Abbreviations used to denote the NBER research programs

\begin{tabular}{|l|l|}
\hline AE & Development of the American Economy \\
\hline CH & Children \\
\hline AG & Aging \\
\hline ED & Economics of Education \\
\hline TWP & Technical Working Papers \\
\hline DEV & Development Economics \\
\hline PR & Productivity, Innovation, and Entrepreneurship \\
\hline POL & Political Economy \\
\hline LE & Law and Economics \\
\hline HC & Health Care \\
\hline IO & Industrial Organization \\
\hline PE & Public Economics \\
\hline EEE & Environment and Energy Economics \\
\hline IFM & International Finance and Macroeconomics \\
\hline HE & Health Economics \\
\hline IS & Labor Studies \\
\hline EFG & Economic Fluctuations and Growth \\
\hline ME & Monetary Economics \\
\hline IT & International Trade \\
\hline CF & Corporate Finance \\
\hline AP & Asset Pricing \\
\hline All & All NBER WPs \\
\hline
\end{tabular}


Table A1

NBER WPs: descriptive statistics for 16 non-Macro/Finance NBER programs, 1999-2016.

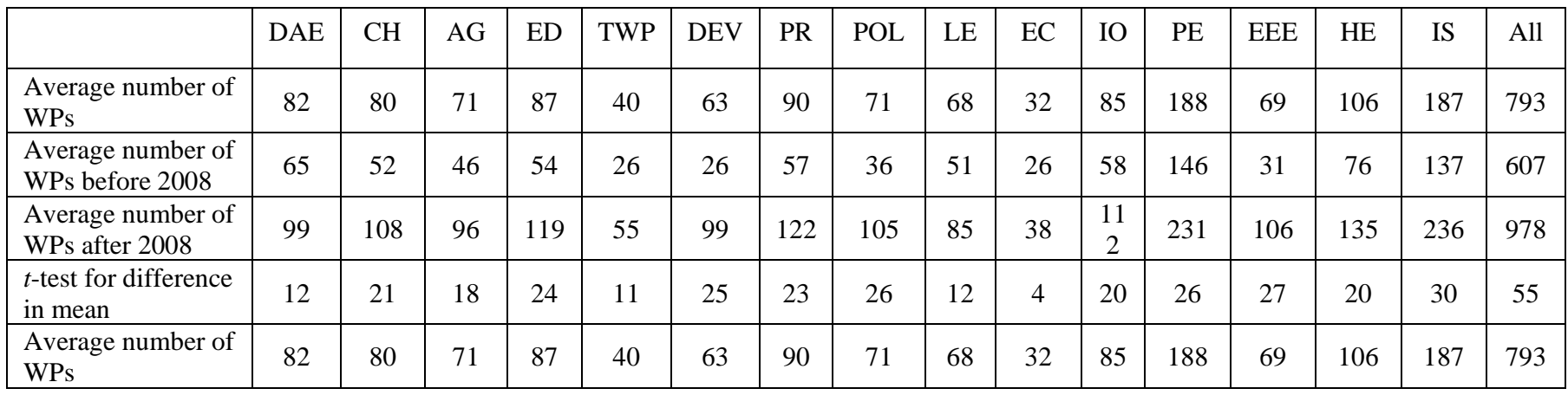

Table A2

The frequency of crisis WPs published by the 16 non-Macro/Finance NBER programs, 1999-2016.

\begin{tabular}{|c|c|c|c|c|c|c|c|c|c|c|c|c|c|c|c|c|}
\hline & DAE & $\mathrm{CH}$ & AG & ED & TWP & DEV & PR & POL & LE & $\mathrm{HC}$ & IO & $\mathrm{PE}$ & EEE & $\mathrm{HE}$ & IS & All \\
\hline $\begin{array}{l}\text { Average \% of } \\
\text { crisis WPs }\end{array}$ & 13 & 3 & 6 & 3 & 5 & 6 & 4 & 6 & 5 & 5 & 4 & 5 & 5 & 4 & 4 & 11 \\
\hline $\begin{array}{l}\text { Min. \% during } \\
\text { 1999-2016 }\end{array}$ & 5 & 0 & 0 & 0 & 0 & 0 & 0 & 0 & 0 & 0 & 0 & 2 & 0 & 0 & 1 & 6 \\
\hline $\begin{array}{l}\text { Max. \% during } \\
\text { 1999-2016 }\end{array}$ & 21 & 12 & 17 & 17 & 17 & 17 & 11 & 17 & 15 & 17 & 14 & 11 & 17 & 10 & 8 & 18 \\
\hline $\begin{array}{l}\text { Average \% } \\
\text { before } 2008\end{array}$ & 10 & 3 & 4 & 3 & 4 & 4 & 3 & 4 & 4 & 4 & 4 & 4 & 5 & 3 & 3 & 8 \\
\hline $\begin{array}{l}\text { Average \% after } \\
2008\end{array}$ & 17 & 4 & 8 & 4 & 5 & 7 & 6 & 9 & 7 & 6 & 5 & 7 & 5 & 5 & 5 & 14 \\
\hline $\begin{array}{l}\text { (\% } \\
\text { after)/(\%before) }\end{array}$ & 2 & 2 & 2 & 1 & 1 & 2 & 2 & 2 & 2 & 1 & 2 & 2 & 1 & 2 & 2 & 2 \\
\hline $\begin{array}{l}\text { z-test for mean- } \\
\text { difference }\end{array}$ & 4 & 2 & 3 & 0 & 1 & 2 & 3 & 3 & 2 & 1 & 2 & 4 & 0 & 2 & 3 & 10 \\
\hline $\begin{array}{l}\text { \% out of all } \\
\text { crisis WPs }\end{array}$ & 12 & 3 & 5 & 3 & 2 & 4 & 4 & 5 & 4 & 2 & 4 & 11 & 4 & 4 & 7 & 100 \\
\hline $\begin{array}{l}\text { Number of crisis } \\
\text { WPs }\end{array}$ & 204 & 66 & 88 & 60 & 51 & 75 & 85 & 100 & 79 & 49 & 83 & 188 & 72 & 83 & 128 & 1,632 \\
\hline
\end{tabular}




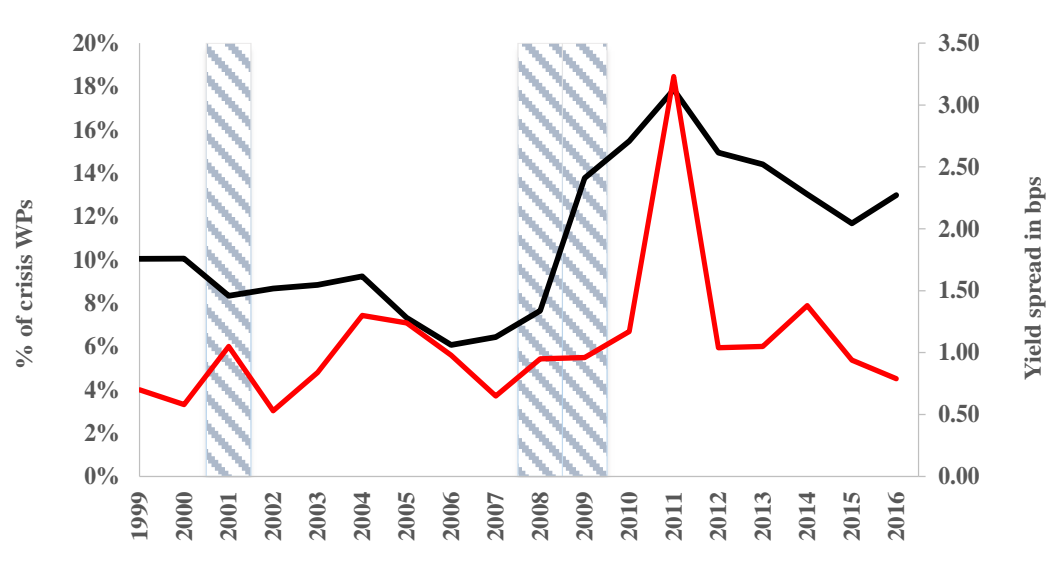

5- NBER recessions $\quad$ \% of NBER Papers with 'Crisis' $\quad$-2y lagged BAA10Y-AAA10Y

Fig. A3. The \% of crisis WPs and 2-year lagged yield spread between the Moody's BAA10Y index (index of 10y bonds with a rating of BAA) and AAA10Y index (index of 10y bonds with a rating of $A A A)$.

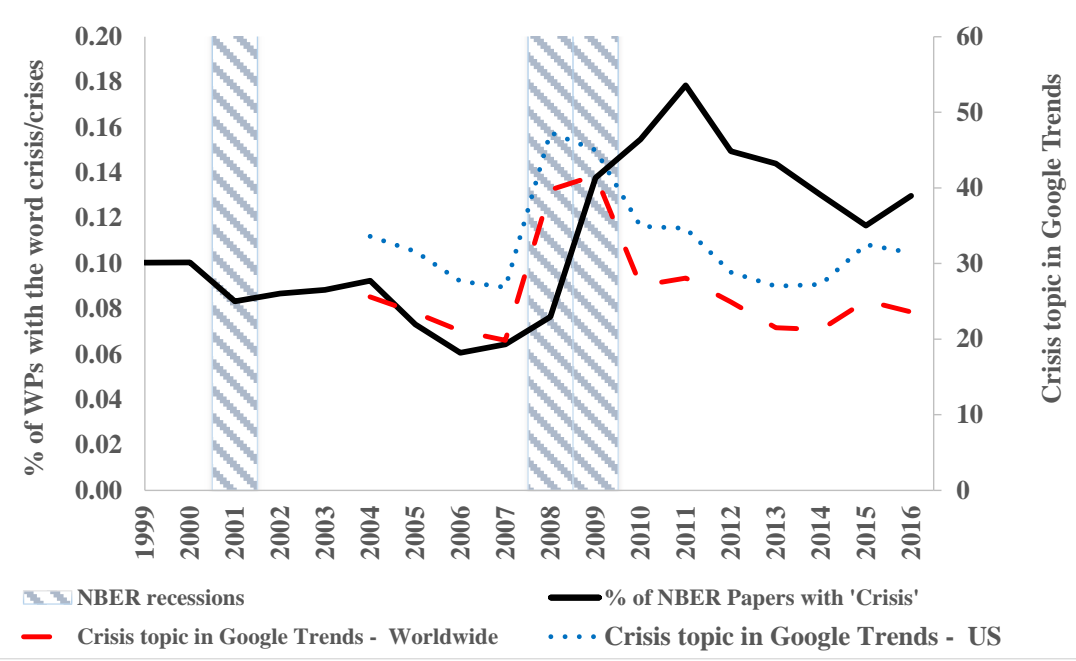

Fig. A3b. The \% of crisis WPs and the average frequency of the topic "crisis" in Google Trends in the US and Worldwide.

Notes: Google Trends' data were generated by setting its search parameters to "topic," “all category,” and "web search.” Google Trends data are available only stating 2004 and onwards and is normalized. The original Google Trend data is monthly, and here we report annual averages. Source: https://trends.google.com/trends/explore. 


\section{Table A4}

Regressions of the annual \% of crisis WPs on different indexes of yield spread.

\begin{tabular}{|c|c|c|c|c|c|c|c|c|}
\hline & (1) & (2) & (3) & (4) & (5) & (6) & (7) & (8) \\
\hline Intercept & $\begin{array}{l}0.09 * * * \\
(6.68)\end{array}$ & $\begin{array}{l}0.07 * * * \\
(3.19)\end{array}$ & $\begin{array}{c}0.08^{* * *} \\
(3.13)\end{array}$ & $\begin{array}{l}0.07 * * * \\
(4.99)\end{array}$ & $\begin{array}{l}0.09 * * * \\
(3.31)\end{array}$ & $\begin{array}{c}0.07 * * * \\
(6.53)\end{array}$ & $\begin{array}{l}0.07^{* * *} \\
(9.55)\end{array}$ & $\begin{array}{l}0.08^{* * * *} \\
(7.36)\end{array}$ \\
\hline $\begin{array}{l}\text { 2y lagged 3-month } \\
\text { LIBOR/T-Bill spread } \\
\text { (TED spread) }\end{array}$ & $\begin{array}{r}0.04 \\
(1.59)\end{array}$ & & & & & & & \\
\hline $\begin{array}{l}\text { 2y lagged Baa/10-year } \\
\text { Treasury spread }\end{array}$ & & $\begin{array}{l}0.02 * * \\
(2.12)\end{array}$ & & & & $\begin{array}{c}0.01 \\
(1.46)\end{array}$ & & $\begin{array}{l}-0.01 \\
(1.21)\end{array}$ \\
\hline $\begin{array}{l}\text { 2y lagged Aaa/10-year } \\
\text { Treasury spread }\end{array}$ & & & $\begin{array}{r}0.06 \\
(1.14) \\
\end{array}$ & & & & & \\
\hline 2y lagged Baa/Aaa spread & & & & $\begin{array}{l}0.03 * * \\
(2.66)\end{array}$ & & & $\begin{array}{l}0.02^{* *} \\
(2.30)\end{array}$ & $\begin{array}{l}0.03 * * \\
(2.07)\end{array}$ \\
\hline $\begin{array}{l}\text { 2y lagged High-yield } \\
\text { bond/Baa spread }\end{array}$ & & & & & $\begin{array}{l}0.002 \\
(0.69)\end{array}$ & $\begin{array}{r}0.002 \\
(0.69)\end{array}$ & & \\
\hline Dummy for post-2008 & & & & & & $\begin{array}{l}0.06^{* * * *} \\
(7.00)\end{array}$ & $\begin{array}{l}0.05^{* * *} \\
(7.23)\end{array}$ & $\begin{array}{l}0.05^{* * *} \\
(7.36)\end{array}$ \\
\hline$p>F, p>\chi^{2}$ & $0.13 \%$ & $4.98 \%$ & $27.2 \%$ & $1.70 \%$ & $49.8 \%$ & $0.00 \%$ & $0.00 \%$ & $0.00 \%$ \\
\hline$R^{2}$ & 0.14 & 0.22 & 0.07 & 0.31 & 0.03 & 0.82 & 0.85 & 0.86 \\
\hline
\end{tabular}

Note:

Crisis WPs are defined as the WPs that mention the word 'crisis/crises' at least once in the first five paragraphs of the introduction. $t$-test statistics are shown in parentheses. The yield spread indexes are defined as follows:

1) 3-month LIBOR/T-Bill spread (TED spread) - the spread between 3-Month LIBOR based on US dollars and 3-Month Treasury Bill, source: https://fred.stlouisfed.org/series/TEDRATE.

2) Baa/10-year Treasury spread - the spread between Moody's Seasoned Baa Corporate Bond Yield and 10-Year Treasury Constant Maturity, source: https://fred.stlouisfed.org/series/BAA10Y.

3) Aaa/10-year Treasury spread - the spread between Moody's Seasoned Aaa Corporate Bond Yield and 10-Year Treasury Constant Maturity, source: https://fred.stlouisfed.org/series/AAA10Y.

4) Baa/Aaa spread - the spread between Moody's Seasoned Baa Corporate Bond Yield and Moody's Seasoned Aaa Corporate Bond Yield, source: the difference between Moody's Seasoned Baa Corporate Bond Yield, https://fred.stlouisfed.org/series/DBAA, and Moody's Seasoned Aaa Corporate Bond Yield, https://fred.stlouisfed.org/series/DAAA.

5) High-yield bond/Baa spread - the spread between ICE Bank of America US High Yield Index Effective Yield and Moody's Seasoned Baa Corporate Bond. Source: computed as a difference between ICE BofA US High Yield Index Effective Yield, https://fred.stlouisfed.org/series/BAMLH0A0HYM2EY and Moody's Seasoned Baa Corporate Bond Yield, https://fred.stlouisfed.org/series/DBAA. 
Table A4b

Regressions of the annual \% change of crisis WPs on the change in CISS index of financial stability with leads and lags.

\begin{tabular}{|c|c|c|c|c|c|c|c|}
\hline & (1) & (2) & (3) & (4) & (5) & (6) & (7) \\
\hline Intercept & $\begin{array}{r}0.00 \\
(0.63) \\
\end{array}$ & $\begin{array}{r}0.00 \\
(0.60) \\
\end{array}$ & $\begin{array}{r}0.00 \\
(0.55) \\
\end{array}$ & $\begin{array}{r}0.00 \\
(0.67) \\
\end{array}$ & $\begin{array}{r}0.00 \\
(0.62)\end{array}$ & $\begin{array}{r}0.00 \\
(0.94) \\
\end{array}$ & $\begin{array}{l}-0.00 \\
(0.63) \\
\end{array}$ \\
\hline 1-year lead CISS index & $\begin{array}{l}-0.00 \\
(0.74) \\
\end{array}$ & & & & & & \\
\hline CISS index & & $\begin{array}{r}0.00 \\
(0.82) \\
\end{array}$ & & & & & \\
\hline 1-year lagged CISS index & & & $\begin{array}{c}0.02^{*} \\
(1.85) \\
\end{array}$ & & & $\begin{array}{c}0.01^{*} \\
(2.07) \\
\end{array}$ & $\begin{array}{c}0.01 \\
(1.49) \\
\end{array}$ \\
\hline 2-year lagged CISS index & & & & $\begin{array}{l}0.02^{* * *} \\
(3.32)\end{array}$ & & $\begin{array}{l}0.02 * * \\
(3.44)\end{array}$ & $\begin{array}{l}0.02 * * \\
(2.32)\end{array}$ \\
\hline 3-year lagged CISS index & & & & & $\begin{array}{c}0.01 \\
(0.63) \\
\end{array}$ & & \\
\hline Dummy for post-2008 & & & & & & & $\begin{array}{c}0.02 * \\
(2.11)\end{array}$ \\
\hline$p>F, p>\chi^{2}$ & $74.1 \%$ & $82.3 \%$ & $8.72 \%$ & $0.55 \%$ & $62.5 \%$ & $0.48 \%$ & $0.31 \%$ \\
\hline$R^{2}$ & 0.01 & 0.00 & 0.21 & 0.46 & 0.02 & 0.62 & 0.74 \\
\hline
\end{tabular}

Note: Crisis WPs are defined as the WPs that mention the word 'crisis/crises' at least once in the first five paragraphs of the introduction. $t$-test statistics are shown in parentheses. We estimate the regression in first differences because the series may contain unit root as ADF tests results were sensitive to specification (drift, trend, number of lags) and thus we could not rule out a possibility of a unit root. 
Table A4c

Regressions of the annual \% change of crisis WPs on the change in KCFSI index of financial stability with leads and lags.

\begin{tabular}{|c|c|c|c|c|c|c|c|}
\hline & (1) & $(2)$ & (3) & (4) & (5) & (6) & (7) \\
\hline Intercept & $\begin{array}{r}0.00 \\
(0.42) \\
\end{array}$ & $\begin{array}{r}0.00 \\
(0.52) \\
\end{array}$ & $\begin{array}{r}0.00 \\
(0.44) \\
\end{array}$ & $\begin{array}{r}0.00 \\
(0.67) \\
\end{array}$ & $\begin{array}{r}0.00 \\
(0.88)\end{array}$ & $\begin{array}{c}0.00 \\
(.112)\end{array}$ & $\begin{array}{c}-0.00 \\
(0.59)\end{array}$ \\
\hline 1-year lead KCFSI index & $\begin{array}{c}-0.01 \\
(1.73)\end{array}$ & & & & & & \\
\hline KCFSI index & & $\begin{array}{c}-0.00 \\
(0.09) \\
\end{array}$ & & & & & \\
\hline 1-year lagged KCFSI index & & & $\begin{array}{l}0.01^{* *} \\
(2.07)\end{array}$ & & & $\begin{array}{l}0.01^{* *} \\
(1.99)\end{array}$ & $\begin{array}{c}0.00 \\
(0.28)\end{array}$ \\
\hline 2-year lagged KCFSI index & & & & $\begin{array}{l}0.06 * * \\
(2.47) \\
\end{array}$ & & $\begin{array}{l}0.01^{* *} \\
(2.44) \\
\end{array}$ & $\begin{array}{c}0.01^{*} \\
(2.06) \\
\end{array}$ \\
\hline 3-year lagged KCFSI index & & & & & $\begin{array}{c}0.01 \\
(.125) \\
\end{array}$ & & \\
\hline Dummy for 2008-2012 & & & & & & & $\begin{array}{l}0.03^{* *} \\
(2.71) \\
\end{array}$ \\
\hline$p>F, p>\chi^{2}$ & $10.6 \%$ & $92.9 \%$ & $5.8 \%$ & $2.96 \%$ & $23.6 \%$ & $1.67 \%$ & $0.34 \%$ \\
\hline$R^{2}$ & 0.19 & 0.00 & 0.19 & 0.34 & 0.11 & 0.49 & 0.69 \\
\hline
\end{tabular}

Note: Crisis WPs are defined as the WPs that mention the word 'crisis/crises' at least once in the first five paragraphs of the introduction. $t$-test statistics are shown in parentheses. We estimate the regression in first differences because the series may contain unit root as ADF tests results were sensitive to specification (drift, trend, number of lags) and thus we could not rule out a possibility of a unit root. 
Table A7

Twenty topics we have identified in 612 crisis WPs.

\begin{tabular}{|c|c|c|c|c|c|c|c|c|c|}
\hline \multicolumn{2}{|c|}{$\begin{array}{c}\text { International } \\
\text { Finance }\end{array}$} & \multicolumn{2}{c|}{ Sudden Stops } & \multicolumn{2}{c|}{$\begin{array}{c}\text { Repo and } \\
\text { Securitization }\end{array}$} & \multicolumn{2}{c|}{ Liquidity } & \multicolumn{2}{c|}{ Crisis Event } \\
\hline Words & Freq. & Words & Freq. & Words & Freq. & Words & Freq. & Words & Freq. \\
\hline differ & 0.08 & sudden & 0.14 & loan & 0.12 & liquid & 0.26 & failur & 0.08 \\
\hline find & 0.08 & stop & 0.12 & market & 0.11 & asset & 0.11 & event & 0.08 \\
\hline data & 0.06 & account & 0.10 & secur & 0.08 & market & 0.10 & lehman & 0.06 \\
\hline recent & 0.06 & current & 0.09 & credit & 0.07 & trade & 0.05 & view & 0.06 \\
\hline literatur & 0.06 & countri & 0.05 & securit & 0.06 & risk & 0.05 & led & 0.06 \\
\hline studi & 0.06 & capit & 0.05 & collater & 0.06 & demand & 0.04 & caus & 0.05 \\
\hline measur & 0.05 & larg & 0.04 & mortgag & 0.05 & illiquid & 0.04 & hous & 0.05 \\
\hline import & 0.05 & revers & 0.04 & lend & 0.05 & investor & 0.04 & septemb & 0.05 \\
\hline evid & 0.05 & deficit & 0.04 & bond & 0.05 & money & 0.04 & mani & 0.05 \\
\hline empir & 0.05 & emerg & 0.04 & rate & 0.05 & time & 0.04 & start & 0.05 \\
\hline time & 0.05 & net & 0.04 & repo & 0.04 & secur & 0.03 & effect & 0.05 \\
\hline countri & 0.05 & economi & 0.03 & corpor & 0.04 & increas & 0.03 & bankruptci & 0.04 \\
\hline effect & 0.04 & asset & 0.03 & agenc & 0.03 & suppli & 0.02 & time & 0.04 \\
\hline sever & 0.04 & global & 0.03 & borrow & 0.03 & treasuri & 0.02 & octob & 0.04 \\
\hline impact & 0.04 & extern & 0.03 & structur & 0.03 & bond & 0.02 & believ & 0.04 \\
\hline perform & 0.04 & imbal & 0.03 & fund & 0.03 & hold & 0.02 & feder & 0.04 \\
\hline relat & 0.04 & collaps & 0.03 & role & 0.03 & yield & 0.02 & rescu & 0.04 \\
\hline term & 0.04 & price & 0.03 & inform & 0.03 & spread & 0.02 & belief & 0.04 \\
\hline factor & 0.04 & adjust & 0.02 & origin & 0.03 & agent & 0.02 & bernank & 0.04 \\
\hline larg & 0.04 & market & 0.02 & subprim & 0.03 & particip & 0.02 & interest & 0.04 \\
\hline
\end{tabular}

\begin{tabular}{|c|c|c|c|c|c|c|c|c|c|}
\hline \multicolumn{2}{|c|}{$\begin{array}{c}\text { Government } \\
\text { Bailout }\end{array}$} & \multicolumn{2}{c|}{ History of Crisis } & \multicolumn{2}{c|}{$\begin{array}{c}\text { International } \\
\text { Reserves }\end{array}$} & \multicolumn{2}{c|}{$\begin{array}{c}\text { Fiscal and Monetary } \\
\text { Policy }\end{array}$} & \multicolumn{2}{c|}{ Systemic Risk } \\
\hline Words & Freq. & Words & Freq. & Words & Freq. & Words & Freq. & Words & Freq. \\
\hline borrow & 0.08 & system & 0.13 & reserv & 0.22 & polici & 0.22 & risk & 0.15 \\
\hline govern & 0.08 & state & 0.11 & countri & 0.12 & monetari & 0.13 & firm & 0.11 \\
\hline guarante & 0.07 & unit & 0.07 & intern & 0.11 & fiscal & 0.09 & system & 0.09 \\
\hline bailout & 0.06 & world & 0.06 & china & 0.05 & central & 0.07 & credit & 0.09 \\
\hline reform & 0.06 & gold & 0.06 & accumul & 0.04 & inflat & 0.05 & sector & 0.08 \\
\hline polici & 0.06 & histor & 0.05 & increas & 0.04 & stabil & 0.05 & regul & 0.06 \\
\hline imf & 0.06 & centuri & 0.05 & hold & 0.04 & respons & 0.04 & institut & 0.05 \\
\hline intern & 0.06 & histori & 0.05 & trade & 0.04 & union & 0.04 & market & 0.05 \\
\hline hazard & 0.05 & standard & 0.04 & global & 0.03 & target & 0.04 & govern & 0.04 \\
\hline privat & 0.05 & recent & 0.04 & foreign & 0.03 & credibl & 0.04 & measur & 0.03 \\
\hline moral & 0.04 & year & 0.04 & hoard & 0.03 & inat & 0.03 & economi & 0.03 \\
\hline problem & 0.04 & global & 0.04 & export & 0.03 & rule & 0.03 & corpor & 0.03 \\
\hline issu & 0.04 & depress & 0.04 & adjust & 0.03 & area & 0.03 & bank & 0.03 \\
\hline institut & 0.04 & bubbl & 0.04 & larg & 0.03 & euro & 0.02 & manag & 0.02 \\
\hline commit & 0.04 & great & 0.04 & cost & 0.03 & govern & 0.02 & claim & 0.02 \\
\hline intervent & 0.04 & center & 0.03 & extern & 0.03 & time & 0.02 & liabil & 0.02 \\
\hline lender & 0.03 & discuss & 0.03 & exchang & 0.03 & countri & 0.02 & analysi & 0.02 \\
\hline cost & 0.03 & section & 0.03 & associ & 0.03 & forecast & 0.02 & capit & 0.02 \\
\hline provid & 0.03 & event & 0.03 & asian & 0.03 & provid & 0.02 & inform & 0.02 \\
\hline program & 0.03 & today & 0.03 & develop & 0.02 & scal & 0.02 & contract & 0.02 \\
\hline
\end{tabular}


Table A7

(Cont.) Twenty topics we have identified in 612 crisis WPs.

\begin{tabular}{|c|c|c|c|c|c|c|c|c|c|}
\hline \multicolumn{2}{|c|}{ Exchange Rates } & \multicolumn{2}{c|}{ Great Recession } & \multicolumn{2}{c|}{ Economic Shocks } & \multicolumn{2}{c|}{ Economic Growth } & \multicolumn{2}{c|}{ Sovereign Debt } \\
\hline Words & Freq. & Words & Freq. & Words & Freq. & Words & Freq. & Words & Freq. \\
\hline rate & 0.29 & recess & 0.15 & model & 0.28 & growth & 0.19 & debt & 0.36 \\
\hline exchang & 0.11 & great & 0.12 & shock & 0.10 & develop & 0.12 & default & 0.10 \\
\hline interest & 0.10 & recoveri & 0.07 & equilibrium & 0.05 & economi & 0.09 & govern & 0.08 \\
\hline polici & 0.09 & declin & 0.06 & constraint & 0.04 & countri & 0.08 & sovereign & 0.07 \\
\hline economi & 0.05 & output & 0.06 & product & 0.04 & gdp & 0.06 & public & 0.05 \\
\hline regim & 0.05 & percent & 0.05 & trade & 0.04 & sector & 0.06 & bond & 0.04 \\
\hline real & 0.05 & unemploy & 0.05 & show & 0.04 & advanc & 0.05 & matur & 0.03 \\
\hline increas & 0.03 & depress & 0.05 & optim & 0.04 & year & 0.04 & countri & 0.03 \\
\hline monetari & 0.03 & labor & 0.05 & friction & 0.04 & world & 0.04 & domest & 0.03 \\
\hline higher & 0.03 & period & 0.04 & studi & 0.04 & rate & 0.03 & borrow & 0.03 \\
\hline macroeconom & 0.02 & market & 0.04 & economi & 0.04 & percent & 0.03 & extern & 0.03 \\
\hline low & 0.02 & follow & 0.03 & effect & 0.04 & decad & 0.03 & risk & 0.02 \\
\hline inflat & 0.02 & downturn & 0.03 & invest & 0.03 & level & 0.02 & shortterm & 0.02 \\
\hline effect & 0.02 & year & 0.03 & dynam & 0.03 & increas & 0.02 & fiscal & 0.02 \\
\hline open & 0.02 & episod & 0.03 & literatur & 0.03 & sinc & 0.02 & ratio & 0.02 \\
\hline currenc & 0.02 & shock & 0.03 & lead & 0.03 & period & 0.02 & privat & 0.02 \\
\hline peg & 0.02 & employ & 0.03 & gener & 0.03 & averag & 0.02 & level & 0.02 \\
\hline stabil & 0.02 & chang & 0.03 & theori & 0.03 & invest & 0.02 & creditor & 0.02 \\
\hline combin & 0.02 & real & 0.03 & develop & 0.03 & share & 0.02 & spread & 0.01 \\
\hline level & 0.02 & rate & 0.03 & agent & 0.03 & neg & 0.02 & tax & 0.01 \\
\hline
\end{tabular}

\begin{tabular}{|c|c|c|c|c|c|c|c|c|c|}
\hline \multicolumn{2}{|c|}{ Banks } & \multicolumn{2}{c|}{ Household Credit } & \multicolumn{2}{c|}{ Asset Pricing } & \multicolumn{2}{c|}{ Emerging Market } & \multicolumn{2}{c|}{ Currency Market } \\
\hline Words & Freq. & Words & Freq. & Words & Freq. & Words & Freq. & Words & Freq. \\
\hline bank & 0.48 & credit & 0.19 & asset & 0.16 & capit & 0.17 & market & 0.16 \\
\hline central & 0.05 & boom & 0.11 & price & 0.15 & countri & 0.11 & currenc & 0.14 \\
\hline deposit & 0.04 & household & 0.10 & market & 0.10 & market & 0.10 & countri & 0.12 \\
\hline fund & 0.04 & incom & 0.08 & investor & 0.06 & intern & 0.08 & global & 0.09 \\
\hline lend & 0.04 & hous & 0.05 & capit & 0.05 & emerg & 0.07 & emerg & 0.08 \\
\hline reserv & 0.03 & show & 0.04 & fund & 0.05 & flow & 0.06 & shock & 0.05 \\
\hline feder & 0.03 & mortgag & 0.04 & equiti & 0.04 & trade & 0.04 & dollar & 0.04 \\
\hline run & 0.03 & busi & 0.04 & stock & 0.04 & develop & 0.04 & contagion & 0.04 \\
\hline institut & 0.03 & cycl & 0.04 & return & 0.04 & domest & 0.04 & foreign & 0.03 \\
\hline loan & 0.03 & increas & 0.03 & valu & 0.03 & foreign & 0.03 & intern & 0.03 \\
\hline provid & 0.03 & aggreg & 0.03 & larg & 0.03 & global & 0.03 & period & 0.03 \\
\hline system & 0.02 & leverag & 0.03 & risk & 0.03 & control & 0.03 & integr & 0.03 \\
\hline swap & 0.02 & borrow & 0.03 & sale & 0.03 & economi & 0.03 & spread & 0.02 \\
\hline oper & 0.02 & larg & 0.03 & expect & 0.03 & inflow & 0.03 & bank & 0.02 \\
\hline balanc & 0.02 & data & 0.03 & invest & 0.03 & latin & 0.03 & factor & 0.02 \\
\hline line & 0.02 & expans & 0.03 & portfolio & 0.03 & liber & 0.03 & exposur & 0.02 \\
\hline fed & 0.02 & save & 0.03 & crash & 0.02 & asian & 0.03 & origin & 0.02 \\
\hline insur & 0.02 & invest & 0.03 & increas & 0.02 & open & 0.02 & develop & 0.02 \\
\hline failur & 0.02 & tax & 0.03 & manag & 0.02 & extern & 0.02 & devalu & 0.02 \\
\hline larg & 0.02 & rise & 0.02 & sell & 0.02 & argentina & 0.02 & sever & 0.02 \\
\hline
\end{tabular}

Note: The table presents the words of the 20 topics we have identified in the 612 crisis WPs. We define a WP as a 'crisis WP' if (1) it includes the word crisis at least once in the first five paragraphs of the introduction, (2) crisis topics comprise at least $10 \%$ of the paper, and (3) crisis topics are among the top-three topics of the paper. Applying this definition, we identified 612 WPs, where 189 WPs were written in the pre-crisis period 1999-2009, 226 during the crisis period 2009-2012, and 197 in the post-crisis period 2008-2016. 
Table A7b

Bigram-LDA Analysis: Seven crisis topics we have identified, and the 10 most frequent words in each topic.

\begin{tabular}{|c|c|c|c|c|c|c|c|c|c|c|}
\hline Crisis Topics & & & & The $\mathrm{m}$ & st freque & words in & he topic & & & \\
\hline & & Finance & & & & & & & global & \\
\hline Financial \& & crisi & crisi & bank & countri & financi & credit & recent & global & financi & show \\
\hline & 719 & 180 & 119 & 99 & 98 & 82 & 59 & 51 & 46 & 43 \\
\hline & liquid & market & asset & illiquid & price & model & investor & increas & capit & crisi \\
\hline & 550 & 159 & 157 & 73 & 64 & 63 & 55 & 55 & 52 & 45 (12) \\
\hline & & Intern & & & & & & centrl & & Develop \\
\hline & reserv & reserv & manag & hold & accumul & countri & crisi & bank & swap & countri \\
\hline & 303 & 54 & 49 & 47 & 42 & 42 & 36 & 33 & 29 & 25 \\
\hline & & & & & & feder & & deposit & & \\
\hline Banks & bank & deposit & lend & liquid & fund & reserv & run & insur & panic & Crisi \\
\hline & 1,024 & 114 & 92 & 78 & 74 & 59 & 54 & 49 & 49 & 45 (12) \\
\hline & bank & risk & credit & asset & market & collater & deriv & crisi & fund & requir \\
\hline & 455 & 171 & 79 & 65 & 64 & 61 & 49 & 46 & 45 & 44 \\
\hline & & emerg & & & & & & Sudden & & \\
\hline $\begin{array}{l}\text { Emerging Markets } \\
\text { \& Sudden Stops }\end{array}$ & countri & market & crisi & economi & intern & currenc & extern & stop & domest & financi \\
\hline & 282 & 183 & 144 & 121 & 96 & 90 & 87 & 84 & 83 & 78 \\
\hline & & & & latin & & & & & & \\
\hline Latin America & brazil & chile & countr & american & crisi & mexico & argentina & region & emerg & reform \\
\hline & 74 & 54 & 45 & 43 & 43 & 33 & 31 & 20 & 15 & 12 \\
\hline
\end{tabular}

Note: The table presents the 10 most frequent words in crisis' topics we have identified for a corpus that includes the abstracts of all the NBER WPs published in 1999-2016. First, the abstracts of the WPs that were published between 1999 and 2016 were analyzed using Bigram LDA, yielding 500 topics, where each topic contains 20 words. Out of the 500 topics, 7 topics contain the word 'crisis' or a combination of crisis and one other word such as 'financial crisis,' 'global crisis,' etc. The table shows the most frequent words in each topic along with the frequency of each word. In case that the word 'crisis' is not a part of the 10 most frequent words, we replace the $10^{\text {th }}$ word with the word "crisis" and indicate in brackets the rank of the word "crisis" within the topics. 
Table A16

The average weights of 20 topics we have identified in the crisis WPs during the pre-crisis period (20052008), across NBER research programs.

\begin{tabular}{|c|c|c|c|c|c|c|}
\hline Topic Name & $\begin{array}{l}\text { Monetary } \\
\text { Economics }\end{array}$ & $\begin{array}{l}\text { Int. } \\
\text { Trade }\end{array}$ & $\begin{array}{l}\text { Corporate } \\
\text { Finance }\end{array}$ & $\begin{array}{l}\text { Asset } \\
\text { Pricing }\end{array}$ & $\begin{array}{l}\text { Int. Finance and } \\
\text { Macro }\end{array}$ & $\begin{array}{l}\text { Econ. Fluct. and } \\
\text { Growth }\end{array}$ \\
\hline International Finance & 6.7 & 5.7 & 5.4 & 6.0 & 9.4 & 6.8 \\
\hline Sudden Stop & 3.4 & 6.4 & 1.7 & 1.4 & 12.7 & 9.3 \\
\hline Repo \& Securitization & 3.7 & 1.5 & 5.4 & 6.7 & 1.4 & 2.0 \\
\hline Liquidity & 3.3 & 1.8 & 8.4 & 20.8 & 2.5 & 3.6 \\
\hline Crisis Event & 5.0 & 0.7 & 6.4 & 3.7 & 2.6 & 3.8 \\
\hline Government Bailout & 2.2 & 6.7 & 5.8 & 1.8 & 5.2 & 4.6 \\
\hline History of Crisis & 11.4 & 1.2 & 3.8 & 6.1 & 5.6 & 4.6 \\
\hline International Reserves & 1.5 & 32.5 & 1.6 & 1.6 & 7.3 & 2.4 \\
\hline Monetary Policy & 3.2 & 2.4 & 4.6 & 2.7 & 2.5 & 4.1 \\
\hline Systemic Risk & 8.9 & 3.0 & 8.0 & 4.4 & 4.0 & 6.1 \\
\hline Exchange Rates & 8.5 & 7.4 & 1.4 & 2.1 & 6.9 & 7.0 \\
\hline Great Recessions & 2.7 & 0.4 & 1.0 & 1.4 & 2.4 & 4.3 \\
\hline Economic Shocks & 6.4 & 8.4 & 7.0 & 9.5 & 7.7 & 13.4 \\
\hline Economic Growth & 4.4 & 5.4 & 5.3 & 4.1 & 5.7 & 5.2 \\
\hline Sovereign Debt & 4.4 & 3.1 & 3.7 & 1.5 & 5.5 & 7.0 \\
\hline Banks & 7.0 & 1.5 & 11.8 & 4.1 & 2.5 & 2.5 \\
\hline Household Credit & 2.4 & 1.6 & 2.9 & 2.7 & 2.3 & 2.4 \\
\hline Asset Pricing & 5.1 & 2.2 & 8.8 & 18.8 & 3.6 & 5.5 \\
\hline Emerging Markets & 6.0 & 11.6 & 9.3 & 4.8 & 13.4 & 8.7 \\
\hline Currency Markets & 10.3 & 2.2 & 3.3 & 1.9 & 6.4 & 3.5 \\
\hline
\end{tabular}

Note: The table presents the average weights of the topics we have identified in the 189 crisis WPs that were published in 1999-2008 by selected NBER programs. Here we follow a stricter definition of a crisis WP, than the one we used in the previous sections of the paper: a WP is a 'crisis WP' if (1) it includes the word crisis at least once in the first five paragraphs of the introduction, (2) crisis topics comprise at least $10 \%$ of the paper, and (3) crisis topics are among the three topics with the highest weight in the paper. 
Table A16b

The average weights of 20 topics we have identified in crisis WPs published during the crisis period (2009-2012) across NBER research programs.

\begin{tabular}{|c|c|c|c|c|c|c|}
\hline Topic Name & $\begin{array}{l}\text { Monetary } \\
\text { Economics }\end{array}$ & $\begin{array}{l}\text { Int. } \\
\text { Trade }\end{array}$ & $\begin{array}{l}\text { Corporate } \\
\text { Finance }\end{array}$ & $\begin{array}{l}\text { Asset } \\
\text { Pricing }\end{array}$ & $\begin{array}{l}\text { Int. Finance and } \\
\text { Macro }\end{array}$ & $\begin{array}{l}\text { Econ. Fluct. and } \\
\text { Growth }\end{array}$ \\
\hline International Finance & 8.6 & 9.3 & 12.2 & 8.3 & 10.6 & 6.3 \\
\hline Sudden Stop & 2.5 & 4.3 & 2.3 & 2.5 & 5.0 & 3.0 \\
\hline Repo \& Securitization & 8.4 & 2.1 & 26.6 & 14.5 & 2.0 & 5.6 \\
\hline Liquidity & 4.7 & 2.3 & 3.8 & 11.1 & 4.0 & 4.1 \\
\hline Crisis Event & 6.5 & 4.6 & 3.3 & 5.4 & 4.0 & 5.5 \\
\hline Government Bailout & 2.1 & 2.6 & 3.6 & 2.3 & 3.0 & 3.2 \\
\hline History of Crisis & 9.8 & 4.0 & 4.5 & 5.9 & 7.4 & 4.7 \\
\hline International Reserves & 2.4 & 18.1 & 2.1 & 1.4 & 6.6 & 1.9 \\
\hline Monetary Policy & 5.5 & 2.6 & 1.6 & 1.5 & 4.5 & 5.8 \\
\hline Systemic Risk & 5.4 & 5.8 & 7.2 & 7.1 & 5.3 & 6.7 \\
\hline Exchange Rates & 4.9 & 2.3 & 2.1 & 2.3 & 4.5 & 3.9 \\
\hline Great Recessions & 8.1 & 6.3 & 2.1 & 4.2 & 6.4 & 10.1 \\
\hline Economic Shocks & 8.0 & 5.4 & 0.8 & 9.9 & 7.2 & 13.7 \\
\hline Economic Growth & 4.9 & 8.7 & 2.4 & 2.4 & 7.1 & 4.4 \\
\hline Sovereign Debt & 5.6 & 4.8 & 3.0 & 3.1 & 6.0 & 3.4 \\
\hline Banks & 6.4 & 4.3 & 21.0 & 7.7 & 4.1 & 6.5 \\
\hline Household Credit & 4.1 & 2.0 & 2.5 & 2.2 & 3.3 & 4.6 \\
\hline Asset Pricing & 4.2 & 3.9 & 6.7 & 11.8 & 4.4 & 6.4 \\
\hline Emerging Markets & 2.6 & 9.4 & 1.9 & 1.1 & 6.3 & 4.1 \\
\hline Currency Markets & 3.9 & 6.4 & 2.5 & 3.8 & 8.9 & 2.5 \\
\hline
\end{tabular}

Note: The table presents the average weights of the topics we have identified in the 423 crisis WPs that were published in 2009-2016 by selected NBER programs. Here we follow a stricter definition of a crisis WP, than the one we used in the previous sections of the paper: a WP is a 'crisis WP' if (1) it includes the word crisis at least once in the first five paragraphs of the introduction, (2) crisis topics comprise at least $10 \%$ of the paper, and (3) crisis topics are among the three topics with the highest weight in the paper. 
Table A16c

The average weights of 20 topics we have identified in crisis WPs during the post-crisis period (2013-2016) across NBER research programs.

\begin{tabular}{|c|c|c|c|c|c|c|}
\hline Topic Name & $\begin{array}{l}\text { Monetary } \\
\text { Economics }\end{array}$ & $\begin{array}{l}\text { Int. } \\
\text { Trade }\end{array}$ & $\begin{array}{l}\text { Corporate } \\
\text { Finance }\end{array}$ & $\begin{array}{l}\text { Asset } \\
\text { Pricing }\end{array}$ & $\begin{array}{l}\text { Int. Finance and } \\
\text { Macro }\end{array}$ & $\begin{array}{l}\text { Econ. Fluct. and } \\
\text { Growth }\end{array}$ \\
\hline International Finance & 7.8 & 14.8 & 8.8 & 7.6 & 8.1 & 8.3 \\
\hline Sudden Stop & 2.6 & 5.2 & 1.6 & 2.0 & 3.6 & 1.9 \\
\hline Repo \& Securitization & 3.9 & 0.7 & 14.1 & 8.4 & 1.2 & 2.8 \\
\hline Liquidity & 5.5 & 0.6 & 6.3 & 14.2 & 3.2 & 4.2 \\
\hline Crisis Event & 6.1 & 1.2 & 6.0 & 4.8 & 3.0 & 5.1 \\
\hline Government Bailout & 4.5 & 3.9 & 6.6 & 3.3 & 4.5 & 5.9 \\
\hline History of Crisis & 6.5 & 6.3 & 2.6 & 4.2 & 6.2 & 5.2 \\
\hline International Reserves & 2.1 & 1.8 & 1.7 & 1.4 & 5.3 & 2.1 \\
\hline Monetary Policy & 8.8 & 0.2 & 2.1 & 4.0 & 8.2 & 7.0 \\
\hline Systemic Risk & 4.0 & 6.6 & 11.1 & 5.9 & 4.5 & 5.8 \\
\hline Exchange Rates & 5.2 & 1.0 & 1.7 & 2.5 & 5.1 & 3.5 \\
\hline Great Recessions & 7.3 & 2.0 & 4.3 & 4.7 & 4.9 & 9.4 \\
\hline Economic Shocks & 11.3 & 36.8 & 9.1 & 11.2 & 8.4 & 12.6 \\
\hline Economic Growth & 3.8 & 3.7 & 2.8 & 3.4 & 6.8 & 5.5 \\
\hline Sovereign Debt & 7.4 & 9.3 & 3.5 & 4.0 & 13.9 & 10.2 \\
\hline Banks & 8.3 & 2.6 & 12.2 & 5.7 & 3.5 & 5.4 \\
\hline Household Credit & 4.3 & 0.2 & 3.8 & 4.8 & 3.3 & 5.7 \\
\hline Asset Pricing & 3.7 & 2.1 & 6.9 & 11.2 & 3.1 & 3.4 \\
\hline Emerging Markets & 2.7 & 11.6 & 2.1 & 2.1 & 5.7 & 2.1 \\
\hline Currency Markets & 2.0 & 3.9 & 1.6 & 2.2 & 5.6 & 2.3 \\
\hline
\end{tabular}

Note: The table presents the average weights of the topics we have identified in the 423 crisis WPs that were published in 2009-2016 by selected NBER programs. Here we follow a stricter definition of a crisis WP, than the one we used in the previous sections of the paper: a WP is a 'crisis WP' if (1) it includes the word crisis at least once in the first five paragraphs of the introduction, (2) crisis topics comprise at least $10 \%$ of the paper, and (3) crisis topics are among the three topics with the highest weight in the paper. 
Table A18

The correlation between the annual weights of the 9 crisis topics and the annual weights of the three most correlated topics out of the 500 topics.

\begin{tabular}{|c|c|c|c|}
\hline Crisis Topics & Topic 1 & Topic 2 & Topic 3 \\
\hline $\begin{array}{l}\text { International } \\
\text { Reserves }\end{array}$ & $\begin{array}{l}\text { Default Risk } \\
(0.79)\end{array}$ & $\begin{array}{l}\text { CEO Turnover } \\
(0.67)\end{array}$ & $\begin{array}{c}\text { Protecting Intellectual Property } \\
(0.63)\end{array}$ \\
\hline $\begin{array}{l}\text { Financial } \\
\text { Intermediaries }\end{array}$ & $\begin{array}{l}\text { Religions } \\
(0.67)\end{array}$ & $\begin{array}{c}\text { Pension Plans } \\
(0.65)\end{array}$ & $\begin{array}{c}\text { Mergers and Acquisitions } \\
(0.63)\end{array}$ \\
\hline $\begin{array}{l}\text { Sudden } \\
\text { Stop }\end{array}$ & $\begin{array}{l}\text { Artist Life Cycle } \\
(0.80)\end{array}$ & $\begin{array}{l}\text { Financial Liberalization and Trade } \\
\qquad(0.77)\end{array}$ & $\begin{array}{c}\text { Corporate Governance } \\
(0.68)\end{array}$ \\
\hline Liquidity & $\begin{array}{l}\text { Oil Price and Inventories } \\
(0.69)\end{array}$ & $\begin{array}{l}\text { Carbon Emission Policy } \\
(0.67)\end{array}$ & $\begin{array}{l}\text { Healthcare Spending } \\
(0.61)\end{array}$ \\
\hline $\begin{array}{l}\text { Sovereign } \\
\text { Debt }\end{array}$ & $\begin{array}{l}\text { Public Programs Subsidy } \\
(0.69)\end{array}$ & $\begin{array}{c}\text { Federal Taxation } \\
(0.59)\end{array}$ & $\begin{array}{c}\text { Biased Estimates } \\
(0.56)\end{array}$ \\
\hline $\begin{array}{l}\text { Emerging } \\
\text { Markets }\end{array}$ & $\begin{array}{c}\text { Consumption habitat } \\
(0.79)\end{array}$ & $\begin{array}{c}\text { Stock Returns } \\
(0.77)\end{array}$ & $\begin{array}{l}\text { Tariff Policy } \\
\quad(0.73)\end{array}$ \\
\hline $\begin{array}{l}\text { Great } \\
\text { Recession }\end{array}$ & $\begin{array}{c}\text { School achievements } \\
(0.86)\end{array}$ & $\begin{array}{c}\text { Treatment Effect } \\
(0.83)\end{array}$ & $\begin{array}{c}\text { Bank Lending } \\
(0.81)\end{array}$ \\
\hline $\begin{array}{l}\text { Global } \\
\text { Crisis }\end{array}$ & $\begin{array}{l}\text { Estimation methods } \\
(0.66)\end{array}$ & $\begin{array}{l}\text { Product Quality } \\
(0.63)\end{array}$ & $\begin{array}{c}\text { Carbon Emission Policy } \\
(0.61)\end{array}$ \\
\hline $\begin{array}{l}\text { Repo and } \\
\text { Securitization }\end{array}$ & $\begin{array}{c}\text { Literature Review } \\
(0.83)\end{array}$ & $\begin{array}{l}\text { Credit Cycle } \\
(0.79)\end{array}$ & $\begin{array}{c}\text { Government Spending } \\
(0.77)\end{array}$ \\
\hline
\end{tabular}

Note: The table presents correlations between the annual weights of the 9 crisis topics and the annual weights of the three most correlated topics out of the 500 topics. It should be noted that there is no correlation between the weights of these topics in the NBER WPs, which means that the correlated topics did not appear in the same papers, rather in different papers, but during the same periods. We label and list in the corresponding cell each one of the top-3 correlated topics, and in parentheses we indicate their correlation with the corresponding crisis topic. 
Table A20

Percentage of NBER WPs that were published between 1999 and 2016 by the two NBER finance programs (Asset Pricing, and Corporate Finance) in the top-3 finance journals.

\begin{tabular}{|l|c|c|}
\hline Journal & Percentage & Number \\
\hline Journal of Finance & $6.6 \%$ & 153 \\
\hline Journal of Financial Economics & $8.2 \%$ & 189 \\
\hline Review of Financial Studies & $6.6 \%$ & 154 \\
\hline Total & $21.4 \%$ & 524 \\
\hline
\end{tabular}

According to the top table, the average percentage of NBER WPs that were published in the top3 finance journals in 2010-2016 is 11\%. According to the bottom table, 21\% of the NBER WPs published between 1999 and 2016 by the two NBER finance programs were published in the top3 journals. These averages are lower bounds because sometimes paper's titles are changed upon publication, or some authors merge two papers, etc.

Table A21

Percentage of NBER WPs published in the top-3 finance journals in the total number of publications in these journals.

\begin{tabular}{|c|c|c|c|c|}
\hline & \multicolumn{4}{|c|}{$\%$ of NBER WPs out of total publications } \\
\hline & $\begin{array}{l}\text { Journal of } \\
\text { Finance }\end{array}$ & $\begin{array}{c}\text { Journal of Financial } \\
\text { Economics }\end{array}$ & $\begin{array}{c}\text { Review of Financial } \\
\text { Studies }\end{array}$ & Total \\
\hline 2004 & $5 \%$ & $11 \%$ & $0 \%$ & $7 \%$ \\
\hline 2005 & $9 \%$ & $9 \%$ & $8 \%$ & $9 \%$ \\
\hline 2006 & $8 \%$ & $6 \%$ & $12 \%$ & $8 \%$ \\
\hline 2007 & $8 \%$ & $8 \%$ & $6 \%$ & $8 \%$ \\
\hline 2008 & $8 \%$ & $9 \%$ & $12 \%$ & $10 \%$ \\
\hline 2009 & $10 \%$ & $7 \%$ & $11 \%$ & $10 \%$ \\
\hline 2010 & $13 \%$ & $8 \%$ & $10 \%$ & $10 \%$ \\
\hline 2011 & $14 \%$ & $13 \%$ & $11 \%$ & $12 \%$ \\
\hline 2012 & $11 \%$ & $11 \%$ & $9 \%$ & $10 \%$ \\
\hline 2013 & $10 \%$ & $14 \%$ & $8 \%$ & $11 \%$ \\
\hline 2014 & $11 \%$ & $16 \%$ & $11 \%$ & $12 \%$ \\
\hline 2015 & $16 \%$ & $8 \%$ & $8 \%$ & $10 \%$ \\
\hline 2016 & $7 \%$ & $15 \%$ & $11 \%$ & $11 \%$ \\
\hline Average 2010-2016 & $11.2 \%$ & $11.7 \%$ & $9.9 \%$ & $10.8 \%$ \\
\hline Average 2004-2009 & $8.0 \%$ & $8.3 \%$ & $10.1 \%$ & $8.7 \%$ \\
\hline Average 2004-2016 & $9.8 \%$ & $10.8 \%$ & $9.8 \%$ & $10.1 \%$ \\
\hline
\end{tabular}




\section{Kansas City Financial Stress Index (KCFSI)}

The goal of KCFSI is to give policymakers a single comprehensive index of financial stress.

\section{Financial Stress Features}

According to Hakkio and Keeton (2009), every episode of financial stress involves at least one of the following phenomena:

1. Increased uncertainty about fundamental value of assets

2. Increased uncertainty about behavior of other investors

3. Increased asymmetry of information

4. Decreased willingness to hold risky assets (flight to quality)

5. Decreased willingness to hold illiquid assets (flight to liquidity)

\section{Variables Used in Constructing the Index}

To construct an index that captures all the above five features of a financial stress, the following variables are used:

1. 3-month LIBOR/T-Bill spread (TED spread)

2. 2-year swap spread

3. Off-the-run/on-the-run 10-year Treasury spread

4. Aaa/10-year Treasury spread

5. Baa/Aaa spread

6. High-yield bond/Baa spread

7. Consumer $\mathrm{ABS} / 5$-year Treasury spread

8. Correlation between returns on stocks and Treasury bonds

9. Implied volatility of overall stock prices (VIX)

10. Idiosyncratic volatility of bank stock prices

11. Cross-section dispersion of bank stock returns

Table A22 lists these variables and the corresponding financial stress attributes they capture. 
Table A22

Variables and the Financial Stress Aspects They Represent.

\begin{tabular}{|l|l|}
\hline Variable & Aspects of financial stress represented by variable \\
\hline $\begin{array}{l}\text { 3-month LIBOR/3-month T-bill } \\
\text { spread (TED) }\end{array}$ & $\begin{array}{l}\text { Flight to quality, flight to liquidity, increased asym- } \\
\text { metry of information }\end{array}$ \\
\hline 2-year swap spread & Flight to liquidity, flight to quality \\
\hline $\begin{array}{l}\text { Off-the-run/on-the run 10-year } \\
\text { Treasury spread }\end{array}$ & Flight to liquidity \\
\hline Aaa/10-year Treasury spread & Flight to liquidity \\
\hline Baa/Aaa spread & Flight to quality, increased asymmetry of information \\
\hline High-yield bond/Baa spread & $\begin{array}{l}\text { Flight to quality, flight to liquidity, increased asym- } \\
\text { metry of information }\end{array}$ \\
\hline $\begin{array}{l}\text { Consumer ABS/ 5-year Treasury } \\
\text { spread }\end{array}$ & Flight to quality, increased asymmetry of information \\
\hline $\begin{array}{l}\text { Negative value of correlation } \\
\text { between stock and Treasury returns }\end{array}$ & Flight to quality \\
\hline $\begin{array}{l}\text { Implied volatility of overall stock } \\
\text { prices (VIX) }\end{array}$ & $\begin{array}{l}\text { Uncertainty about fundamentals and behavior of other } \\
\text { investors }\end{array}$ \\
\hline $\begin{array}{l}\text { Idiosyncratic volatility (IVOL) of } \\
\text { bank stock prices }\end{array}$ & $\begin{array}{l}\text { Uncertainty about fundamentals and behavior of other } \\
\text { investors }\end{array}$ \\
\hline $\begin{array}{l}\text { Cross-section dispersion (CSD) of } \\
\text { bank stock returns }\end{array}$ & \begin{tabular}{l} 
Increased asymmetry of information \\
\hline
\end{tabular}
\end{tabular}

\section{Combining the Variables in an Index of Financial Stress}

Financial stress is assumed to be the factor most responsible for the co-movement of the above variables. This factor is then identified by the method of principal components, using the following steps:

1. Express the 11 variables in the same units by subtracting the sample mean and dividing by the standard deviation.

2. Choose the coefficients of the variables in the index so that the index explains the maximum possible amount of the total variation in the 11 variables. 
3. Scale the coefficients so that the standard deviation of the index equals 1 .

\section{KCFSI - Example}

Figure A9 shows the value of the KCFSI index from February 1990 to March 2009. The figure reflects nicely the effect of the 2008 financial crisis.

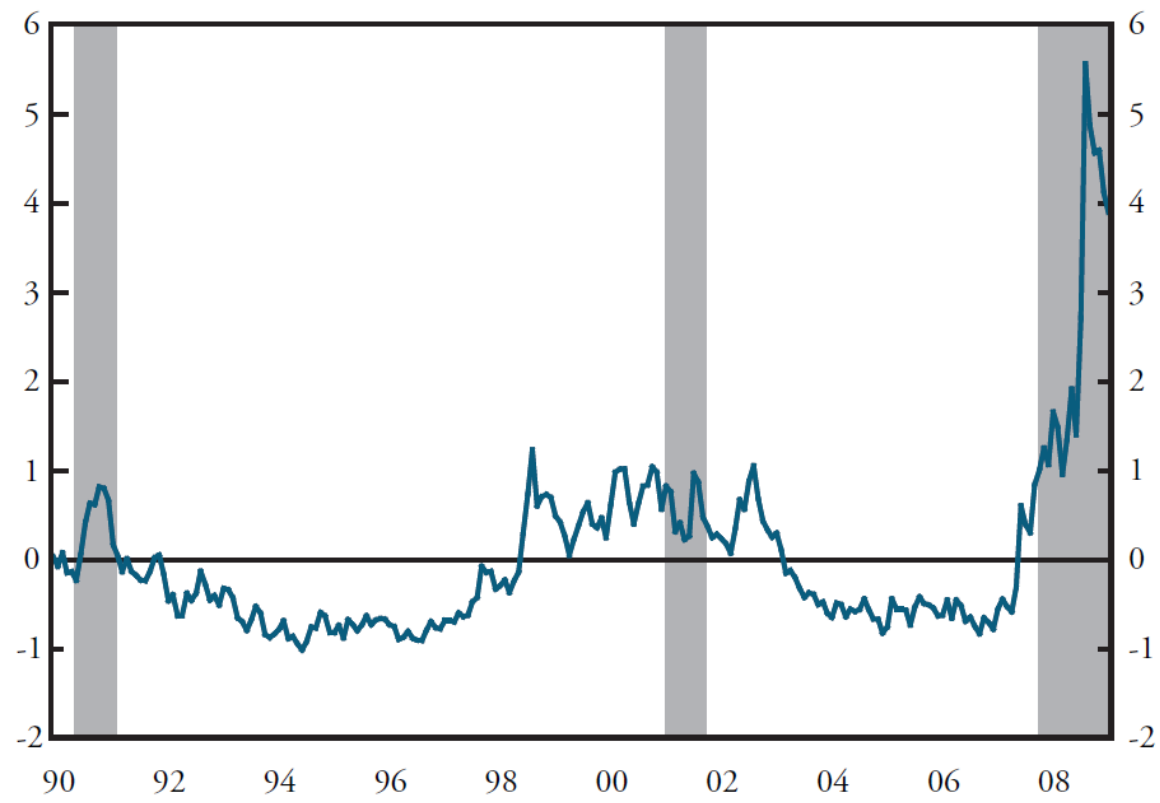

Fig. A9. KCFSI, February 1990 - March 2009.

Note: Shaded areas indicate recessions.

More details about the KCFSI can be found in:

Hakkio, C. and W. Keeton (2009), "Financial Stress: What Is It, How Can It Be Measured, and Why Does It Matter?” Federal Reserve Bank of Kansas City Economic Review, $2^{\text {nd }}$ Quarter, $5-50$. 


\section{Composite Indicator of Systemic Stress (CISS)}

The goal of the CISS is to capture the extent of financial stress using a methodology that is based on portfolio theory. It emphasizes the systemic nature of existing stresses, interpreting it as an ex-post measure of systemic risk, i.e. risk which has already materialized.

The CISS permits real time monitoring and assessment of the stress level in the financial system and gauging the impact of policy measures directed towards mitigating systemic stress. It can also help in delineating historical episodes of "financial crises" which might then be better compared and studied empirically in the context of early warning signal models.

The key advantage of CISS over alternative indicators is its explicit foundation on standard definitions of systemic risk and the adoption of a statistical measurement framework suitable to capture some of the main symptoms characterizing systemic crises.

\section{Segments of the Financial System CISS Captures}

The CISS comprises the five most important segments of the financial system of an economy:

1. Bank financial intermediaries

2. Non-bank financial intermediaries

3. Money markets

4. Securities (equities and bonds) markets

5. Foreign exchange markets

The current level of stress in each of these five segments is measured on the basis of three raw stress indicators capturing certain symptoms of financial stress such as increases in agents' uncertainty, investor disagreement or information asymmetries. Thus, in total 15 individual financial stress measures are employed. Some of the raw stress indicators capture flight-toquality and flight-to-liquidity effects, respectively.

The CISS measures such stress symptoms mainly based on securities market indicators such as volatilities, risk spreads and cumulative valuation losses, which according to Holló et al. (2012), are quite standard in the literature. 


\section{$\underline{\text { Key Requirements }}$}

The key requirements are as follows:

1. The data should be available on a daily or weekly basis with a short publication lag.

2. The stress indicators should represent market-wide developments.

3. The index should be computable for a wide range of countries and be based on a comparable set of indicators.

4. The index should be available for sufficiently long data samples so as it comprises several episodes of financial stress.

\section{Individual Stress Indicators}

The individual stress indicators that comprise the index are as follows:

\section{$\underline{\text { Money Market }}$}

- Realized volatility of the 3-month Euribor rate

- Interest rate spread between 3-month Euribor and 3-month French T-bills

- Monetary Financial Institution's emergency lending at Eurosystem central banks

\section{Bond Market}

- Realized volatility of the German 10-year benchmark government bond index

- Yield spread between A-rated non-financial corporations and government bonds (7-year maturity)

- 10 -year interest rate swap spread

\section{Equity Market}

- Realized volatility of the Datastram non-financial sector stock market index

- CMAX for the Datastream non-financial sector stock market index

- Stock-bond correlation

\section{Financial Intermediaries}

- Realized volatility of the idiosyncratic equity return of the Datastream bank sector stock market index 
- over the total market index

- Yield spread between A-rated financial and non-financial corporations (7-year maturity)

- CMAX as defined above interacted with the inverse price-book ratio (book-price ratio) for the

- financial sector equity market index

\section{Foreign Exchange Market}

- Realized volatility of the euro exchange rate vis-à-vis the US dollar, the Japanese Yen and the British Pound

\section{Aggregation of Sub-Indexes}

The main methodological innovation of the CISS compared to alternative financial stress indicators is the application of standard portfolio theory to the aggregation of subindices. The subindices are aggregated analogously to the aggregation of individual asset risks into overall portfolio risk by considering the cross-correlations between all individual asset returns and not only their variances. It is essential for our purpose that we allow for time-variation in the crosscorrelation structure between subindices. In this case, the CISS puts more weight on situations in which high stress prevails in several market segments at the same time. The stronger financial stress is correlated across subindices, the more widespread is the state of financial instability.

Figure A10 shows, as an example, a plot of the CISS index from January 1999 to June 2011, based on weekly Euro area data.

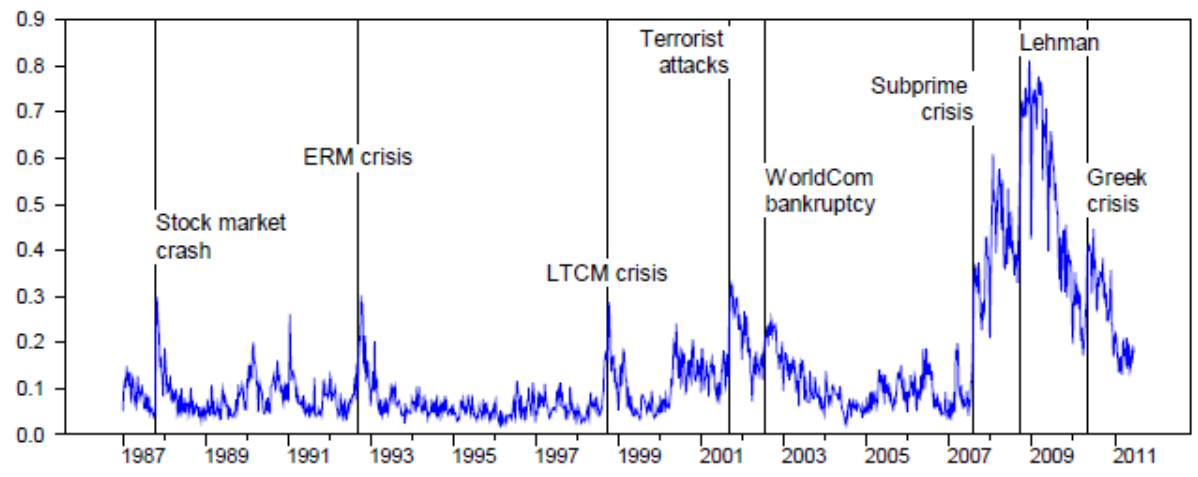

Fig. A10. CISS Index for the Euro Area, January 1999 - June 2011. 
More details about the CISS index can be found in:

Holló, D., M. Kremer, and M. Lo Duca (2012), “CISS - A Composite Indicator of Systemic Stress in the Financial System,” Working Paper No. 1426, European Central Bank. 